\title{
CALCULATIONAL FRAMEWORK FOR SAFETY ANALYSES of \\ NON-REACTOR NUCLEAR FACILITIES
}

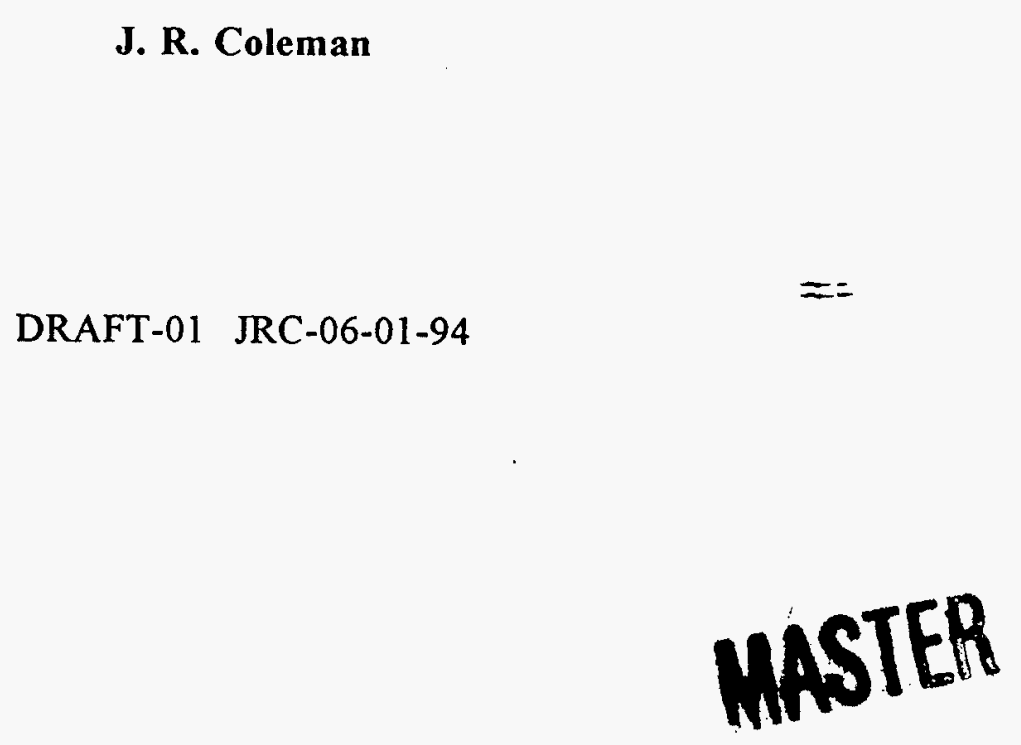




\section{DISCLAIMER}

This report was prepared as an account of work sponsored by an agency of the United States Government. Neither the United States Government nor any agency thereof, nor any of their employees, makes any warranty, express or implied, or assumes any legal liability or responsibility for the accuracy, completeness, or usefulness of any information, apparatus, product, or process disclosed, or represents that its use would not infringe privately owned rights. Reference herein to any specific commercial product, process, or service by trade name, trademark, manufacturer, or otherwise does not necessarily constitute or imply its endorsement, recommendation, or favoring by the United States Government or any agency thereof. The views and opinions of authors expressed herein do not necessarily state or reflect those of the United States Government or any agency thereof. 


\title{
RECEIVEO \\ MAY 281998 \\ OSTI
}

This report documents the fulfillment of the deliverable described for TASK-2 of Subcontract 6625K0014-96 between the University of Calafornia (Los Alamos National Laboratory) and James R. Coleman, Consulting. The task is stated as follows:

Task-2: Overall Safety Analysis Framework: This task consists of translating the framework developed for analyzing the accident risk for space nuclear systems to an appropriate framework for waste tank accidents. This is an effort to develop a logical organization of the data, analyses, and calculations related to waste tank accidents into a systematic structure for describing the probability distribution of risk.

\begin{abstract}
A calculational framework for the consequences analysis of non-reactor nuclear facilities is presented. The analysis framework starts with accident scenarios which are developed through a traditional hazard analysis and continues with a probabilistic framework for the consequences analysis. The framework encourages the use of response continuua derived from engineering judgement and traditional deterministic engineering analyses.

The general approach consists of dividing the overall problem into a series of interrelated analysis cells and then devising Markov-chain-like probability transition matrices for each of the cells. An advantage of this division of the problem is that intermediate output (as probability state vectors) are geneated at each calculational interface. The series of analyses when combined yield risk analysis output.

The analysis approach is illustrated through application to two non-reactor nuclear analyses: the Ulysses Space Mission, and a hydrogen burn in the Hanford waste storage tanks.
\end{abstract}




\section{TABLE OF CONTENTS}

Section Title $\quad \underline{\text { Page }}$

ES Executive Summary $\quad$ ES-1

A. Introduction ES-1

B. Application to Ulysses Space Mission ES-2

C. Application to a Hydrogen Burn in Tank 241-SY-101 ES-3

D. Concluding Remarks ES-5

I. Introduction and Background $\quad$ I-1

II. Description of Approach II-1

A. Accident Frequencies (Cell \#1) II-2

B. Accident Environments (Cell \#2) II-2

C. System Response (Cell \#3) II-3

D. Source Terms (Cell \#4) II-3

E. Environmental Transport (Cell \#5) II-3

F. Biological Interaction (Cell \#6) II-4

G. Risk valuation (Cell \#7) II-4

H. Summary of Model Approach II-5

III. Application to Ulysses Space Mission III-1

A. Accident Frequencies Cell (Cell \#1) III-3

B. Accident Environments Cell (Cell \#2) III-8

C. System Response Cell (Cell \#3) III-11

1. Face-on Side Hit (FOSH) III-12

2. Edge-on Side Hit (EOSH) III-12

3. Edge-on End Hit (EOEH) III-14

4. Face-on End Hit (FOEH) III-14

5. Cell \#3 Probability Transition Matrix and Output State Vector III-15

D. Source Terms Cell (Cell \#4) III-23

E. Environmental Transport Cell (Cell \#5) III-31

F. Biological Interaction Cell (Cell \#6) III-40

G. Risk valuation Cell (Cell \#7)

H. Summary Comments III-48

IV. Application to a Hydrogen Burn in Tank 241-SY-101 IV-1

A. Accident Frequencies Cell (Cell \#1) IV-4

1. Gas Generation as a Function of Time IV-4

2. Gas Release Probabilities IV-4

B. Accident Environments Cell (Cell \#2) IV-8

1. Gas Moles Per Inch of Expansion IV-12

2. Volume of Free Dome Space and Initial Moles of Air IV-12 
3. Gas Composition and Thermodynamic Parameters

IV -13

4. Cell \#2 Initial Pressure States and State Vector

IV -15

System Response Cell (Cell \#3)

IV -19

D. Source Terms Cell (Cell \#4)

IV -23

1. Aerosol Production

IV -23

2. Venting of Tank Under Pressure

IV -25

3. Uncertainty

IV -27

E. Environmental Transport Cell (Cell \#5)

IV -35

1. Uncertainty

IV -35

F. Biological Interaction Cell (Cell \#6)

IV -40

G. Risk valuation Cell (Cell \#7)

IV -43

H. Summary Comments

IV -46 


\section{EXECUTIVE SUMMARY}

\section{A. Introduction.}

A major challenge in safety analyses is translating the analysts view of the accident progression (an accident scenario) into an appropriate and understandable analysis structure. A most important step toward providing clear and understandable safety analyses is devising a systematic structure for organizing the data, models, and calculations into an understandable analysis structure.

The objective of this report is to present an approach to consequences analysis that starts with the accident scenarios, which can be developed through a traditional hazard analysis, and continues with a probabilistic framework for the consequences analysis. The framework encourages the use of response continuua derived from engineering judgement and traditional deterministic engineering analyses.

The general approach consists of dividing the overall problem into a series of interrelated analysis cells and then devising Markov-chain-like probability transition matrices for each of the cells. An advantage of this division of the problem is that intermediate output (as probability state vectors) are generated at each calculational interface. The series of analyses when combined yield risk analysis output (risk analysis output implies the quantitative exposition of both the frequency distribution of accidents and the probability distribution of their associated risk consequences) but is focused primarily on the probability distributions of consequence.

The overall risk analysis calculation is divided into the following broad analysis compartments which provide a convenient framework for the overall analysis.

- Accident Frequencies

- Accident Environments

- System Response

- Source Terms

- Environmental Transport

- Biological Interaction

- Risk Valuation

This framework is the foundation of the proposed analysis. It compartmentalizes the analysis into a set of independent but connected analysis steps (for convenience these steps will be referred to as analysis cells or simply cells) that are separated at more-or-less natural analytical interfaces.

In the analysis itself, each analysis cell is defined as a transition matrix (similar to a Markovchain transition matrix) expressing the transition probabilities between a set of initial input states 
(and an associated probability-state vector) and a set of resulting output states (the multiplication of the two yields an output probability-state vector).

Two illustrations of the application of the framework are presented.

\section{B. Application to Ulysses Space Mission.}

Ulysses was launched in October 1990 aboard the space shuttle from Kennedy Space Center on a five year mission to investigate the polar regions of the sun. The power source for the experimental package is a General Purpose Heat Source Radioisotopic Thermal Generator (GPHSRTG) containing approximately $11 \mathrm{~kg}(131,000 \mathrm{Ci})$ of plutonium-238 oxide.

The goal of the approach proposed here is to describe the physical transition from an RTG to free and potentially ruptured fueled clads in a probabilistic manner. The approach structures the calculations into a stepwise analysis with intermediate output distributions that facilitate understanding and evaluation.

This analysis produced the following results:

1. An accident frequency state vector as output from Cell \#1. Mean accident frequency $=0.01$

2. A fragment velocity state vector (the only environment of interest) as the output from Cell \#2. Fragment hit occurrence probability given accident $=0.145$.

3. A failed clad state vector (giving the probability distribution of clad failure) as the output from Cell \#3. Failure occurrence probability given fragment hit $=0.022$.

4. A source term state vector (giving the probability of fuel releases, both total release and respirable releases) as the outputs from Cell \#4. Source term release occurrence probability given fragment hit and clad failure $=1.0$

5. A set of exposure probability state vectors in $s / \mathrm{m}^{3}$ and $\mu \mathrm{Ci}-\mathrm{s} / \mathrm{m}^{3}$ for eleven (11) distances from the release point as the output from Cell \#5. Exposure occurrence probability given release $=0.56$

6. A corresponding set of dose probability state vectors in rems for the eleven (11) distances from the release point as the output from Cell \#6. Dose occurrence probability given exposure $=1.0$. A corresponding overall probability of consequences per mission of

$$
0.01 \times 0.145 \times 0.022 \times 1.0 \times 0.56 \times 1.0=1.8 \times 10^{-5} \text { per mission }
$$


for the event characterized as: catastrophic accident -- fragment impact -- clad failure and fuel release -- first flight exposure.

7. And finally, an overall expected mission risk of 0.39 cancers fatalities and the distribution of risk frequency as the output from Cell \#7.

The results of these calculations are shown in Figure ES-1. This figure is the transposed cumulative probability function given a launch, which shows the $5^{\text {th }}$ percentile, median, mean, and $95^{\text {th }}$ percentile frequency distributions of cancer fatalities for the mission.

The mission risk distribution calculated here is about an order-of magnitude below the comparable distribution given by the INSRP, and the average case is about the same as the average case for the total mission distribution given by GE/NUS. It is not clear where differences arise (because comparable intermediate data are not clearly given in current documentation) or what these differences imply about the different calculational models.

In summary, because of the lack of clear intermediate data in the Ulysses documentation it is not possible to determine where difference arise or what they imply about the various analyses. However, it is clear that the availability of the intermediate data produced here is a significant benefit and clearly illuminates a shortcoming in the current documentation.

\section{Application to a Hydrogen Burn in Tank 241-SY-101.}

High level radioactive wastes (HLRW) are stored at the Hanford site by the U.S. Department of Energy. Generation of HLRW began in late 1944 and continued periodically until late 1983. The wastes are stored in 149 single-shelled tanks (SSTs) and 28 double-shelled tanks (DSTs). Five of the DSTs and 18 of the SSTs have been identified as generators of combustible gases, particularly hydrogen; and Tank $241-S Y-101$ has been identified as the tank that produces the greatest quantity of such gases.

The gases may be releases to the dome space above the crust by natural instability due to gas build up, by agitation, or as a result of invasive activities. If an ignition source is available during the release of the combustible gases a serious burn can occur. The accident considered in this example is a hydrogen burn initiated by natural causes. Specifically the accident scenario considered is:

An earthquake yielding a ground acceleration in the range of about $15 \%$ to $20 \%$ of gravity which results in the release of stored gases from the slurry layer and, at the same time, produces an ignition source for the gases in the tank dome. It is assumed that this accident has a frequency (random) of about $4 \times 10^{-4}$ per year. 
This analysis produced the following results:

1. An accident frequency of 0.0004 per year for an earthquake with an associated ground acceleration of greater than about $0.2 \mathrm{~g}$ (the accident case); and a probability state vector related to the size of the combustible gas release as the output from Cell \#1.

2. A tank pressure probability state vector (the only environment of interest) as the output from Cell \#2, with a pressurization and ignition occurrence probability of 1.0 , given an earthquake in 1 . above.

3. A failed HEPA state vector as the output from Cell \#3. The failure occurrence probability is 0.927 given the pressurization state vector of cell \#2 and the conditions of 1 and 2 above.

4. A source term state vector for respirable release $(<10 \mu \mathrm{m}$ AED) as the output from Cell \#4. Source term occurrence probability is 1.0 given the conditions of 1,2 , and 3 above.

5. An exposure probability state vector in $\mathrm{g}-\mathrm{s} / \mathrm{m}^{3}$ calculated from information in the SA (Rev. 8) for the Highway 240 location as the output from Cell \#5. Exposure occurrence probability is 1.0 given a release.

6. A corresponding dose probability state vectors in rems (EDE) for the Highway 240 site boundary as the output from Cell \#6. Dose occurrence probability given exposure $=1.0$

7. A comparison of the dose distribution at the Hwy 240 location to the Westinghouse off site acceptance criteria [identified in the SA (Rev.8)] as the output from Cell \#7. The earthquake event considered here has a event-frequency of $1 \times 10^{-4}$ and therefore the Westinghouse criteria apply. This comparison shows the consequences calculated here to be well within those criteria. $=$

The dose-frequency distributions for the Hwy 240 location (the site boundary) together with the Westinghouse off-site dose criteria [EDE (rem)] are shown in Figure ES-2. Two dose frequency distributions are shown, one including multiplication by the normalized event occurrence probability calculated from this analysis, and the other without the multiplication of the earthquake frequency.

The first of these pertains to the accident considered here. The second of the curves is comparable (in concept) to the individual data points in Figure 5-1 (page 5-7) in the SA (Rev. 8 ) if the curve is multiplied by some average accident event-occurrence frequency. 
Unfortunately, no exact comparison with the current documentation is appropriate: (1) because of the difference in source term calculation methodology, and (2) because the doses calculated here are distributed by the uncertainty in the source term calculation, the uncertainty in the Gaussian dispersion model, and the uncertainty due to meteorology.

In summary, the methodology used here has produced a relatively lucid exposition of the consequences of an hydrogen burn accident and provides a set of intermediate results that promote a clearer understanding of the problem. It is obvious that the availability of the intermediate data is a significant benefit to understanding the problem and illuminates a shortcoming in the less structured approach currently used to document consequence analyses .

\section{Concluding Remarks.}

The consequences analysis structure proposed here starts with the accident scenarios that arise from a traditional hazards analysis and provides a framework that enhances the use of occurrence probability distributions developed from engineering judgement and uncertainty calculations. The calculational framework serves as a template for organizing the necessary data, models, and analyses into a focused structure that forces the analyst to exercise discipline to assure a balanced effort in obtaining the information and models necessary to the analysis. The methodology produces a lucid exposition of the accident analysis and provides a set of intermediate results that promote a clear understanding of the complete problem. 


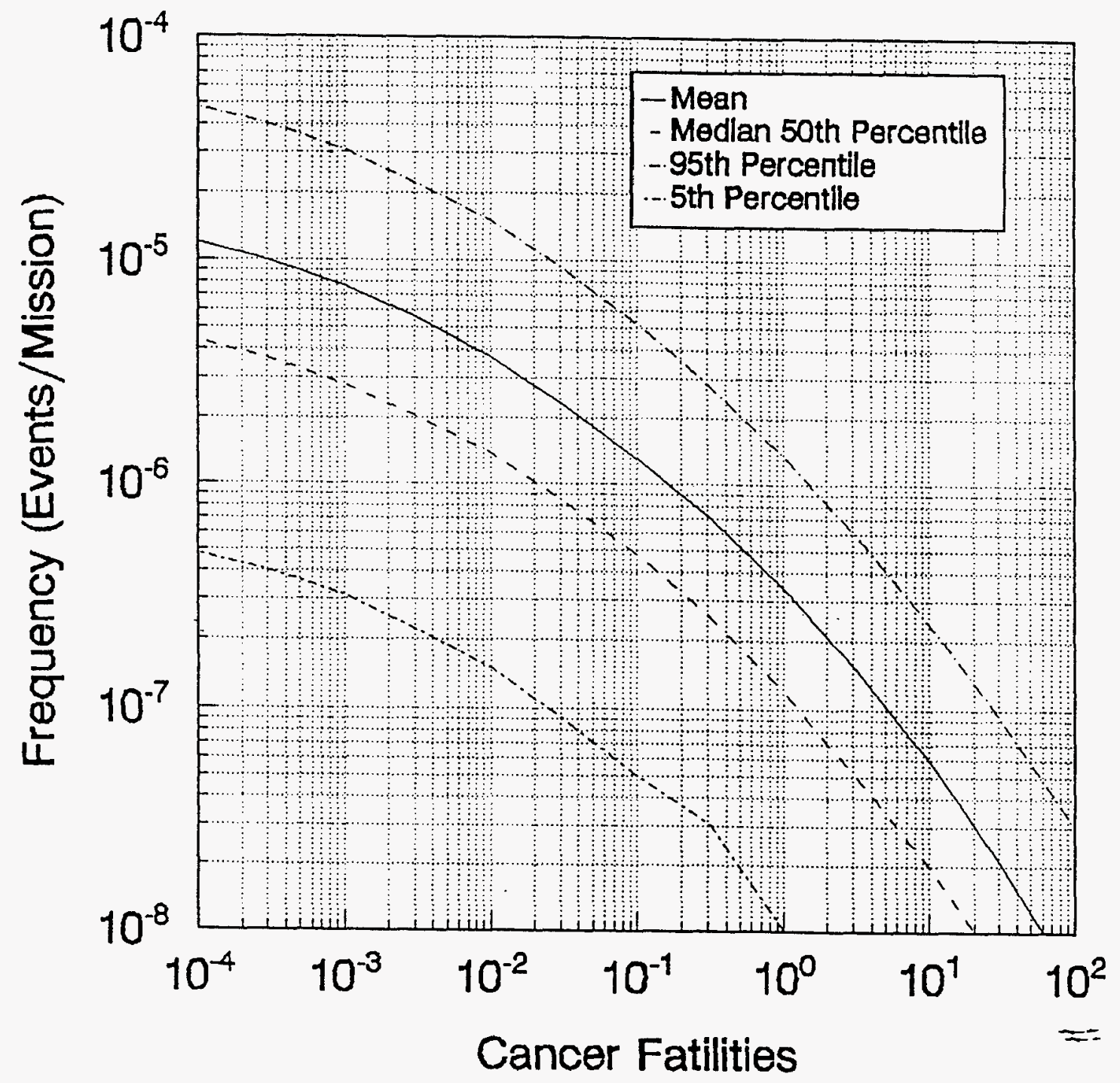

Figure ES-1

Radiological Risk Distribution

Florida (to $70 \mathrm{~km}$ from launch pad)

Sum of All Scenarios to 87 s MET

ES-6 


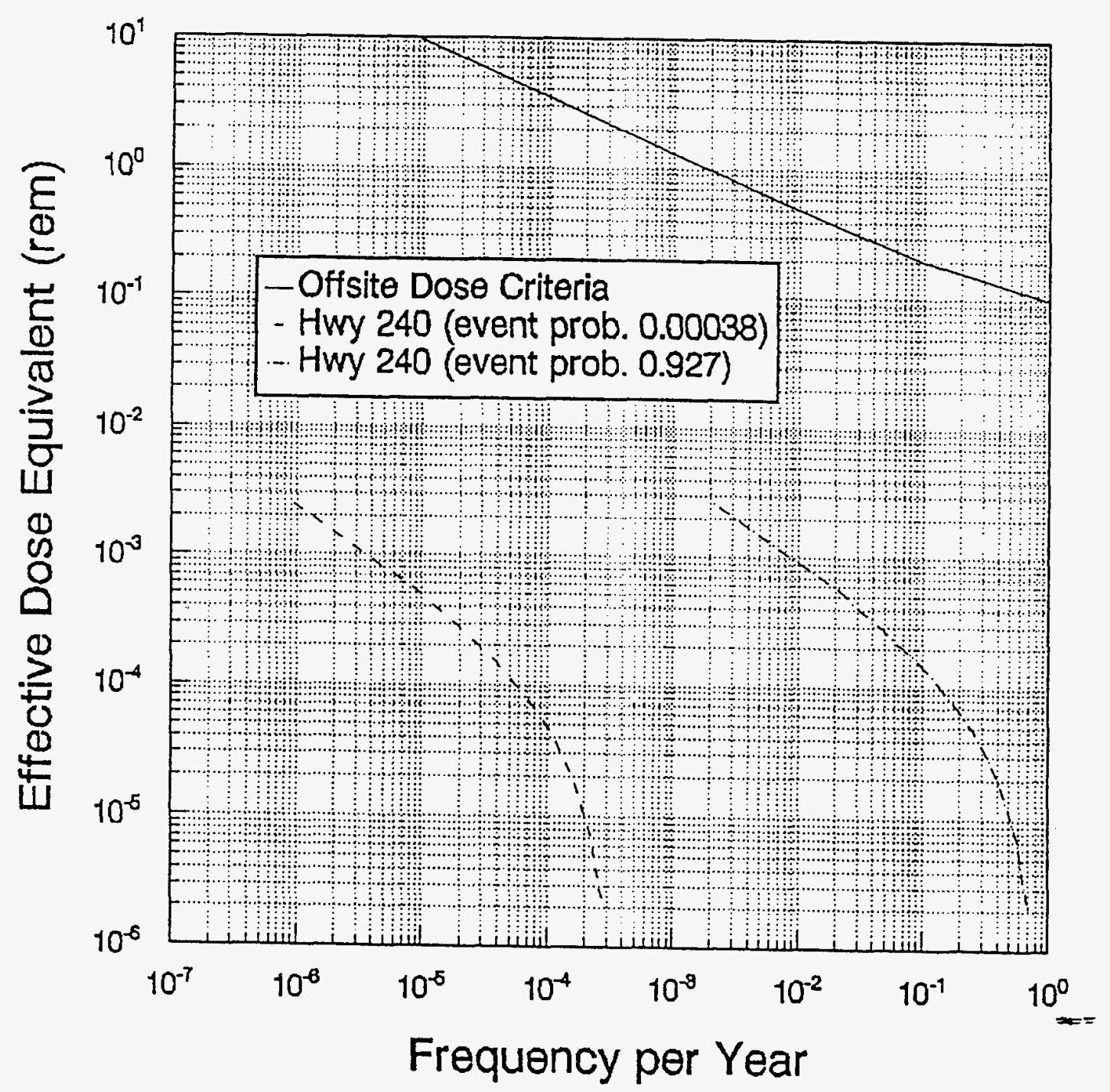

Figure ES-2

Comparison of Calculated Doses (rem EDE) with Offsite Dose Criteria as Complements of the Cumulative Probability Distribution 


\section{INTRODUCTION and BACKGROUND}

A major challenge in safety analyses is translating the analysts view of the accident progression (an accident scenario) into an appropriate and understandable analysis structure. In this regard, a through and complete safety analysis requires an extremely broad range of technological understandings and interpretations; ranging from probability theory, through mechanics of materials and environmental transport, to health physics. Thus, a most important step toward providing clear and understandable safety analyses is devising a systematic structure for organizing the data, models, and calculations into an understandable analysis structure. The propose of this task is to describe such a structure for non-reactor nuclear facilities.

In general, the approach to this type of problem is Probabilistic Risk Analysis (PRA). However, traditional PRA is most effective for well defined systems in which an accident sequence can be related to the failure or non-failure of specific components (or subsystems) for which statistical failure rate information is available or can be reasonably obtained. PRA is not very effective when one attempts to apply it to more-or-less passive systems in which failure is expressed as a continuum of diminishing integrity in sequential protective barriers and/or where consequences are the result of complex physical/chemical interactions. The storage of radioactive wastes in tanks such as at Hanford and the use of radioisotopic thermoelectric generators (RTGs) in space are two examples of passive systems that are not very amenable to traditional PRA. In both of these systems safety is achieved simply by maintaining full or partial integrity in multiple protective barriers subsequent to an accident event.

In addition, most importantly, traditional PRA is focused mainly on the accident evaluation side of risk analysis (failure mode and effects analysis, event trees, accident sequences etc.) while offering lesser attention to consequence analysis. However, particularly for non-reactor systems, it is the consequences analysis side that introduces the most difficulty and the greatest uncertainty.

The objective of this report is to present an approach to consequences analysis that starts with the accident scenarios, which can be developed through a traditional hazard analysis, and continues with a probabilistic framework for the consequences analysis. The framework encourages the use of response continuua derived from engineering judgement and traditional deterministic engineering analyses.

The general approach consists of dividing the overall problem into a series of interrelated analysis cells and then devising Markov-chain-like probability transition matrices for each of the cells. An advantage of this division of the problem is that intermediate output (as probability state vectors) are generated at each calculational interface. The series of analyses when combined 
yield risk analysis output (risk analysis output implies the quantitative exposition of both the frequency distribution of accidents and the probability distribution of their associated risk consequences) but is focused primarily on the probability distributions of consequence.

The analysis approach is described in the following paragraphs and two illustrations of its application are developed and presented in later sections. This report consists of four sections: I. Introduction and Background, II. Description of Approach, III. Application to the Ulysses Space Mission, and IV. Application to Hydrogen Burn in the Hanford waste storage tanks. 


\section{DESCRIPTION OF APPROACH}

The consequences analysis structure propose here starts with the accident scenarios that arise from a traditional hazards analysis. It is directed at providing an analysis structure that enhances the use of occurrence probability distributions developed from engineering judgement and calculations. In this regard the problem is twofold: to provide a calculational framework that allows the generation of risk analysis output; and by that calculational framework provide an organizing structure for analyzing the physical problem itself. In this latter regard, the calculational framework serves as a template for organizing the necessary data, models, and analyses into a focused structure that forces the analyst to exercise discipline to assure a balanced effort in obtaining the information and models necessary to the analysis.

In this approach, the initial step is to recognize that the analysis problem can be separated into a series of independent but connected calculational steps rather than one single continuous calculation. The key then, is to select calculational interfaces that separate the analysis at moreor-less natural analytical boundaries. In the current approach, the analytical boundaries have been selected at interfaces where a new or different analytical expertise may be required. Thus, the overall risk analysis calculation is divided into the following broad analysis compartments which provide a convenient framework for the overall analysis.

- Accident Frequencies

- Accident Environments

- System Response

- Source Terms

- Environmental Transport

- Biological Interaction

- Risk Valuation

[Note: The Interagency Nuclear Safety Review Panel (INSRP) is organized along this line with technical subpanels on Launch Abort (dealing with accident frequencies and environments), Power Systems (dealing with system response and source terms), Meteorology (dealing with meteorology and diffusion), and Biomedical and Environmental Effects (dealing with environmental and human interaction, dose and effects).

This framework is the foundation of the proposed analysis. It compartmentalizes the analysis into a set of independent but connected analysis steps (for convenience these steps will be referred to as analysis cells or simply cells) that are separated at more-or-less natural analytical interfaces. In the analysis itself, each analysis cell is defined as a transition matrix (similar to a Markovchain transition matrix) expressing the transition probabilities between a set of initial input states 
(and an associated probability-state vector) and a set of resulting output states (the multiplication of the two yields an output probability-state vector). The effort within each cell must be planned and organized to assure that all of the information and models appropriate to the physical and chemical processes within that cell are included for consideration.

In any specific application the transition matrices, by incorporating engineering judgement and calculations into the analysis, offer the opportunity to include uncertainty within the calculations of each specific cell. Thus, the analysis cells are used not only to structure the calculations but also to expose and incorporate our understanding (or lack of understanding) of the information inputs and information products at the several analytical intersections.

The seven calculational cells are described briefly in the following paragraphs. Each description is accompanied by a simple mathematical statement of the cell calculations which is carried through the cell descriptions and is summarized at the end.

\section{A. Accident Frequencies (Cell \#1).}

This cell consists of those analytical steps necessary to develop the credible accident scenarios and their associated occurrence probabilities (this is the primary accident analysis). The inputs are the physical descriptors of the system and a knowledge of potential hazards. The initial product of this cell is a set of accident scenarios and their associated frequencies of occurrence. The frequency distributions are reduced to discrete distributions and normalized to one ( thus yielding a probability state vector and a accident state occurrence frequency). That is, the distributions would be characterized by $\phi_{i}$ (the accident state occurrence frequency) and a probability state vector $F_{i}$ (where the summation over all states, $\Sigma_{i} F_{i}=1$ ).

The accident scenarios together with the appropriate probability state vector(s) constitute the output from this cell. $\mathbf{F}_{\mathrm{i}}$ (whether for a single scenario or a combination of scenarios) is the initial probability state vector for the next cell.

\section{B. Accident Environments (Cell \#2).}

The accident environment cell consists of those analytical steps necessary to describe the distribution of physical conditions (pressure, temperature, physical impacts, fragment velocity etc.) that result from or are associated with the credible accident scenarios and the related probabilities of those conditions (environments) occurring. This cell utilizes the credible accident scenarios from the event frequency cell together with experimental data, engineering judgement, and analysis models to develop a set of accident environment states and the transition probabilities to those states from initial conditions. The result is the set of accident environment states and the associated transition probability matrix $\left(t_{i j}\right)$ to those states from the initial accident event states. 
The output of this cell is an environment state vector which is the product of the initial probability state vector from the previous cell and the transition probability matrix from this cell. The environment state vector would be normalized to an environment occurrence probability $\varepsilon_{\mathrm{j}}$ and a probability state vector $\mathbf{E}_{\mathrm{j}}$ (where $\Sigma \mathbf{E}_{\mathrm{j}}=1$ ). $\mathbf{E}_{\mathrm{j}}$ is the initial state vector for the next cell.

\section{System Response (Cell \#3).}

The system response cell consists of those analytical steps necessary to describe the distribution of physical damage to the system as a result of the environment states defined in the previous cell and the associated probabilities of those damage states occurring. This cell utilizes the accident environments described in the previous cell together with engineering judgement, data, and analyses to develop a set of system response states (e.g., ruptured tank, vented leaks, ruptured HEPA) and the associated transition probabilities $\left(t_{j k}\right)$ to those states from the previously defined environment states.

The output of this cell is a response state vector -- the product of the environment probability state vector from the previous cell and the derived transition matrix from this cell. The response state vector would be normalized to a damage occurrence probability $\rho_{k}$ and a probability state vector $\mathbf{R}_{\mathrm{k}}$ (where $\Sigma \mathbf{R}_{\mathrm{k}}=1$ ). $\mathbf{R}_{\mathrm{k}}$ is the initial state vector for the next cell.

\section{Source Terms (Cell \#4).}

The source term cell consists of those analytical steps necessary to describe the probability distribution of releases associated with the damage states defined in the previous cell. This cell utilizes the system response states and the accident environments together with engineering judgement, data, and analyses to estimate the quantity and characteristics of potentially released hazardous materials. The released materials form a set of source term states, which together with the associated transition probabilities to those states $\left(t_{k i}\right)$ comprise the end-product of this analysis cell.

The output of this cell is a source term state vector - the product of the damage probability state vector from the previous cell and the derived transition matrix from this cell. The source term state vector would be normalized to a source term release occurrence probability $\sigma_{1}$ and a probability state vector $S_{1}$ (where $\Sigma S_{1}=1$ ). $S_{1}$ is the initial state vector for the next cell.

\section{E. Environmental Transport (Cell \#5).}

The environmental transport cell consists of those analytical steps necessary to describe the probability distribution of human exposure to hazardous material associated with the source term states defined in the previous cell. This cell utilizes the source term states together with environmental data and models to estimate the spatial and temporal distribution of released hazardous materials in the environment, which can be expressed as environmental exposure states. 
These exposure states together with the associated transition probabilities to those states $\left(t_{\operatorname{lm}}\right)$ comprise the end-product of this analysis cell.

The output of this cell is an exposure state vector -- the product of the source term probability state vector from the previous cell and the derived transition matrix from this cell. The exposure state vector would be normalized to an exposure occurrence probability $\tau_{m}$ and a probability state vector $\mathbf{T}_{\mathrm{m}}$ (where $\Sigma \mathbf{T}_{\mathrm{m}}=1$ ). $\mathbf{T}_{\mathrm{m}}$ is the initial state vector for the next cell.

\section{F. Biological Interaction (Cell \#6).}

The biological interaction cell consists of those analytical steps necessary to describe the probability distribution of human dose associated with the exposures states output from the previous cell. This cell utilizes the exposure states, biological models (lung, GI tract, external exposure etc.), diet and/or intake assumptions and population data to estimate the distribution of human insult expressed as dose states. These dose states together with the associated transition probabilities to those states $\left(t_{\mathrm{mn}}\right)$ comprise the end-product of this analysis cell.

The output of this cell is a dose state vector -- the product of the exposure probability state vector from the previous cell and the derived transition matrix from this cell. This dose state vector would be normalized to an exposure occurrence probability $\delta_{n}$ and a probability state vector $\mathbf{D}_{n}$ (where $\Sigma D_{n}=1$ ). $\quad \mathbf{D}_{n}$ constitutes the dose probability distribution (or other consequences distribution) resulting from the accident scenarios used as a starting point in the event probabilities cell. This is the final probability state vector.

\section{G. $\quad$ Risk Valuation (Cell \#7).}

This cell is not a true calculational cell as are the previous cells. It is more accurately the application of some set of value judgements about risk. However it is included here so as not to overlook or underestimate its importance to the safety analysis. It includes the application of risk coefficients, acceptable risk criteria (e. g., de minimis doses or credible limits on occurrence frequencies) or other mechanisms to arrive at the comparable value base necessary to ascribe a relative risk value to the accident dose/consequences calculated. It_should also include a discussion of the technical basis for those value judgements. It may be extremely complicated or it may be as simple as selecting commonly accepted minimum dose and/or credible frequency limit values.

In many current approaches to risk analysis the output state vector from cell \#6 would simply be multiplied by a risk factor [effects (e.g. cancers) per person-Gray or per person-rad (rem) whatever the taste in units] to yield effects, thus eliminating any significant calculation in this cell (this is what is done in the Ulysses application).

In summary, the purpose of this cell is to provide the technical and/or logical basis for valuing 
the calculated human exposure distributions as risks and viewing those risks in the context of other human risks.

\section{H. Summary of Model Approach}

The approach can be summarized mathematically quite simply. As described above the dose consequences probability distribution is given by:

$D_{n}=F_{i} \times t_{i j} \times t_{j k} \times t_{k l} \times t_{1 m} \times t_{m n}$ and the occurrence probability for this set of dose consequences is $\phi_{\mathrm{i}} \times \varepsilon_{\mathrm{j}} \times \varphi_{\mathrm{k}} \times \sigma_{\mathrm{l}} \times \tau_{\mathrm{m}} \times \delta_{\mathrm{n}}$.

And the following represent the intermediate output state vectors from each cell.

$$
\mathbf{E}_{\mathrm{j}}=\mathbf{F}_{\mathrm{i}} \times \mathrm{t}_{\mathrm{ij}} \quad \mathbf{R}_{\mathrm{k}}=\mathbf{E}_{\mathrm{j}} \times \mathrm{t}_{\mathrm{jk}} \quad \mathbf{S}_{\mathrm{l}}=\mathbf{R}_{\mathrm{k}} \times \mathrm{t}_{\mathrm{kl}} \quad \mathbf{T}_{\mathrm{m}}=\mathbf{S}_{1} \times \mathrm{t}_{\mathrm{lm}} \quad \mathbf{D}_{\mathrm{n}}=\mathbf{T}_{\mathrm{m}} \times \mathrm{t}_{\mathrm{mn}}
$$

A probability distribution for the accident frequency can be generated external to the foregoing by using the uncertainty in the frequency of occurrences for individual scenarios to express them as probability state vectors. The probability distribution for accident frequency would be the appropriate combination of the several individual probability state vectors. 


\section{APPLICATION TO ULYSSES SPACE MISSION}

Ulysses was launched in October 1990 aboard the space shuttle from Kennedy Space Center on a five year mission to investigate the polar regions of the sun. The power source for the experimental package is a General Purpose Heat Source Radioisotopic Thermal Generator (GPHS-RTG) containing approximately $11 \mathrm{~kg}(131,000 \mathrm{Ci})$ of plutonium-238 oxide. The radioactive material is contained in 72 individual "fueled clads" which are (approximately) l" $\mathrm{x}$ $1 "$ right circular cylinders made of iridium containing roughly $1800 \mathrm{Ci}$ of $\mathrm{Pu}^{238} \mathrm{O}_{2}$ each. Additionally each pair of fueled clads is packaged in a fine-weave-pierced-fabric (FWPF) Graphic Impact Shell (GIS); and each pair of GISs is contained in an FWPF graphite aeroshell (the GPHS module).

GE and NUS documented the final Safety analysis Report in six (6) separate volumes. In addition the Interagency Nuclear Safety Review Panel (INSRP) produced an independent Safety Evaluation Report (SER) which is documented in ten (10) separate volumes (including reports of five subpanels and two documents on uncertainty). Because of the extensive documentation, this space mission serves as an ideal vehicle to illustrate the analysis approach proposed here. This is done in the following paragraphs where each of the cells is addressed in turn. It must be reemphasized that the intent here is to illustrate an approach to the analysis and not necessarily to reproduce the safety evaluation. As a first step in describing this effort it is helpful to illustrate, pictorially, the general progression of the accidents considered. This is shown in the following figure which encompasses the Accident Environments and System Response cells.

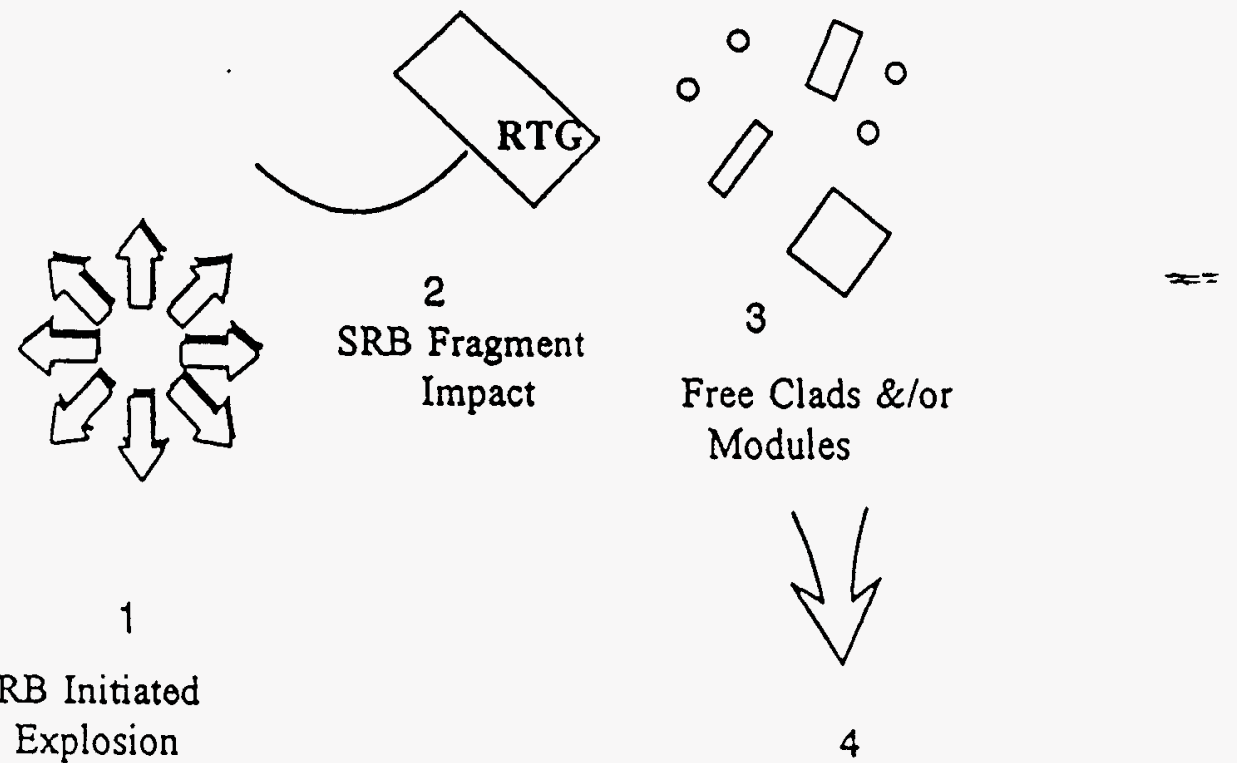

Ground Impact 
The goal of the approach proposed here (as was the goal of the GE/NUS and INSRP analyses of Ulysses) is to describe the physical transition from an RTG to free (and potentially ruptured fueled clads) in a probabilistic manner. However, the GE/NUS and INSRP analyses of Ulysses utilized a Monte Carlo model (LASEP3) to address this problem; running 100,00 trials for each accident case to determine occurrence probabilities of specific source terms. That approach makes it essentially impossible to construct probability distributions of consequences (from the information given), follow the probabilistic flow of individual events, or ascertain the influence of specific calculations; thus, it is essentially impossible to devise a clear assurance that the results make sense. The approach proposed here is intended to alleviate these problems by structuring the calculations into a stepwise analysis with intermediate output distributions that facilitate understanding and evaluation.

The analysis model has been described in Section II. It structures the calculations into a stepwise analysis with intermediate output distributions that facilitate understanding and evaluation. In brief, the approach divides the overall problem into the following broad analysis compartments (referred to as analysis cells or just cells) which provide a convenient framework for the analysis.

- Accident Frequencies

- Accident Environments

- System Response

- Source Terms

- Environmental Transport

- Biological Interaction

- Risk Valuation

The following paragraphs summarize the calculational approach, calculations, results, and output of the individual cells. Brief summary comments are offered at the end of the presentation. 


\section{A. Accident Frequencies Cell (Cell \#1).}

As mentioned above, the accident frequencies are defined by the accident scenarios specified. The accident scenarios and their frequencies for the Ulysses Mission have been defined by GE/NUS in the SAR and those of interest to the INSRP identified in their SER. The accident frequency probability state vectors for this cell are based on the selected accident scenarios and accident frequencies summarized in Volume I of the INSRP SER. That summary is reproduced as Table ULY-Cl-1.

The data in this table can be used to generate accident frequency probability state vectors for the individual scenarios (INSRP has not done this). It has been done here assuming that, within the range between $1 \%$ and $99 \%$, the frequency distributions can be taken to be lognormally distributed (this appears reasonable from the results although it gives means about $10 \%$ below those reported in the INSRP tabulation). There are two options at this point for calculating the probability state vector: (1) to select a set of ranges of interest in the state variable (the distributed frequency of occurrence for each scenario) and calculate the probability within that range; or (2) to select a set of probability ranges of interest and calculate the boundaries of the state variable for this probability set. In the case at hand, because the state variables are expressed as lognormal distributions (as equations), it is convenient to define the states by selecting probability ranges and calculating the state variable boundaries for the selected probability ranges. The results are presented for Scenarios \#1 and \#6 (as examples) in Figures ULY-Cl-1 and ULY-Cl-2 respectively.

Although lognormal distributions have been fitted to all of the scenario data, not all of the accident scenarios presented in Table ULY-Cl-1 are of significance. The INSRP determined that a subset of these scenarios were "key accident scenarios" (those that encompasses the majority of the radiological risks) and were thus included for presentation in their SER. Aside from the "Inadvertent Reentry and Land Impact" the INSRP subset of accidents included only those that affected the local Florida area.

In the current analysis, because of the similarities of these events, the individual accident frequency data for all accidents occurring prior to 88 seconds Mission Elapsed Time(MET) have been combined into a mission cumulative accident frequency function and this has been converted into a mission accident frequency state vector. Because of later similarities in accident time-lines, this combination of scenarios provides some simplification in the subsequent calculations. The total mission Accident Frequency Probability State Vector is presented in Figure ULY-Cl-3. In this case, as opposed to the approach mentioned above, the probability state vector was calculated by selecting a set of frequency ranges of interest and calculating the sum of probabilities within that range (from the distributed frequency of occurrence for each scenario). 
Table ULY-C1-1

INITIATING ACCIDENT FREQUENCY SUMMARY

from INSRP Safety Evaluation Report for Ulysses Mission

\begin{tabular}{|c|c|c|c|c|}
\hline \multirow{2}{*}{$\begin{array}{l}\text { ACCIDENT } \\
\text { SCENARIO }\end{array}$} & \multicolumn{4}{|c|}{ ACCIDENT FREQUENCY $\left(\right.$ launch $\left.^{-1}\right)$} \\
\hline & $5^{\text {th }}$ Percentile & Median & Mean & $95^{\text {th }}$ Percentile \\
\hline $\begin{array}{l}\text { On pad External Tank } \\
\text { Fire/Explosion }\end{array}$ & $8.8 \times 10^{-4}$ & $2.2 \times 10^{-3}$ & $2.9 \times 10^{-3}$ & $7.2 \times 10^{-3}$ \\
\hline Tipover-Tower Impact & $6.0 \times 10^{-6}$ & $4.9 \times 10^{-5}$ & $1.9 \times 10^{-6}$ & $6.8 \times 10^{-4}$ \\
\hline $\begin{array}{l}\text { Near Pad External } \\
\text { Tank Explosion }\end{array}$ & $3.4 \times 10^{-4}$ & $8.4 \times 10^{-4}$ & $1.2 \times 10^{-3}$ & $2.8 \times 10^{-3}$ \\
\hline $\begin{array}{l}\text { Aft Compartment } \\
\text { Explosion }\end{array}$ & $6.5 \times 10^{-5}$ & $3.3 \times 10^{-4}$ & $7.5 \times 10^{-4}$ & $2.5 \times 10^{-3}$ \\
\hline $\begin{array}{l}\text { Early Ascent External } \\
\text { Tank Explosion }\end{array}$ & $2.2 \times 10^{-4}$ & $6.5 \times 10^{-4}$ & $1.1 \times 10^{-3}$ & $3.3 \times 10^{-3}$ \\
\hline $\begin{array}{l}\text { Mid \& Late External } \\
\text { Tank Explosion - }\end{array}$ & $1.6 \times 10^{-3}$ & $5.1 \times 10^{-3}$ & $8.6 \times 10^{-3}$ & $2.3 \times 10^{-2}$ \\
\hline $\begin{array}{l}\text { Near pad SRB Random } \\
\text { Failure }\end{array}$ & $1.3 \times 10^{-4}$ & $7.5 \times 10^{-4}$ & $1.5 \times 10^{-3}$ & $4.8 \times 10^{-3}$ \\
\hline $\begin{array}{l}\text { Early Ascent SRB } \\
\text { Random Failure } \\
\end{array}$ & $1.7 \times 10^{-5}$ & $1.5 \times 10^{-4}$ & $3.7 \times 10^{-4}$ & $1.3 \times 10^{-3}$ \\
\hline $\begin{array}{l}\text { Mid-Ascent SRB } \\
\text { Random Failure }\end{array}$ & $5.7 \times 10^{-5}$ & $3.2 \times 10^{-4}$ & $5.7 \times 10^{-4}$ & $1.8 \times 10^{-3}$ \\
\hline $\begin{array}{l}\text { Late, Mid-Ascent SRB } \\
\text { Random Failure }\end{array}$ & $1.7 \times 10^{-5}$ & $1.5 \times 10^{-4}$ & $3.6 \times 10^{-4}$ & $1.3 \times 10^{-3}$ \\
\hline $\begin{array}{l}\text { Late Ascent SRB } \\
\text { Random Failure }\end{array}$ & $7.9 \times 10^{-6}$ & $7.1 \times 10^{-5}$ & $1.7 \times 10^{-6}$ & $6.3 \times 10^{-6}$ \\
\hline $\begin{array}{l}\text { Near Pad Inadvertent } \\
\text { Range Destruct }\end{array}$ & $1.1 \times 10^{-8}$ & $6.5 \times 10^{-8}$ & $1.3 \times 10^{-7}$ & $4.6 *-10^{-7}$ \\
\hline $\begin{array}{l}\text { Early Ascent Inadver- } \\
\text { tent Range Destruct }\end{array}$ & $5.2 \times 10^{-8}$ & $3.2 \times 10^{-7}$ & $6.2 \times 10^{-7}$ & $2.3 \times 10^{-6}$ \\
\hline $\begin{array}{l}\text { Mid-Ascent Inadver- } \\
\text { tent Range Destruct }\end{array}$ & $2.4 \times 10^{-8}$ & $2.4 \times 10^{-7}$ & $6.4 \times 10^{-7}$ & $2.4 \times 10^{-6}$ \\
\hline $\begin{array}{l}\text { Late Ascent Inadver- } \\
\text { tent Range Destruct }\end{array}$ & $1.1 \times 10^{-8}$ & $1.2 \times 10^{-7}$ & $3.1 \times 10^{-7}$ & $1.1 \times 10^{-6}$ \\
\hline $\begin{array}{l}\text { Inadvertent Reentry and } \\
\text { Land Impact }\end{array}$ & $1.7 \times 10^{-4}$ & $1.7 \times 10^{-3}$ & $1.7 \times 10^{-3}$ & $4.6 \times 10^{-3}$ \\
\hline
\end{tabular}


Figures ULY-CI-1

Accident Frequency Probability State Vector Ulysses Mission, INSRP scenario \#1

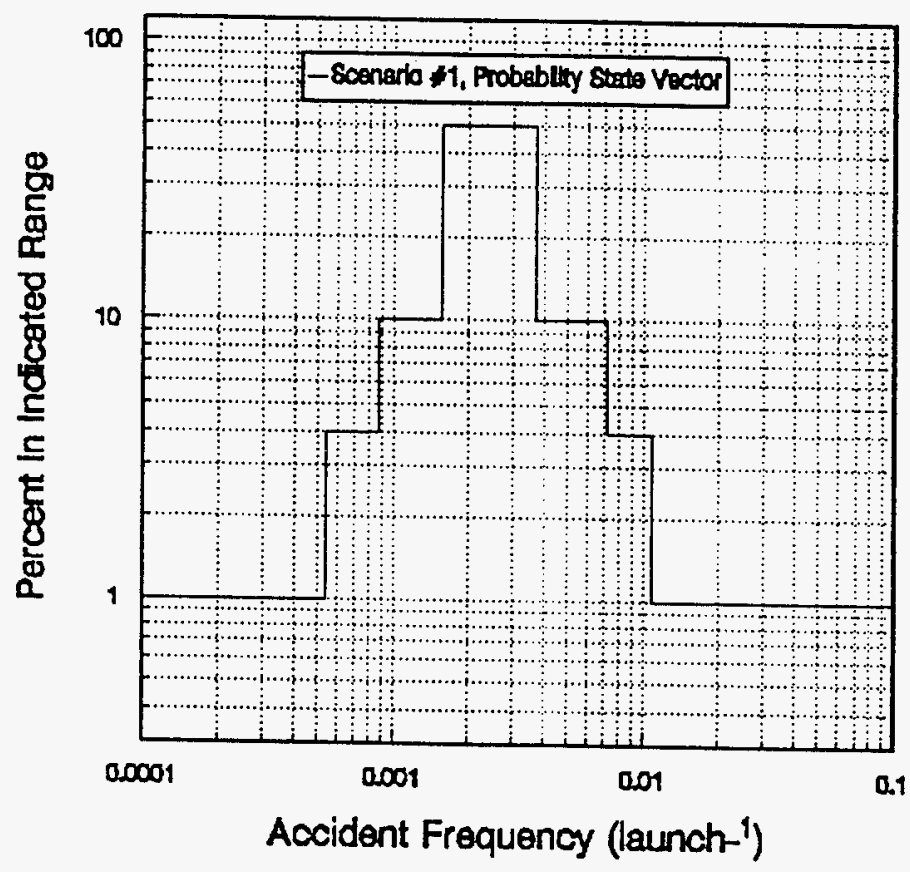

Median accident frequency: 0.0022 per launch.

Mean accident frequency: 0.0029 per launch.

\section{State}

$\underline{\text { Range of Frequency }}$

$f_{1}<0.00054$

$.00054<\mathrm{f}_{2}<0.00088$

$.00088<\mathrm{f}_{3}<0.00124$

$.00124<\mathrm{f}_{4}<0.00156$

$.00156<f_{5}<0.00371$

$.00371<f_{6}<0.00467$

$.00467<\mathrm{f}_{7}<0.00720$

$.00720<\mathrm{f}_{8}<0.01000$

$.01000<\mathrm{f}_{9}$

\section{Fraction Within Range}

0.01

0.04

0.10

0.10

0.50

0.10

0.10

0.04

0.01 
Figures ULY-Cl-2

Accident Frequency Probability State Vector

Ulysses Mission, INSRP scenario \#6

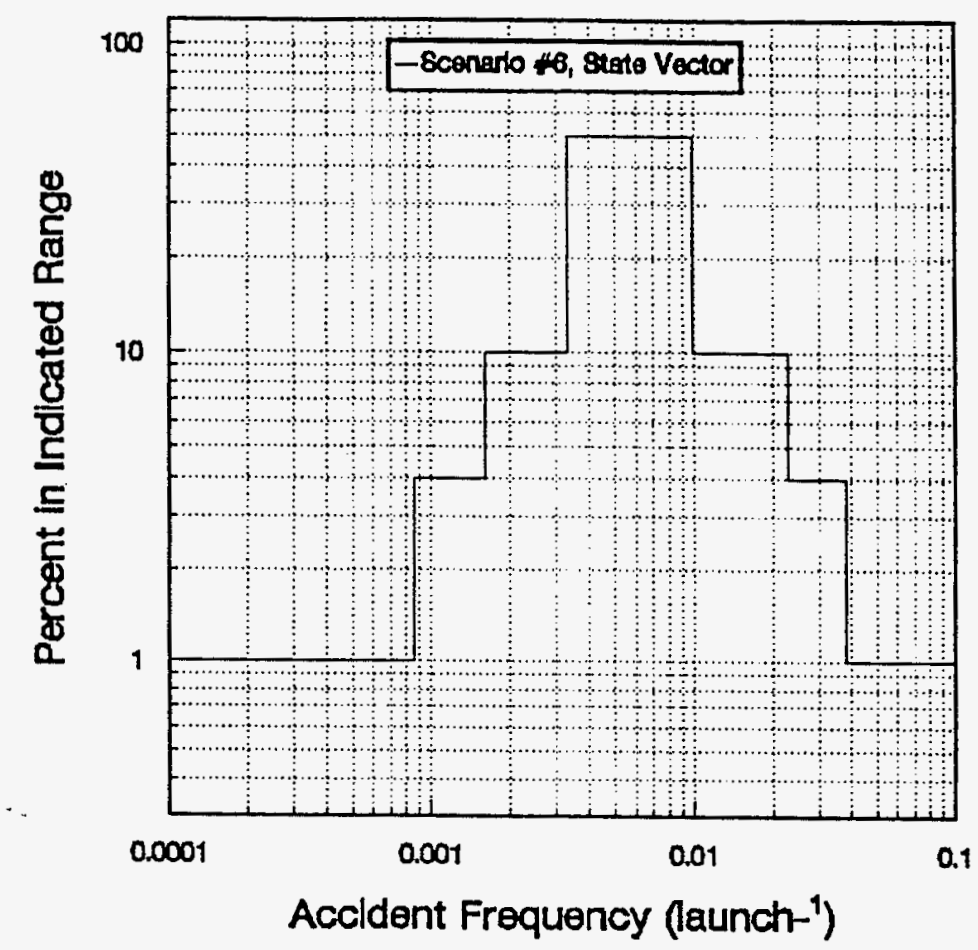

Median accident frequency: 0.0051 per launch.

Mean accident frequency: 0.0086 per launch.

$\begin{array}{cr}\begin{array}{c}\text { State } \\ \text { Range of Frequencies }\end{array} & \text { Fraction Wit } \\ & \mathrm{f}_{1}<0.00086 \\ .00086<\mathrm{f}_{2}<0.00160 & 0.01 \\ .00160<\mathrm{f}_{3}<0.00247 & 0.04 \\ .00247<\mathrm{f}_{4}<0.00330 & 0.10 \\ .00330<\mathrm{f}_{5}<0.00990 & 0.10 \\ .00990<\mathrm{f}_{6}<0.01330 & 0.50 \\ .01330<\mathrm{f}_{7}<0.02300 & 0.10 \\ .02300<\mathrm{f}_{8}<0.03800 & 0.10 \\ .03800<\mathrm{f}_{9} & 0.04 \\ & 0.01\end{array}$


Figures ULY-Cl-3

Accident Frequency Probability State Vector Ulysses Mission, All Scenarios Occurring Prior to 88 s MET

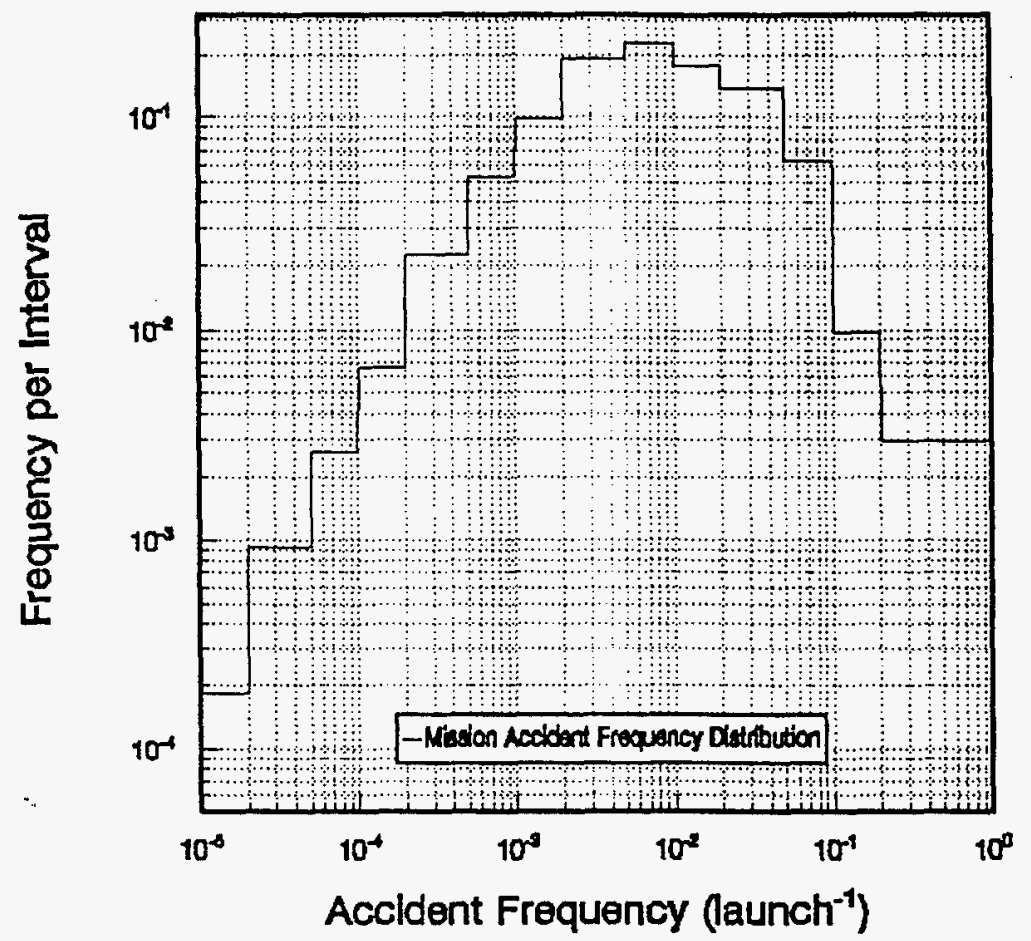

$5^{\text {th }}$ percentile accident frequency: 0.0005 per launch. Median accident frequency: 0.004 per launch. Mean accident frequency: 0.01 per launch. $95^{\text {th }}$ percentile accident frequency: 0.04 per launch.

State

Range of Frequencies

$$
\begin{gathered}
\mathrm{f}_{1}<0.00002 \\
0.00002<\mathrm{f}_{2}<0.00005 \\
0.00005<\mathrm{f}_{3}<0.00010 \\
0.00010<\mathrm{f}_{4}<0.00020 \\
0.00020<\mathrm{f}_{5}<0.00050 \\
0.00050<\mathrm{f}_{6}<0.00100 \\
0.00100<\mathrm{f}_{7}<0.00200 \\
0.00200<\mathrm{f}_{8}<0.00500 \\
0.00500<\mathrm{f}_{9}<0.01000 \\
0.01000<\mathrm{f}_{10}<0.02000 \\
0.02000<\mathrm{f}_{11}<0.05000 \\
0.05000<\mathrm{f}_{12}<0.10000 \\
0.10000<\mathrm{f}_{13}<0.20000 \\
0.20000<\mathrm{f}_{14}
\end{gathered}
$$

\section{Fraction Within Range}
0.00018
0.00094
0.0027
0.0066
0.022
0.053
0.10
0.19
0.23
0.18
0.14
0.063
0.0098
0.003 


\section{B. Accident Environments (Cell \#2).}

The pictorial view of the accident shown above illustrates the assumption that only large Solid Rocket Booster (SRB) fragments pose a significant hazard to the RTG. The RTG is expected to survive the explosion itself (overpressure, dynamic response etc), small fragments (termed shrapnel) as well as ground impact. Thus the accident environment of concern is related to the number and velocity of large SRB fragments and the probability of impacting the RTG. The velocity distribution for SRB fragments is provided in the Ulysses documentation based on NASA's analysis of the STS-51L (Challenger) and the Titan 34D-9 accidents. Both the GE/NUS and INSRP have taken the position that fragment size and weight is an unimportant variable (all fragments of concern are very large and heavy in relation to the RTG). Only velocity and spatial distribution were assumed to be important and thus fragment velocity becomes the output state for this cell. The velocity distribution curves provided in the documentation have been reduced to a set of fragment velocity state vectors for three different Mission Elapsed Times (METs). These state-vectors give the probability of finding a fragment in the given velocity range and are shown in Table ULY-C2-1. The state-vector for the MET $<88$ s (the only one used in this analysis consistent with the INSRP SER) is shown in Figure ULY-C2-1.

In addition to velocity, the probability of hitting the RTG (total probability of a hit is given as 0.145 ) and the orientation of the hit are important to the analysis. The four types of hits defined for Ulysses and their conditional hit probabilities (i.e., assuming a that a hit occurs) for a random failure of an SRB during MET 0 s to 120 s are summarized below.

1. A fragment hitting the side of the RTG in a flat or face-on position (FOSH). Conditional hit probability $=0.492$.

2. A fragment hitting the end (top/bottom) of the RTG in a flat or face-on position (FOEH). Conditional hit probability $=0.432$.

3. A fragment hitting the side of the RTG in an edge-on position (EOSH). Conditional hit probability $=0.058$.

4. A fragment hitting the end (top/bottom) of the RTG in an edge-on position (FOEH). Conditional hit probability $=0.018$.

The probabilities given above are the GE/NUS probabilities. There was a difference of optinion between INSRP and the GE/NUS team of exactly how these various cases should be defined. However, for the purposes of illustration here, those differences are unimportant and the GE/NUS probabilities have been used.

In any event, the velocity state-vectors (Table ULY-C2-1 and Figure ULY-C2-1), the fragment hit definitions, and the hit probabilities given here represent the output of the accident environments cell. 
Table ULY-C2-1

SRB Random Failure

Fragment Velocity State Vectors

for

Three Mission Elapsed Times (MET)

\begin{tabular}{|c|c|c|c|c|}
\hline \multicolumn{2}{|c|}{ Fragment Velocity (ft/sec) } & \multicolumn{3}{|c|}{ Velocity Probability State Vector } \\
\hline Range & Index Velocity & MET $0-87 \mathrm{~s}$ & MET 88-104s & MET $104-120 \mathrm{~s}$ \\
\hline $0-20$ & 10 & 0.199 & 0.053 & 0.025 \\
\hline $20-25$ & 22.5 & 0.022 & 0.008 & 0.004 \\
\hline $25-30$ & 28 & 0.029 & 0.011 & 0.006 \\
\hline $30-40$ & 35 & 0.041 & 0.016 & 0.009 \\
\hline $40-50$ & 44 & 0.056 & 0.024 & 0.014 \\
\hline $50-60$ & 55 & 0.071 & 0.035 & 0.021 \\
\hline $60-75$ & 69 & 0.093 & 0.053 & 0.034 \\
\hline $75-95$ & 86 & 0.116 & 0.081 & 0.057 \\
\hline $95-120$ & 107 & 0.131 & 0.121 & 0.093 \\
\hline $120-150$ & 134 & 0.121 & 0.164 & 0.145 \\
\hline $150-186$ & 168 & 0.081 & 0.186 & 0.195 \\
\hline $186-232$ & 209 & 0.033 & 0.154 & 0.206 \\
\hline $232-291$ & 262 & 0.0065 & 0.078 & 0.142 \\
\hline $291-364$ & 328 & 0.004 & 0.015 & $\overline{0} .043$ \\
\hline $364-455$ & 410 & 0.0001 & 0.0008 & 0.004 \\
\hline$>455$ & 455 & 0.0 & 0.0002 & 0.002 \\
\hline
\end{tabular}


Figure ULY-C2-1

SRB Fragment Velocity

Probability State Vector

MET $0 \mathrm{~s}$ to $87 \mathrm{~s}$

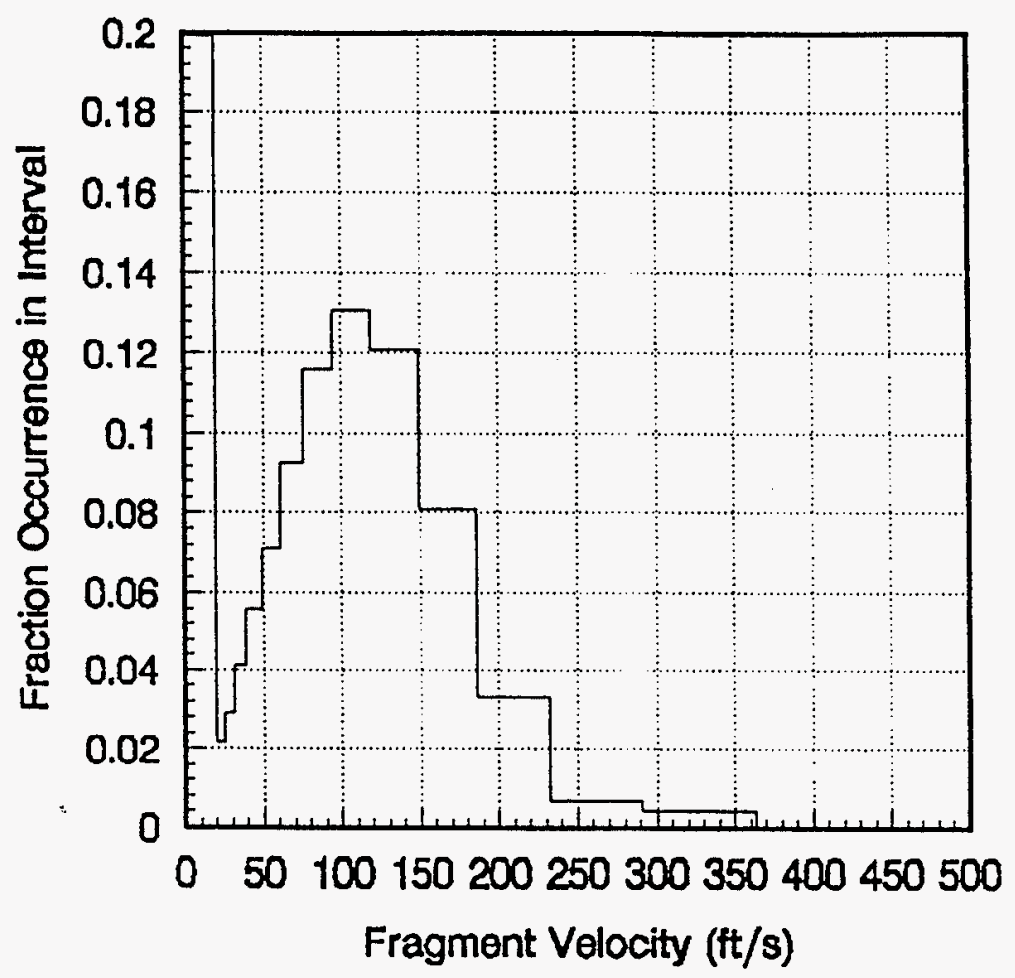

State

$\underline{\text { Range of Velocity (ft/s) }}$

Fraction Within Range

$$
\begin{aligned}
\mathrm{v}_{1} & <20 \\
20 & <\mathrm{v}_{2}<25 \\
25 & <\mathrm{v}_{3}<30 \\
30 & <\mathrm{v}_{4}<40 \\
40 & <\mathrm{v}_{5}<50 \\
50 & <\mathrm{v}_{6}<60 \\
60 & <\mathrm{v}_{1}<75 \\
75 & <\mathrm{v}_{8}<95 \\
95 & <\mathrm{v}_{9}<120 \\
120 & <\mathrm{v}_{10}<150 \\
150 & <\mathrm{v}_{11}<186 \\
186 & <\mathrm{v}_{12}<232 \\
232 & <\mathrm{v}_{13}<291 \\
291 & <\mathrm{v}_{14}<364 \\
364 & <\mathrm{v}_{15}<455 \\
455 & <\mathrm{v}_{16}
\end{aligned}
$$

0.029

0.041

0.056

0.071

0.093

0.116

0.131

0.121

0.081

0.033

0.0065

0.004

0.0001

0.00 


\section{System Response (Cell \#3).}

Although several system response states are possible (failed and/or unfailed RTG, GPHS, GIS and clads) the state of interest here is failed clads (leading to the release of fuel). Thus the goal of the system response cell is to describe the probability distribution of failed clads following an accident (i.e., the probability that " $n$ " clads will be failed). To do this a method of estimating the probability of failure as a function of the fragment velocity and its orientation must be devised. Both the GE/NUS and the INSRP used an intermediate parameter (designated as deformation or distortion) to describe clad damage. GE/NUS then applied a threshold value of the deformation parameter below which all clads survived and above which all clads failed. The INSRP used a probabilistic failure parameter that was a function of the deformation parameter (they also applied a threshold deformation for failure although the INSRP threshold was about one-half the GE/NUS threshold). There is essentially no basis for assuming either threshold value of the deformation parameter.

For the purposes of this investigation, the INSRP failure probability calculation is used (without applying the deformation threshold for failure) and the vector-matrix approach will be applied. The clad failure probability used by INSRP is a lognormal function of the calculated deformation. This function (for impacts involving the RTG) is shown graphically in Figure ULY-C3-1. The foremost problem is to devise the transition matrix describing the probability distribution of clad failures for each fragment velocity and orientation. Thus, for each of the fragment-hit definitions and the velocity-states, a deformation must be calculated, a failure probability must be calculated from the deformation, and the distribution of failed clads constructed.

Two simplifications of the accident progression have been made in the current calculations, one of which is consistent with both the GE/NUS SAR and the INSRP SER, and a second which is not. The first simplification is to disregard the possibility of a second hit by an SRB fragment. Only the initial fragment impact has been considered. The probability of multiple fragment impacts (possible only in range destruct cases) in combination with the range destruct event probability yielded events with such low probability as to be inconsequential. The second simplification was to disregard the deformation effect of ground impacts following the accident. Ground impact are important only for impact on solid surfaces, thus their consideration would require the inclusion of a calculation of the probability of hitting concrete and/or steel on impact and including this impact in the deformation calculation. From intermediate calculations it is estimated that the effect of these additional impacts would be much less than a factor of two in terms of the probability of at least one clad failing and about the same order of effect on source term.. Thus it was considered of only secondary importance to this illustration. This latter simplification is non-conservative in relation to the INSRP analysis, but unfortunately, it is not possible to make an actual comparison because of the lack of intermediate output in the existing documentation. A number of velocity thresholds are also important. It is assumed that the following thresholds obtain.

$\begin{array}{lll}\text { Case Rupture: } & \text { Face-on side hit: } & 90 \mathrm{~m} / \mathrm{s}(295 \mathrm{ft} / \mathrm{s}) \\ & \text { Face-on end hit: } & 40 \mathrm{~m} / \mathrm{s}(131 \mathrm{ft} / \mathrm{s}) \\ & \text { Edge-on side hit: } & 20 \mathrm{~m} / \mathrm{s}(66 \mathrm{ft} / \mathrm{s}) \\ & \text { Edge-on end hit: } & 20 \mathrm{~m} / \mathrm{s}(66 \mathrm{ft} / \mathrm{s}) \\ \text { Aeroshell Rupture: } & \text { Face-on: } & 115 \mathrm{~m} / \mathrm{s}(377 \mathrm{ft} / \mathrm{s}) \\ & \text { Edge-on } & 37 \mathrm{~m} / \mathrm{s}(121 \mathrm{ft} / \mathrm{s})\end{array}$


The calculations for each of the fragments orientations identified previously are discussed in the following paragraphs.

\section{Face-on Side Hit (FOSH).}

The conditional probability for the FOSH is 0.492 and all clads (72) are involved. The deformation is calculated from equations fitted to hydrocode data and provided by GE/NUS. The deformation is calculated for 36 leading and 36 aft clads in five different module locations, and the clad failure model is used to calculate the expected number of failed clads at each velocity. In light of the relatively large number of clads involved (72) and the small number of expected failures (close to zero), the number of failures was distributed by Poisson statistics at each velocity. This produces a set of statevectors that together yield the transition matrix for this cell -- which is shown below. In simple terms, each entry in this table gives the probability that $\mathbf{n}$ clads (indicated by the column) will fail given a hit by a fragment of the specified velocity $i$ (indicated by the row).

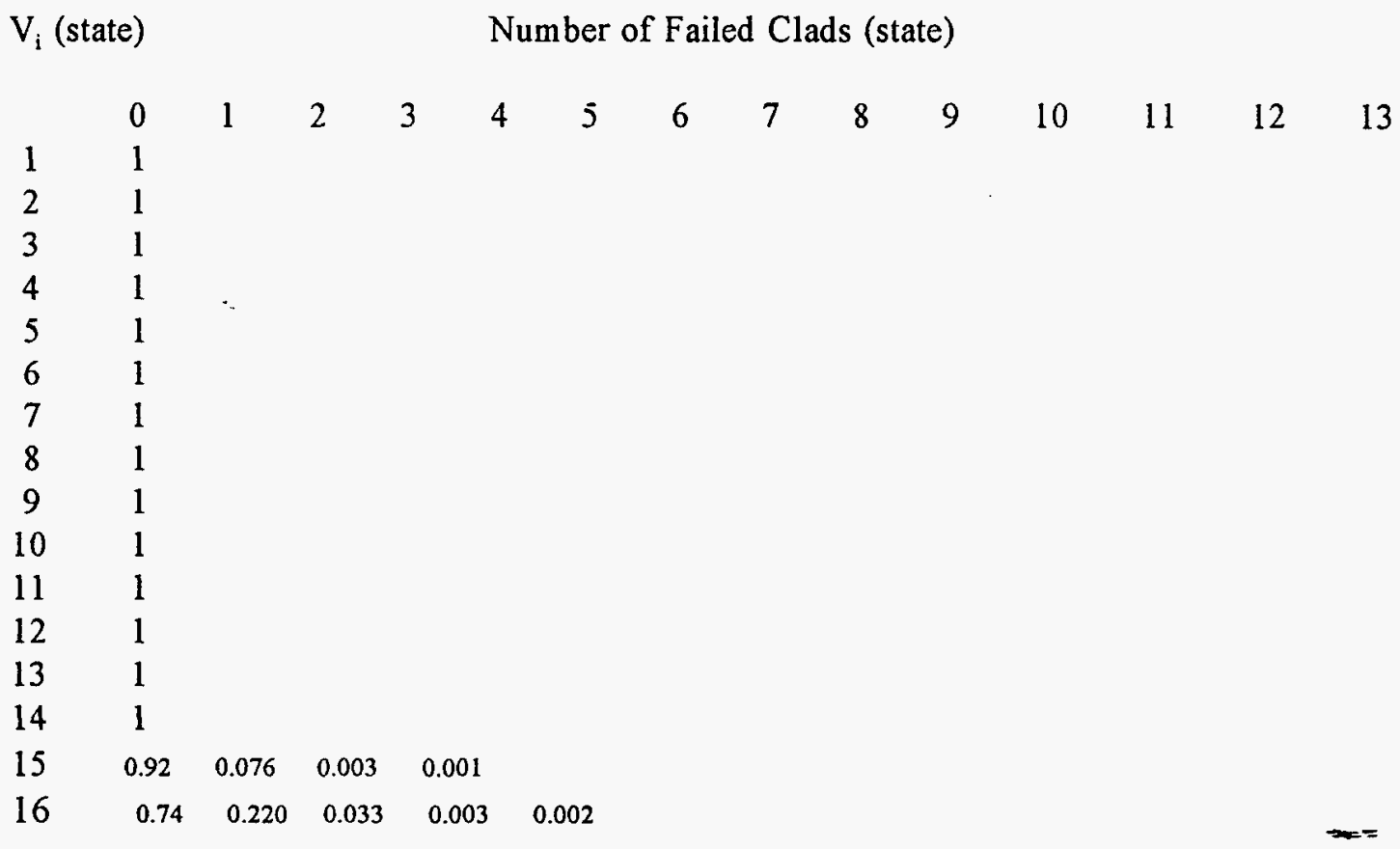

Thus for the event considered here (FOSH) only the highest two velocity states yield the possibility of failed fuel clads. This transition matrix is combined with the transition matrices from other fragment impacts to yield the Cell 3 Probability Transition Matrix at the end of this discussion.

2. Edge-on Side Hit (EOSH).

The conditional probability for the EOSH is 0.058 and all clads (72) may be involved. The GE/NUS documentation graphs the probability that a given number of modules (containing 
4 clads) will be hit. From that graph it has been approximated that the probability that all 18 modules will be hit is about 0.49 , while the probability that $1,2, \ldots$ or 17 modules will be hit is about 0.03 for each case. For each case the deformation for the one leading and one trailing clad in each module have been calculated. The deformation is calculated from a linear fit to the tabular data presented by GE/NUS (it is not really clear how this calculation is made in the LASEP3 code). The GE/NUS tabulated data and the fitted approximations are shown in Figure ULY-C3-2.

Although the deformation calculations were made for both leading and trailing clads the trailing clads did not add significantly to the failure probabilities. Thus, for simplicity, they were not included in the completion of the transition matrix. The transition matrix was calculated by distributing the number of failures binomially (the probability of " $n$ " failed clads out of the total of 18 affected clads) given the individual clad failure probability. The transition matrix for this event is shown below (note this is transposed from the previous matrix). Only the highest five velocity states yielded failures because of a zero deformation intercept at velocity of $143 \mathrm{ft} / \mathrm{s}$ in addition to the $121 \mathrm{ft} / \mathrm{s}$ threshold for aeroshell rupture.

\begin{tabular}{lccccc} 
Clads & \multicolumn{5}{c}{ Velocity State } \\
$\mathrm{N}$ & V12 & $\mathrm{V} 13$ & $\mathrm{~V} 14$ & $\mathrm{~V} 15$ & $\mathrm{~V} 16$ \\
& $\ddots$ & & & & \\
0 & 0.247 & 0.041 & 0.013 & 0.005 & 0.003 \\
1 & 0.285 & 0.072 & 0.043 & 0.034 & 0.033 \\
2 & 0.231 & 0.073 & 0.043 & 0.034 & 0.033 \\
3 & 0.140 & 0.078 & 0.043 & 0.034 & 0.033 \\
4 & 0.064 & 0.089 & 0.043 & 0.034 & 0.033 \\
5 & 0.025 & 0.105 & 0.043 & 0.034 & 0.033 \\
6 & 0.006 & 0.121 & 0.043 & 0.034 & 0.033 \\
7 & 0.002 & 0.126 & 0.044 & 0.034 & 0.033 \\
8 & & 0.113 & 0.049 & 0.034 & 0.033 \\
9 & & 0.085 & 0.058 & 0.034 & 0.033 \\
10 & & 0.053 & 0.075 & 0.035 & 0.033 \\
11 & & 0.027 & 0.196 & 0.036 & 0.033 \\
12 & & 0.011 & 0.114 & 0.041 & 0.033 \\
13 & & 0.004 & 0.114 & 0.055 & 0.037 \\
14 & & 0.001 & 0.092 & 0.084 & 0.049 \\
15 & & & 0.056 & 0.126 & 0.085 \\
16 & & & 0.025 & 0.149 & 0.144 \\
17 & & & 0.008 & 0.117 & 0.179 \\
18 & & & 0.001 & 0.044 & 0.111
\end{tabular}

As with the previous case, this transition matrix is combined with the transition matrices from 
other fragment impacts to yield the Cell 3 Probability Transition Matrix at the end of this discussion.

\section{Edge-on End Hit (EOEH).}

The conditional probability for the EOEH is 0.018 and it has been assumed that only 4 clads will be affected (two in each of the first two modules in the stack). The deformation has been calculated from a linear fit to the tabular data presented by GE/NUS (note that again it is not really clear how LASEP3 does this calculation). These data and the fitted approximations are shown in Figure ULY-C3-3. The probability distribution of failed clads was calculated assuming an uncertainty in the deformation calculation of $\pm 20 \%$ at each velocity and position. This was done for illustration and in this case is relatively simple because only four clads are involved. Failed capsules were predicted only for velocity states 9 through 16 (i.e., velocities greater than $95 \mathrm{ft} / \mathrm{s}$ ) as a result of a threshold for aeroshell failure at the top of this velocity range ( 95 to $120 \mathrm{ft} / \mathrm{s}$ ). The transition matrix for this case is reproduced below. As with the previous cases, this transition matrix is combined with the transition matrices from other fragment impacts to yield the Cell 3 Probability Transition Matrix at the end of this discussion.

V(i state)

Number of failed Clads (n state)

$\begin{array}{clcccc} & 0 & 1 & 2 & 3 & 4 \\ 1 & 1 & & & & \\ 2 & 1 & & & & \\ 3 & 1 & & & & \\ 4 & 1 & & & & \\ 5 & 1 & & & & \\ 6 & 1 & & & & \\ 7 & 1 & & & & \\ 8 & 1 & & & & \\ 9 & 0.992 & 0.008 & & & \\ 10 & 0927 & 0.071 & 0.002 & & \\ 11 & 0.741 & 0.231 & 0.026 & 0.001 & 0.001 \\ 12 & 0.460 & 0.397 & 0.126 & 0.016 & 0.010 \\ 13 & 0.201 & 0.402 & 0.298 & 0.089 & 0.058 \\ 14 & 0.06 & 0.250 & 0.387 & 0.245 & 0.394 \\ 15 & 0.012 & 0.012 & 0.099 & 0.31 & \\ 16 & 0.005 & 0.055 & 0.241 & 0.424 & 0.275\end{array}$

4. Face-on End Hit (FOEH).

The conditional probability for the FOEH is 0.432 . It has been assumed that 16 clads will 
be affected (four in each of the first four modules in the stack). This is consistent with velocities above about $200 \mathrm{ft} / \mathrm{s}$ (velocity state 12 ) and is conservative below this velocity state. The deformation has been calculated from a linear fit to the tabular data presented by GE/NUS (again it is not really clear how LASEP3 does this calculation). These data and the fitted approximations are shown in Figure ULY-C3-4. The probability distribution of failed clads was calculated assuming a binomial distribution in each of the two sets of four clads and then combining these distributions. Again, failed capsules were predicted only for velocity states 9 through 16 (i.e., velocities greater than $120 \mathrm{ft} / \mathrm{s}$ ) as a result of a threshold for aeroshell failure of $131 \mathrm{ft} / \mathrm{s}$ and a threshold for deformation of about $66 \mathrm{ft} / \mathrm{s}$ (see Figure ULY-C3-4). The transition matrix is reproduced in the following table. As with the previous cases, this transition matrix is combined with the transition matrices from other fragment impacts to yield the Cell 3 Probability Transition Matrix at the end of this discussion.

V(i state) Number of failed Clads (n state)

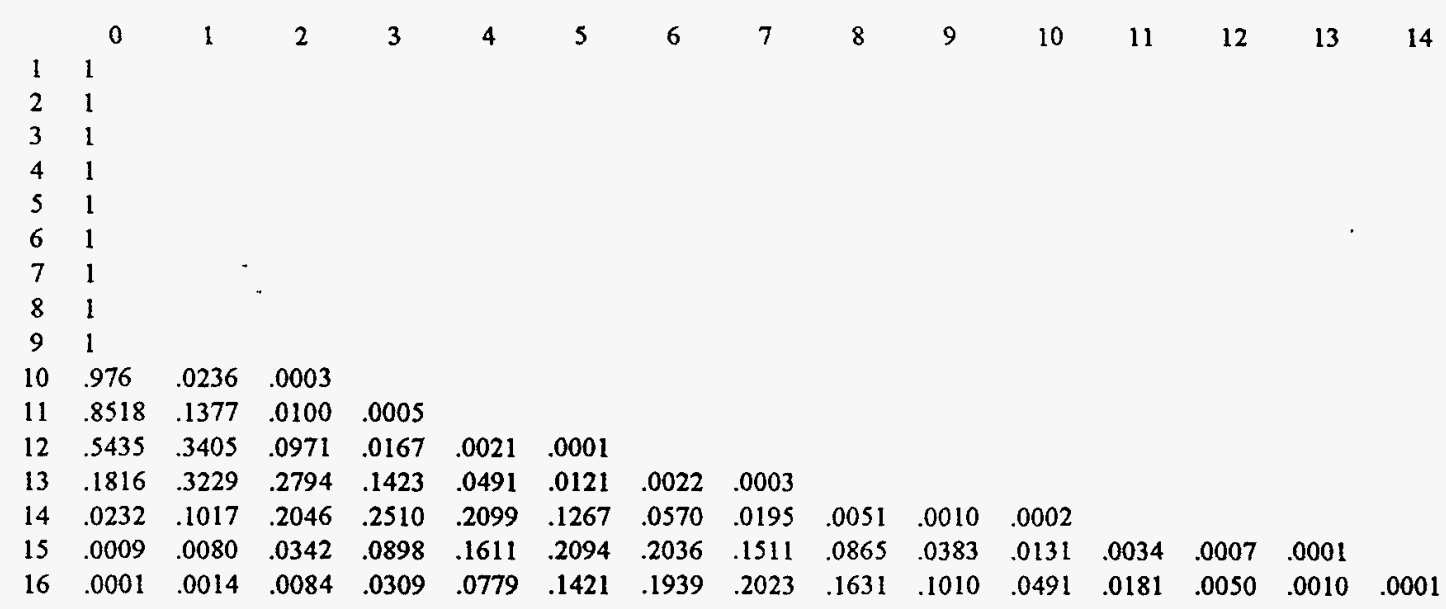

\section{Cell 3 Probability Transition Matrix and the Output State-Vector.}

The summary transition matrix for this cell is shown in Table ULY-C3-1. This matrix is obtained by weighting each of the previous matrices by their conditional occurrenceprobabilities and adding the results. The final transition matrix is then multiplied by the velocity state-vector to yield the failed capsule state-vector (including zero failures), which is then normalized to one by subtracting out the zero failure probability $\left(f_{0}=0.978\right)$ and dividing by the remainder -- i.e., the total probability that one or more capsules will be failed $\left(1-f_{0}\right)$. This normalizing probability (one minus the zero failure probability) is the conditional failure probability for this cell.

The output from this cell is the failed capsule probability state-vector and the conditional release probability to which it is normalized. These results are summarized on the following page and the failed capsule probability stated vector is shown graphically in Figure ULY-C3-5. 
Summary of Cell \#3 capsule failure state vector and conditional release probability.

Mean accident probability:

Conditional release probability, given an accident:

$$
\text { Number of }
$$

Failed Capsules

1

2

3

4

5

$\cdot 6$

7

8

9

10

11

12

13

14
Probability of

Occurrence

0.662

0.186

0.076

0.030

0.016

0.009

0.005

0.004

0.003

0.002

0.002

0.002

0.002

0.001

III-16

0.01 per launch

0.022 
Table ULY-C3-1

CELL 3 PROBABILITY TRANSITION MATRIX

(Velocity to the Number of Failed Fueled Clads)

NUMBER OF FAILED CLADS

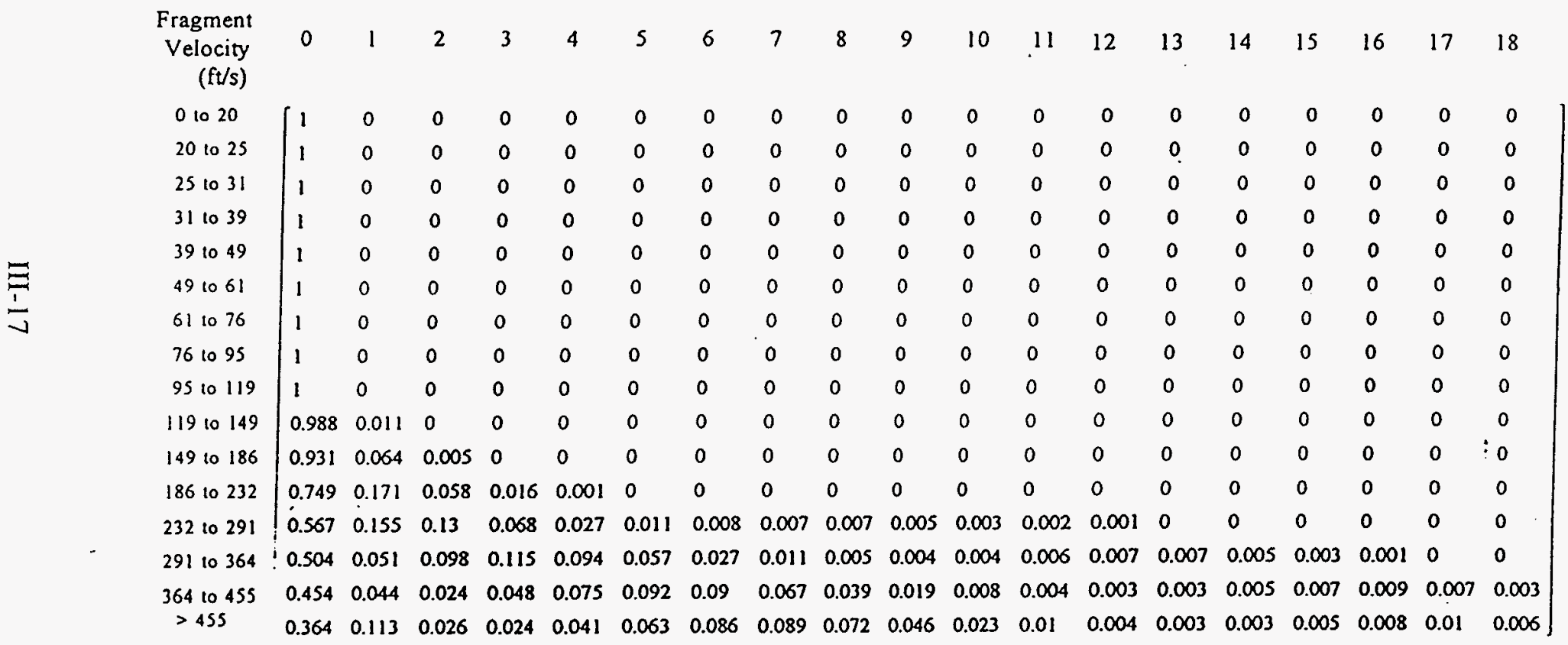




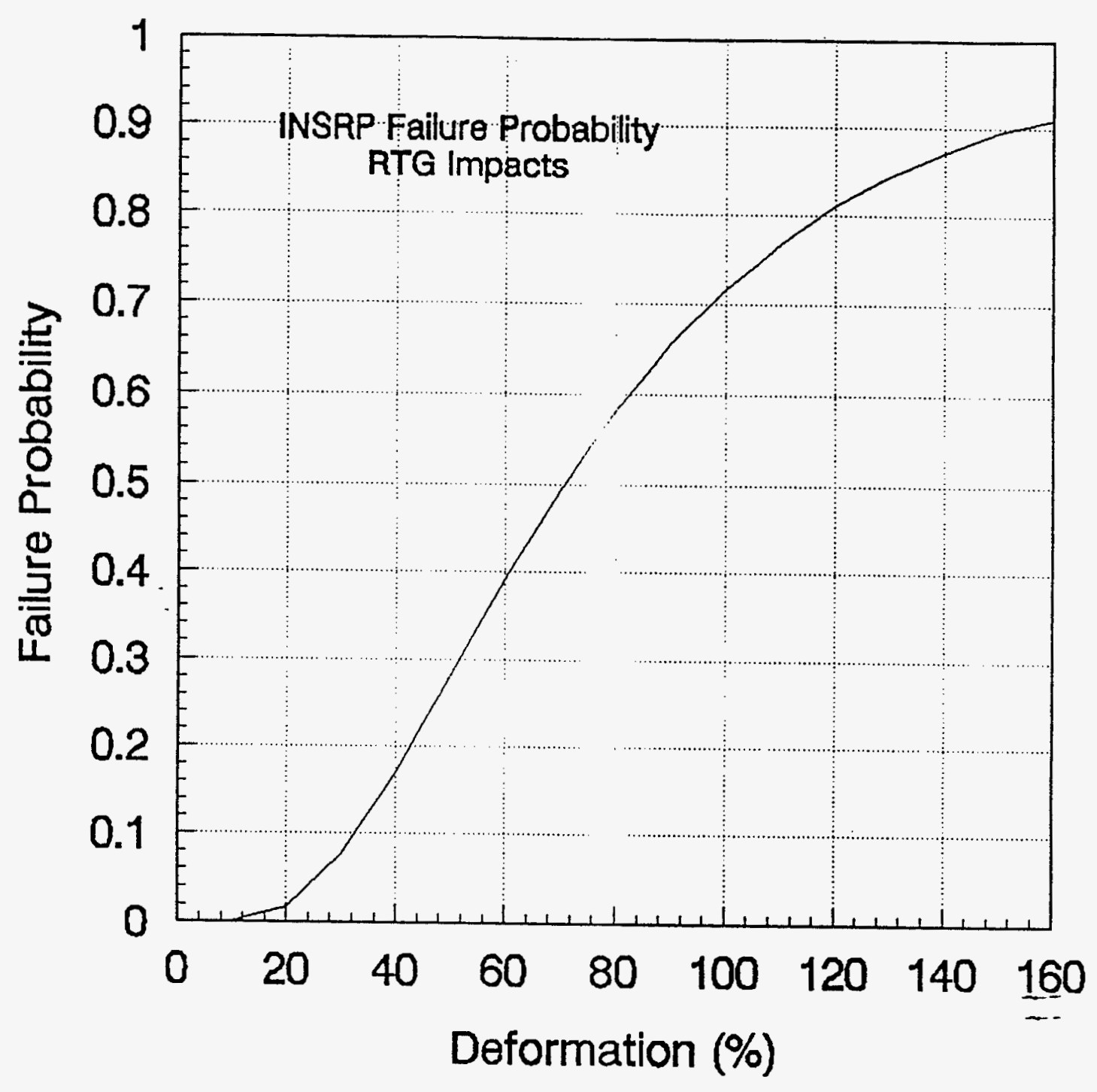

FIGURE ULY-C3-1

CLAD FAILURE vs DEFORMATION

From INSRP 


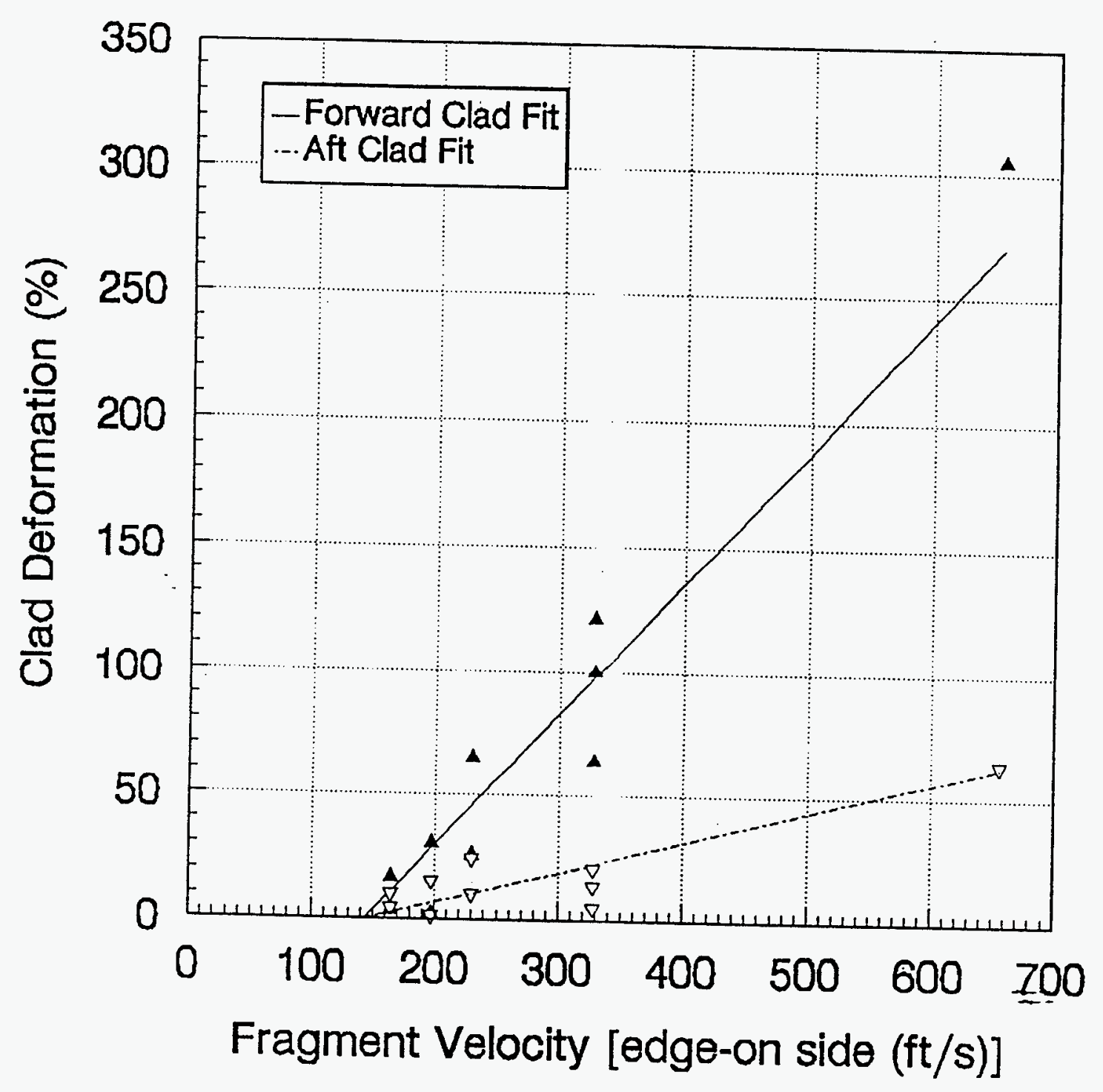

FIGURE ULY-C3-2

DEFORMATION vS FRAGMENT IMPACT VELOCITY

Edge-on Side Hit 


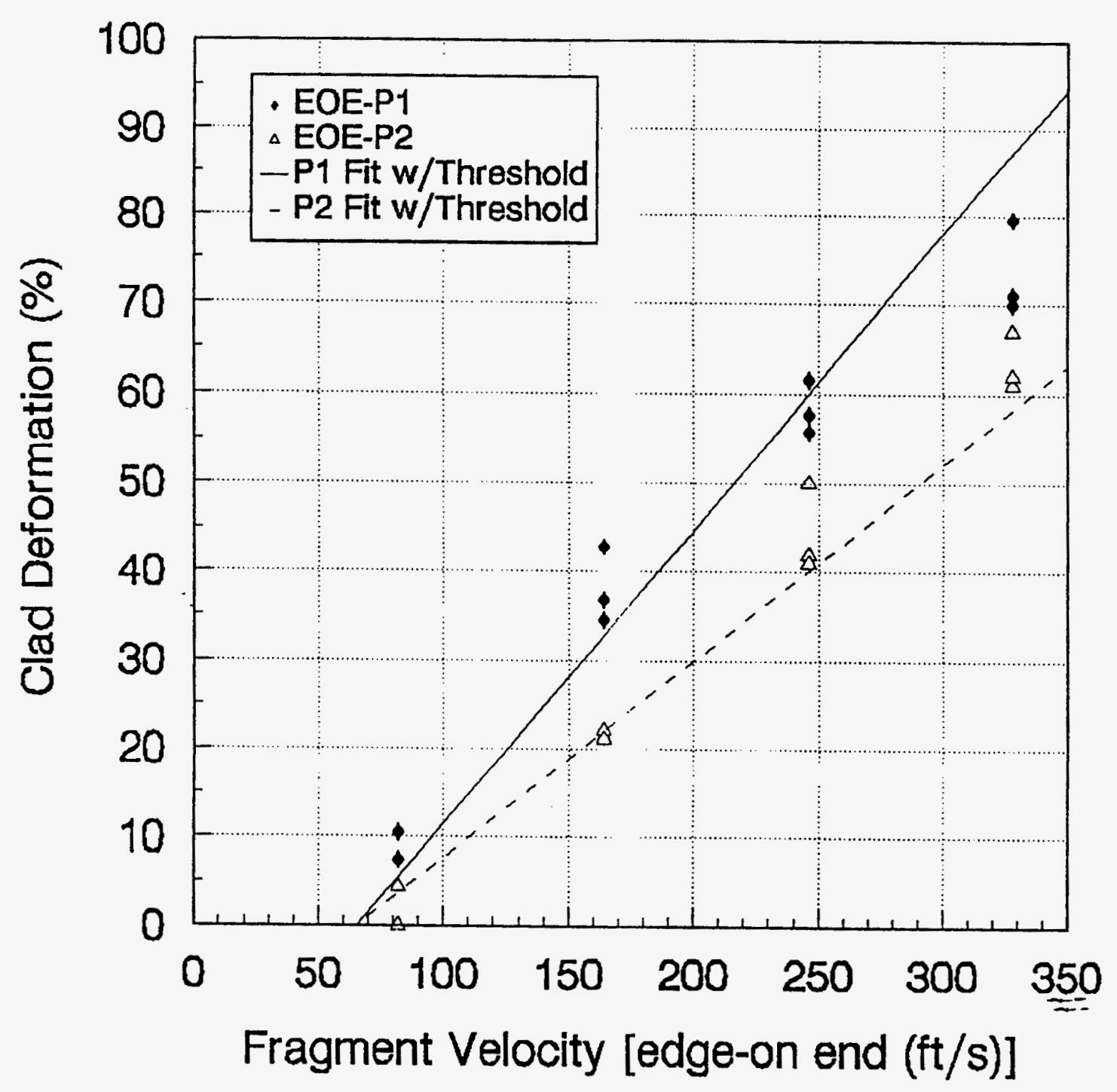

FIGURE ULY-C3-3

DEFORMATION vS FRAGMENT IMPACT VELOCITY

Edge-on End Hit 


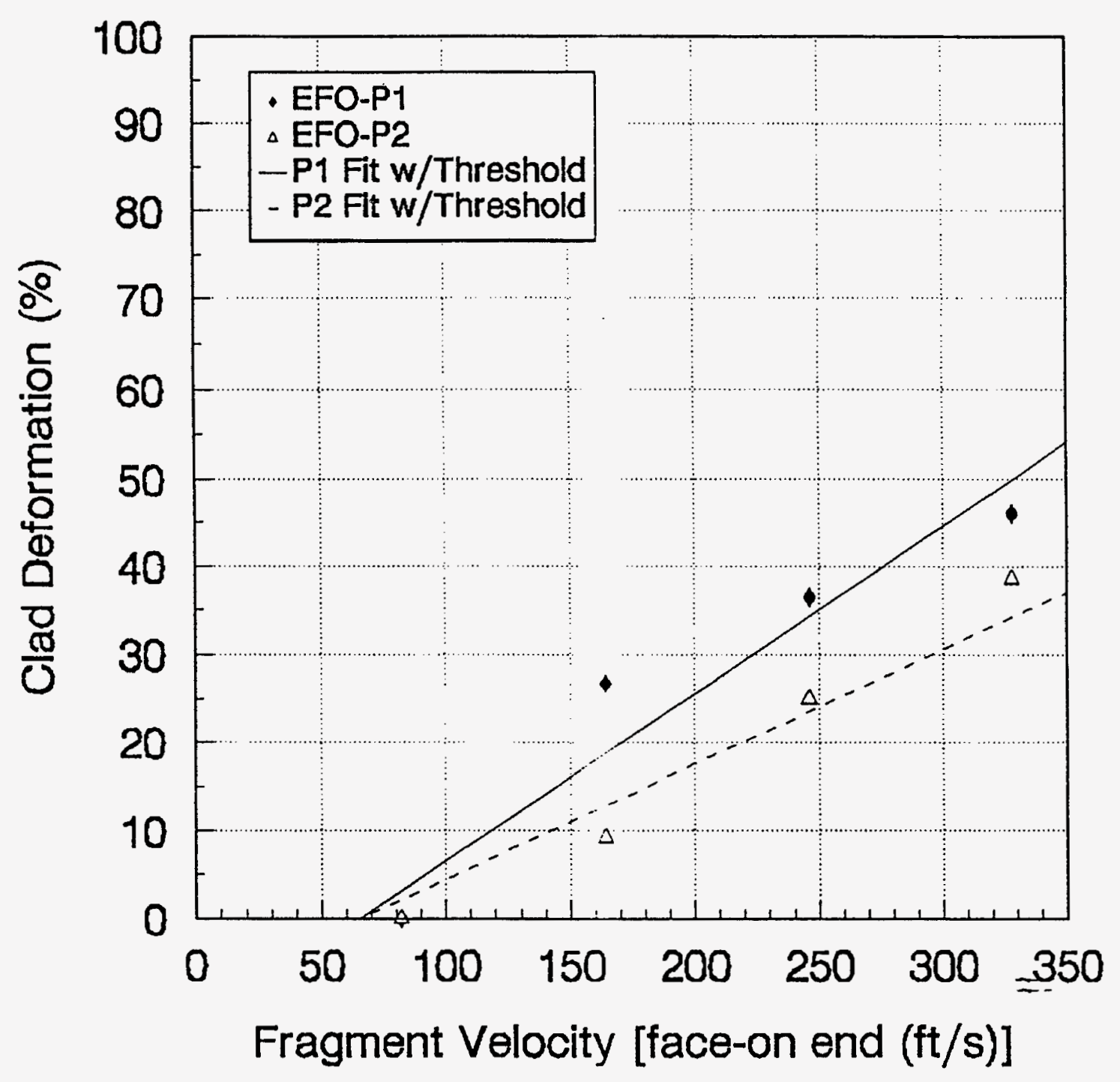

FIGURE ULY-C3-4

DEFORMATION vS FRAGMENT IMPACT VELOCITY

Face-on End Hit 


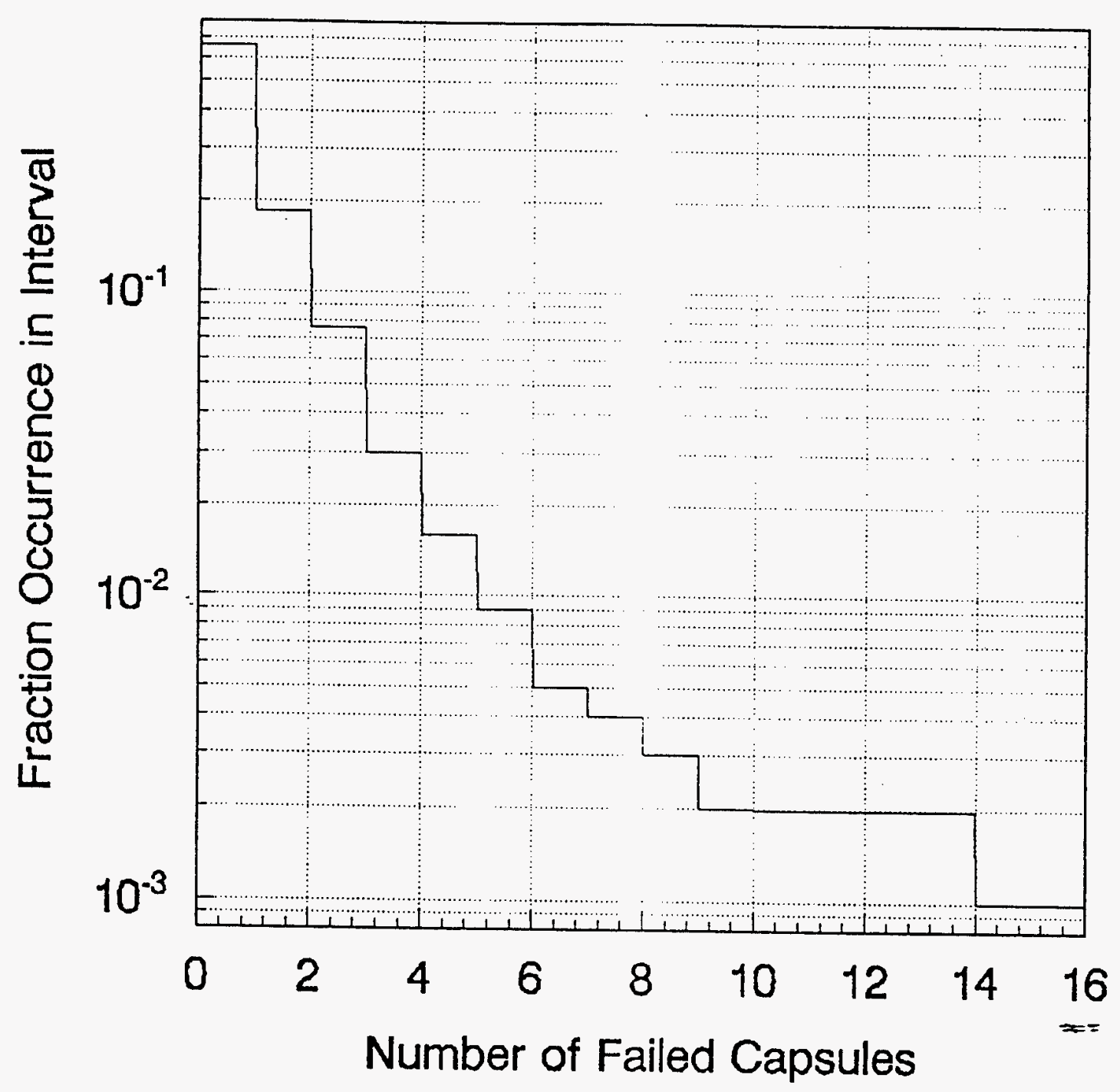

FIGURE ULY-C3-5

FAILED CAPSULES - PROBABILITY STATE VECTOR

(conditional release probability given and accident $=0.022$ ) 


\section{Source Terms (Cell \#4).}

The goal of the source term cell is to describe the probability distribution of released fuel as a function of the number of failed fueled clads (the failure states from Cell \#3 and the associated probability state vector). Both the GE/NUS and the INSRP constructed a method of estimating fuel release using an equation to calculate the fuel release (as a percentage of clad loading) as a function of the calculated deformation. The equation included a threshold deformation below which no release occurred (all clads survived) and above which all clads failed The GE/NUS equation is illustrated in Figure ULY-C4-1 along with the experimental data on fuel release as a function of the deformation parameter. Clearly the approximating equation is barely representative of the observed data -- although it is more representative of the $\mathrm{Pu}$ oxide than the U oxide -- and the very high variability in the observed releases is lost. The INSRP, recognizing this problem, fitted a set of equations (of the GE/NUS form) to the individual Pu oxide data points and selected from these randomly in the Monte Carlo analysis. The INSRP approach is an improvement but it does not take account of the broader range observed in the U oxide data.

A third method was used here. First, all of the data are used. Then, as with the INSRP approach, the total data set is taken to be a limited sample of random events. This is a recognition of the extreme scatter and the sensitivity to deformation (deformation ranging from $10 \%$ to $70 \%$ and associated releases ranging over five orders of magnitude). Here however, rather than assume a release-deformation relationship, it is assumed that no clear deformation relationship can be divined. Therefore, the observed data are taken to be limited samples of random events and a distribution is fitted to the data. To illustrate the distribution, the experimental data of Figure ULY-C4-I are plotted again in Figure ULY-C4-2, however in this case as two sets of cumulative frequency distributions on a log-probability graph. For this investigation, the best straight-line curve was used to define the fuel release distribution on a per capsule basis.

Once the form of the release distribution has been decided upon, the next problem is to devise a set of source term states that cover the entire range of possible releases. In the case at hand, considering a minimum release of about $7 \mathrm{mCi}$ (BCI \#24) and a maximum of fourteen breached clads, the released source can range from 0.007 to $25,600 \mathrm{Ci}$ (about 6 orders-of magnitude). In order to cover this broad range in a reasonable number of states the source term states were defined by multiples of two. That is, the upper limit of the first source term state was taken as $0.007 \mathrm{Ci}$ and the upper limit of each subsequent state a factor of two above the previous state. For the range assumed, the upper limit of the set of states is given by $0.007 \times 2^{\mathrm{n}}$ where $\mathrm{n}$ ranges from 0 to 22 . This gives a set of 23 states and covers the entire range of possible releases. In fact, due to occurrence probability, only 21 states were necessary.

A second problem is that not all of the released material is respirable (i.e., aerodynamic diameter $<10 \mu \mathrm{m}$ ). For plutonium dioxide (density about $10 \mathrm{~g} / \mathrm{cc}$ ) this is roughly $4 \mu \mathrm{m}$ actual diameter. To simplify the problem for this analysis, it was decided to focus the analysis on that fraction 
of the released material. Reported particle size data for released material was used for estimating the material in the $<4 \mu \mathrm{m}$ range. Figure ULY-C4-3 is a graph of the material $<10 \mu \mathrm{m}$ physical diameter as a function of the total release for all of the BCI data. A arbitrary curve has been fitted to that information (shown on graph as "Approximation") and the portion $<4 \mu \mathrm{m}$ is assumed to be one-half that in the $<10 \mu \mathrm{m}$ range (this latter assumption is a reasonable approximation of the measured data).

The next step for this cell is to generate a transition matrix, where each row (n) represents the source term distribution from $1,2, \ldots . . n$ failed capsules. This is done by combining the appropriate number of capsule distribution using a single capsule distribution derived from Figures ULY-C4-2 and ULY-C4-3. Finally, the output state vectors for this cell are obtained by the appropriate vector-matrix multiplication. The output probability state vectors for the total release and the $<4 \mu \mathrm{m}$ size range are shown in Figures ULY-C4-4 and ULY-C4-5 respectively and summarized in the following table (Table ULY-C4-1). 
Table ULY-C4-1

Summary of Cell \#4 Output Probability State Vectors

Mean accident probability:

Conditional release probability given and accident:
0.01 per launch

0.022

\begin{tabular}{|c|c|c|c|}
\hline \multicolumn{3}{|c|}{ Vector States } & \multirow[b]{3}{*}{ Probability } \\
\hline \multirow{2}{*}{\multicolumn{2}{|c|}{$\begin{array}{l}\text { Range Total } \\
\text { Release (Ci) }\end{array}$}} & Range Respirable & \\
\hline & & $\underline{\text { Release }(\mathrm{Ci}<4 \mu \mathrm{m})}$ & \\
\hline \multicolumn{2}{|c|}{$<0.007$} & $<0.00038$ & 0.02853 \\
\hline 0.007 & $-\quad 0.014$ & $0.00038-0.00076$ & 0.03407 \\
\hline 0.014 & -0.028 & $0.00076-0.00153$ & 0.03968 \\
\hline 0.028 & -0.055 & $0.00153-0.00305$ & 0.04534 \\
\hline 0.055 & -0.111 & $0.00305-0.00610$ & 0.05094 \\
\hline 0.111 & $-\quad 0.222$ & $0.00610-0.01221$ & 0.05619 \\
\hline 0.222 & $-\quad 0.442$ & $0.01221-0.02441$ & 0.06094 \\
\hline 0.442 & $-\quad 0.887$ & $0.02441-0.04883$ & 0.06488 \\
\hline 0.887 & - $\quad 1.773$ & $0.04883-0.08525$ & 0.06772 \\
\hline 1.773 & $-\quad 3.547$ & $0.08525-0.13533$ & 0.06935 \\
\hline 3.547 & -7.09 & $0.13523-0.21482$ & 0.06965 \\
\hline 7.09 & -14.2 & $0.21482-0.34100$ & 0.06840 \\
\hline 14.2 & -28.4 & $0.34100-0.54130$ & 0.06557 \\
\hline 28.4 & -56.8 & $0.54130-0.85926$ & 0.06158 \\
\hline 56.8 & -114 & $0.85926-1.364$ & 0.05626 \\
\hline 114 & -227 & $1.364-2.165$ & 0.05022 \\
\hline 227 & -454 & -3.437 & 0.04349 \\
\hline 454 & -908 & -5.456 & 0.03660 \\
\hline 908 & -1820 & -8.661 & 0.02992 \\
\hline 1820 & -3630 & -13.75 & 0.00053 \\
\hline 3630 & -7260 & -21.82 & 0.00002 \\
\hline
\end{tabular}




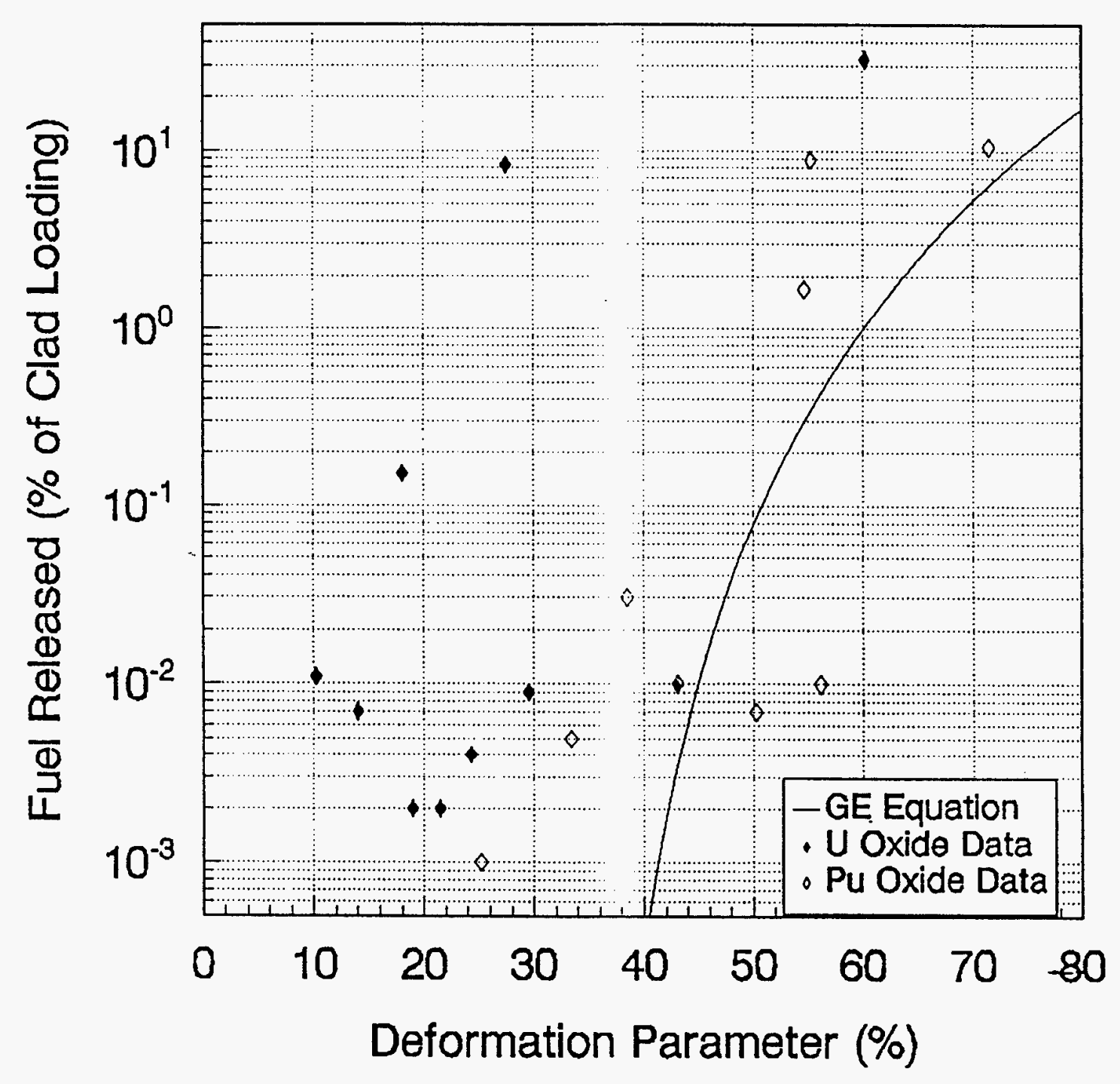

Figure ULY-C4-1

Fuel Release vs Deformation Parameter

All Failed Bare Clad Impact Tests 


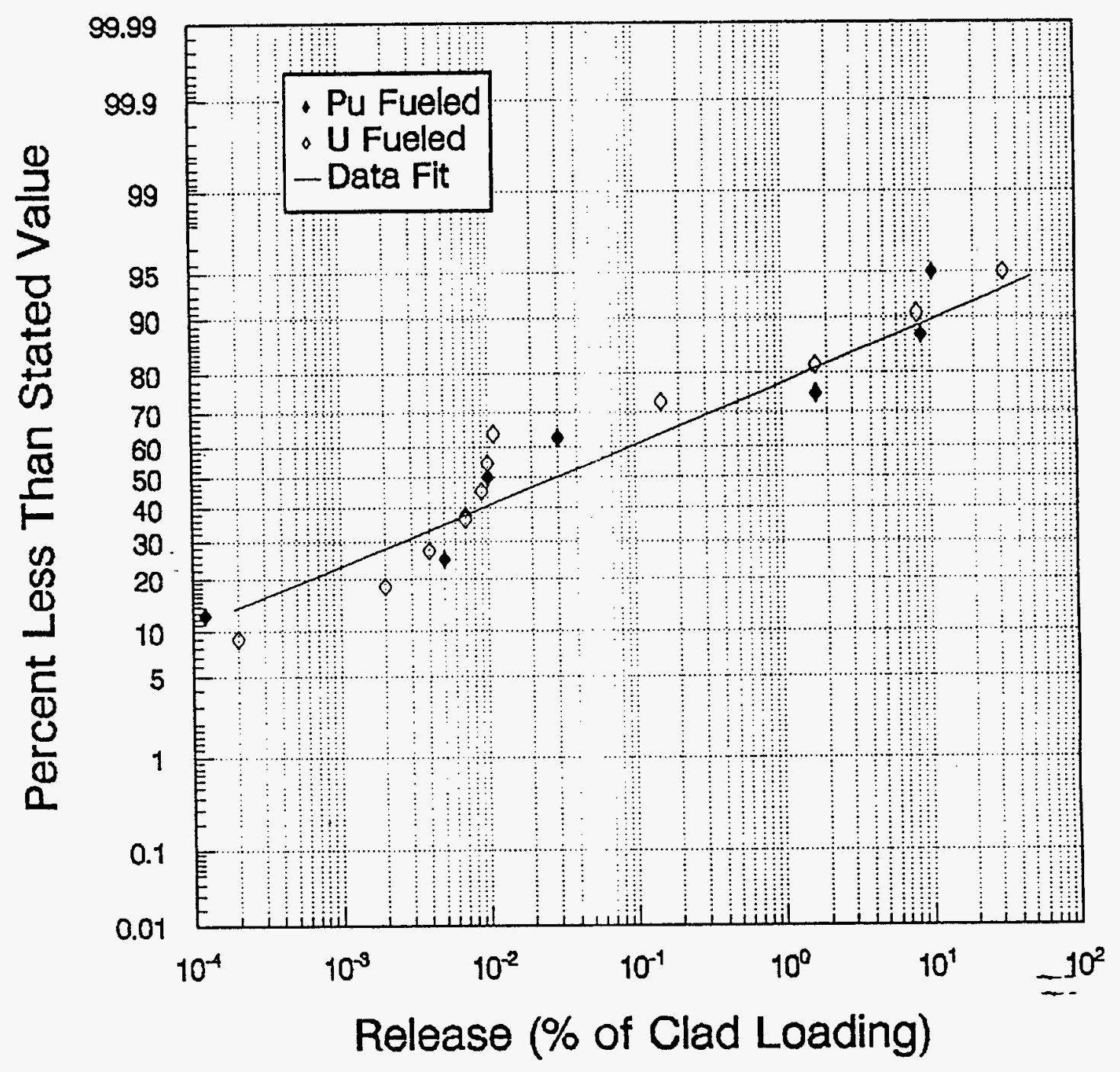

Figure ULY-C4-2

Fuel Release as Cumulative Distribution Function

All Failed Bare Clad Impact Tests 


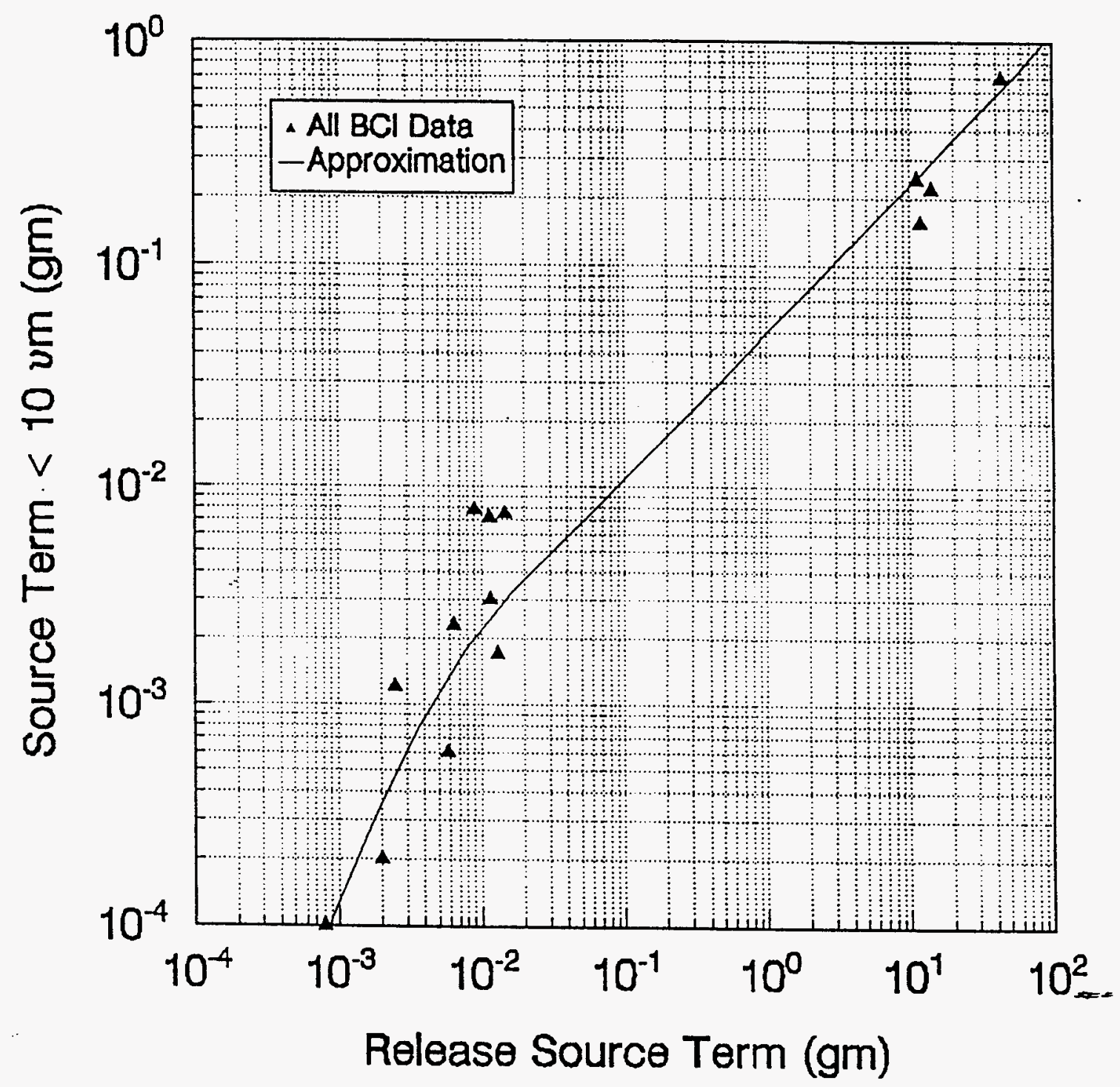

Figure ULY-C4-3

$<10 \mu \mathrm{m}$ Size Fuel Release vs Total Fuel Release

All Failed Bare Clad Impact Tests 
Probability of Occurrence Within Range

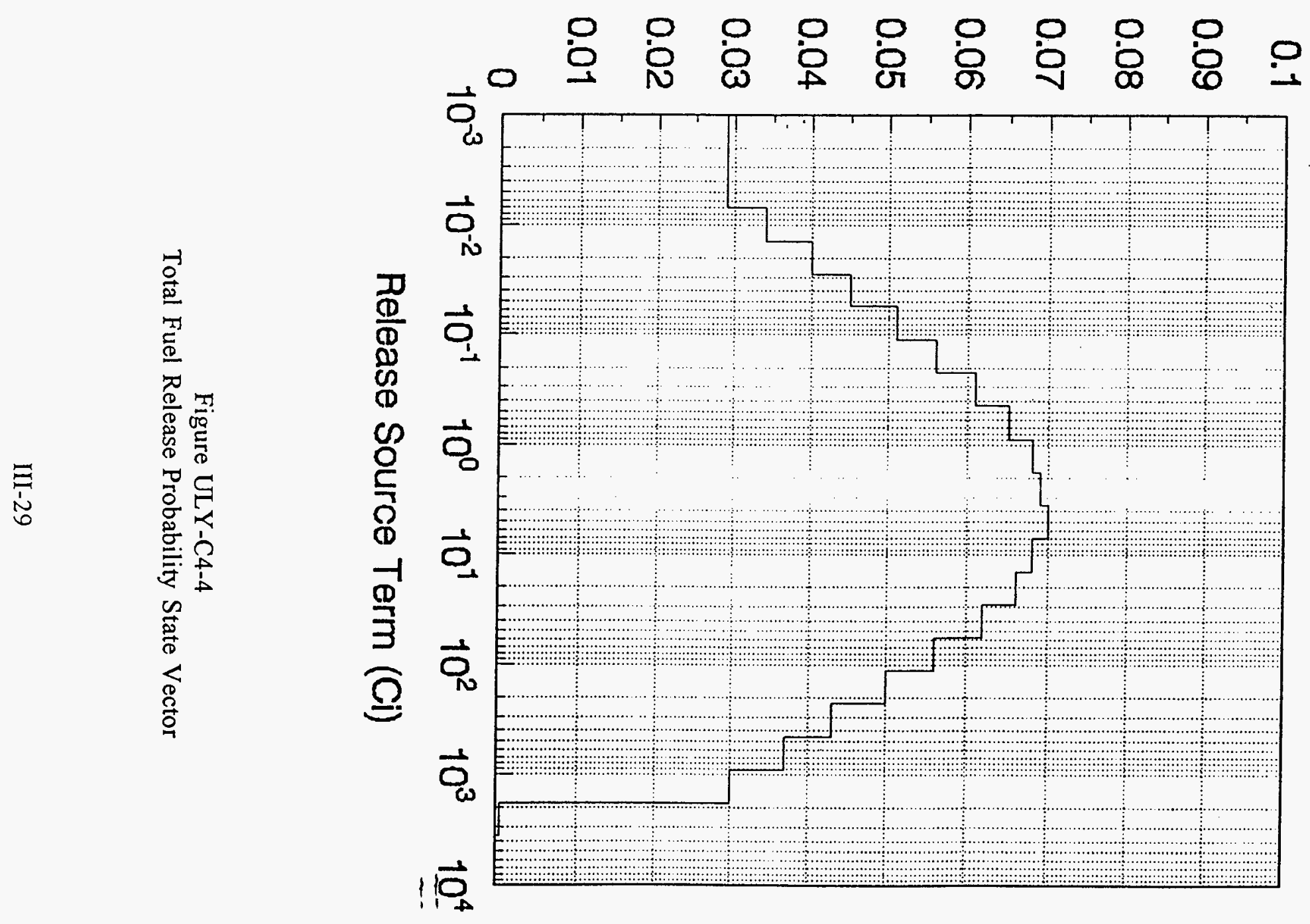

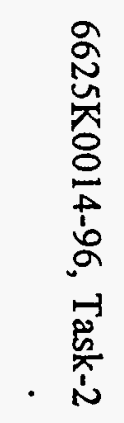

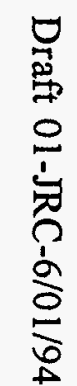



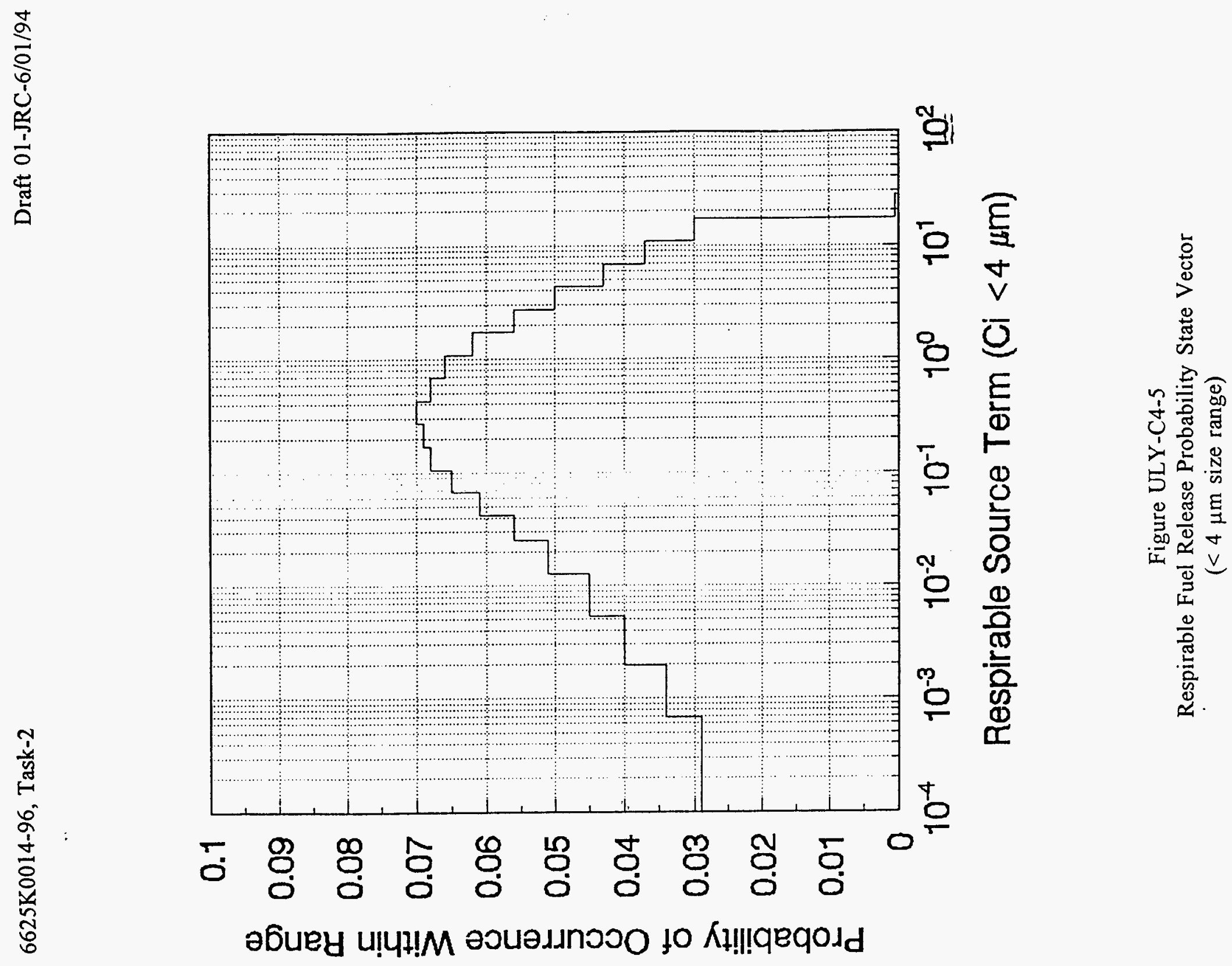


\section{E. Environmental Transport (Cell \#5).}

The goal of the environmental transport cell is to describe the probability distribution of environmental exposure to released fuel. The inputs to this cell are the source term probability state vector from Cell \#4, meteorological and atmospheric transport data, and engineering analysis. GE/NUS used a near real-time computer model (EMERGE) to predict the ground level or near ground level exposure to released radioactive fuel. That model is essentially a Gaussian puff model in a three dimensional wind field that accounts for particle-size dependent transport, deposition, plume depletion and resuspension, as well as the effect of sea breeze recirculation in the KSC vicinity. The INSRP used the Livermore National Laboratory (LLNL) Atmospheric Release Advisory Capability (ARAC) computer dispersion model. They describe that model as: " . . a three-dimensional model that uses a mass-adjusted wind field model, and an explosive plume rise model to estimate meteorological dispersion of radioactive source terms." INSRP limited it consideration to the local Florida area and the major concern was limited to ground level releases. Neither of the models used in the current documentation is available nor necessary for this investigation.

The INSRP Meteorology Subpanel (MET) offered the following perceptive and pertinent remarks in their assessment of the use of atmospheric transport and dispersion models in risk assessment:

$"$ ". . the goal of most dispersion models is not to predict the behavior associated with a specific atmospheric occurrence, but rather to predict the average of an ensemble of situations with the same atmospheric characteristics and to express the probability of exposure in probabilistic terms. The familiar 'Gaussian plume' model is an obvious first step towards implementing ideas of these kinds, using relatively simple methods to propagate both averages and variabilities through a complicated calculation."

With these perceptive words in mind, this effort uses an extremely simple Gaussian calculation to estimate airborne exposure and uses the transition matrix approach to introduce the complexity added by uncertainty. This model approach considers only the ground level releases (which constitute the major risk) and only the dispersion of the respirable particle. The calculation uses a straight line Gaussian sector average for calculating exposure, uses average ground level meteorology, and does not include plume depletion, resuspension, or any dose other than that resulting from first-flight airborne exposure.

Given a simple Gaussian cloud at ground level (semi-infinite space) the ground level crosswind integrated sector average exposure is given by the following equation; where $\mathrm{Q}$ is the source term, $\sigma_{z}$ the standard deviation of the cloud in the vertical $\Psi=\sqrt{\frac{2}{\pi}} \frac{8 Q}{\sigma_{z} u x}$ direction, $u$ the applicable wind speed, and $x$ the downwind distance to the center of the traveling cloud. This equation has been used with site meteorology to calculate the central value for the exposure as a function of distance from the release point. The 
use of the sector average is considered an appropriate calculation here in that the results are to be used in combination with population data which are provided in sector wide areas in annuler rings (for convenience these will be called population cells). The distances used (the distances to centers of the population cells) are 1000,3500,7500, 12500, 17500, 22500, 27500, 35000, 45000,55000 , and 65000 meters. The meteorological data used are the average fall (SeptemberNovember) distribution of atmospheric stability and wind speed at the 18 meter level (from the NASA $150 \mathrm{~m}$ tower as reported in the SAR), and are shown below (more extensive data were available but this set was taken to be appropriate for this application).

\begin{tabular}{lllllllll} 
& & \multicolumn{9}{c}{ Stability Class } & & \\
& A & $\underline{B}$ & & $\underline{C}$ & $\underline{D}$ & $\underline{E}$ & $\underline{F}$ & G \\
Percent Occurrence & 0.9 & 2.4 & 13.6 & 49.7 & 21.9 & 9.9 & 1.6 \\
Wind Speed $(\mathrm{m} / \mathrm{sec})$ & 2.6 & 4.0 & 4.8 & 5.0 & 3.1 & 2.4 & 2.1
\end{tabular}

Using the simple Gaussian sector average described above, a set of exposure states $\left(\mathrm{sec} / \mathrm{m}^{3}\right)$ were devised to encompass the total range of calculated values. The lowest calculated exposure is on the order of $1 \times 10^{-8}$ and the highest on the order of $1 \times 10^{-4}$ a total range of approximately four orders of magnitude. The range of each state was selected to be a factor of two and an order of magnitude was added at each end to allow for the uncertainty discussed below. Thus, based on these considerations, the upper limit of each state range in the set of exposure states was calculated by the relationship $\left[1 \times 10^{-9} \times 2^{n}\right]$ where $n$ takes on values of 0 to 20 ( a total range of approximately $10^{-9}$ to $10^{-3}$ ).

The foregoing calculational model is far less complicated than the approach used by either GE/NUS or INSRP, and thus may include a far greater uncertainty. However, the transition matrix approach facilitates the inclusion of uncertainty in the calculations. The INSRP subpanel (MET) report and the INSRP uncertainty analysis both provide discussion of uncertainty. However, this latter report includes an uncertainty distribution for Gaussian dispersion (INSRP 90-07, Volume II, Table 4-4). That distribution was used for this example (distributing $90 \%$ occurrence in a range roughly a factor of 5 below the mean and a factor of 3 above the mean lognormally -- about a factor of 4 around the median). It should be noted that the MET subpanel report implies that a much broader distribution may be appropriate here. In any event, given a mean of 1.0 (median 0.7), the following table shows how the occurrence probability was distributed in the current example.

\begin{tabular}{lc} 
Relative Range & Probability \\
\hline 0.177 to 0.354 & 0.05 \\
0.345 to 0.707 & 0.25 \\
0.707 to 1.414 (mean state) & 0.4 \\
1.414 to 2.828 & 0.25 \\
2.828 to 5.66 & 0.05
\end{tabular}


In application, the method of using the uncertainty distribution involves calculating the exposure for each meteorological regime and distance, determining the exposure state in which it falls, and distributing the probable occurrence into the four adjacent states consistent with the above table. This yields one row vector for the transition matrix from the set of meteorological regime states to the sector airborne exposure state. Thus, the set of deterministic calculation for each meteorological regime generated the transition matrix which, when multiplied by the probability state vector for the seven (7) meteorological regime states, yields the probability state vector for the airborne exposure states. And, this state vector provides the rows for a second transition matrix (source term to radiation exposure) which leads to the output state vectors from this cell, i.e., the probability distribution of exposure $\left(\mu \mathrm{Ci}-\mathrm{s} / \mathrm{m}^{3}\right)$ for the several distances where population data are given.

Thus, two sets of output are generated in this calculational cell: a set of integrated exposure $\left(\mathrm{s} / \mathrm{m}^{3}\right)$ state vectors and a set of radiation exposure $\left(\mu \mathrm{Ci}-\mathrm{s} / \mathrm{m}^{3}\right)$ for each of the eleven (11) distances to the centers of the population cells. The state vectors for three distances $(1000 \mathrm{~m}$, $3500 \mathrm{~m}$, and $45000 \mathrm{~m}$ ) are illustrated in Figures ULY-C5-1a \& b through ULY-C5-3a \& b respectively (the "a" figures are the $\mathrm{s} / \mathrm{m}^{3}$ state vectors and the "b" figures are the $\mu \mathrm{Ci}-\mathrm{s} / \mathrm{m}^{3}$ vectors). However because the complete output of this cell consists of twenty-two state vectors the graphs will not all be reproduced here nor will they be tabulated. They are all used in the next cell (Cell \#6). 
1

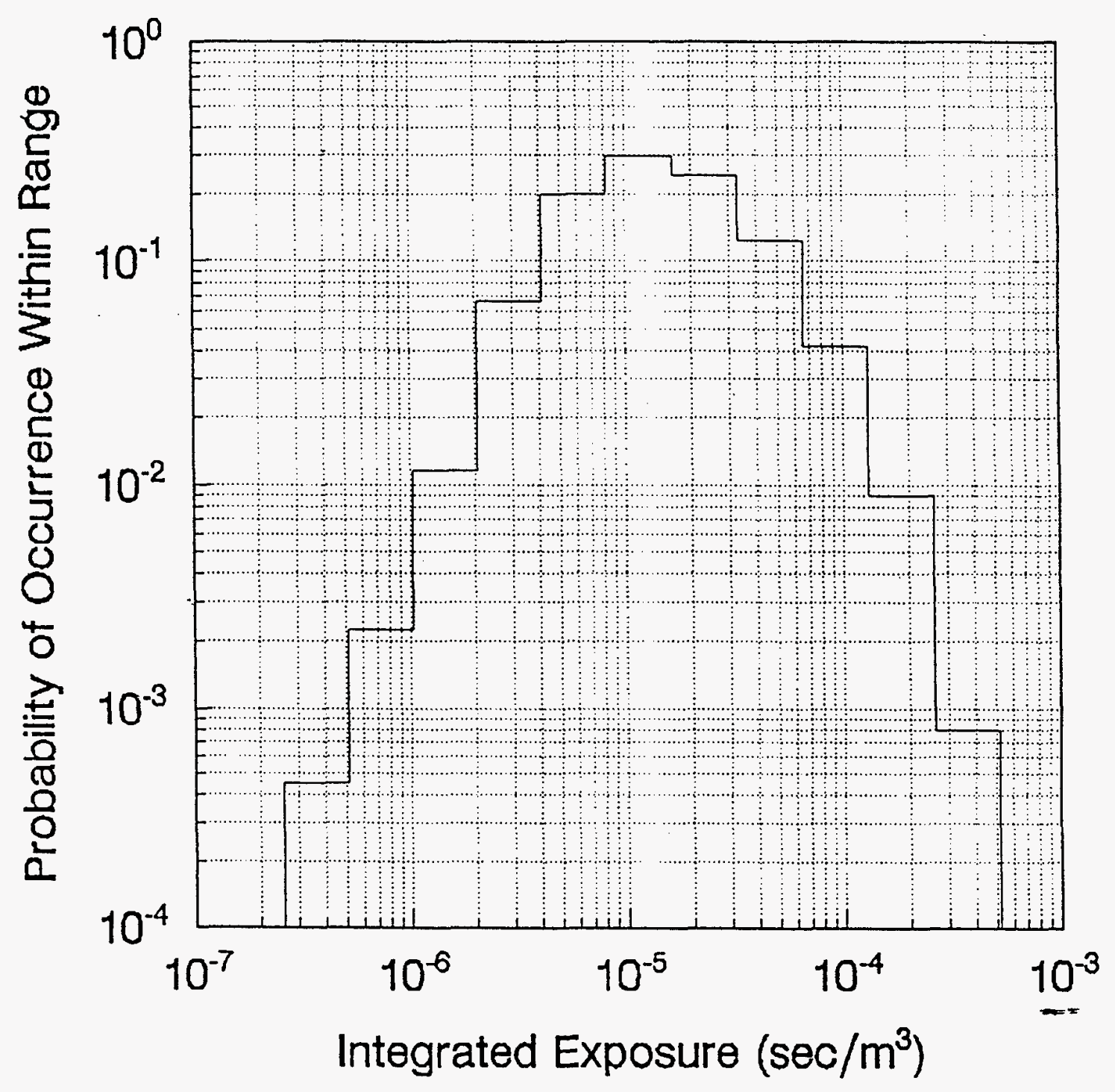

Figure ULY-C5-1a

Integrated Exposure Probability State Vector

(1000 m distance) 


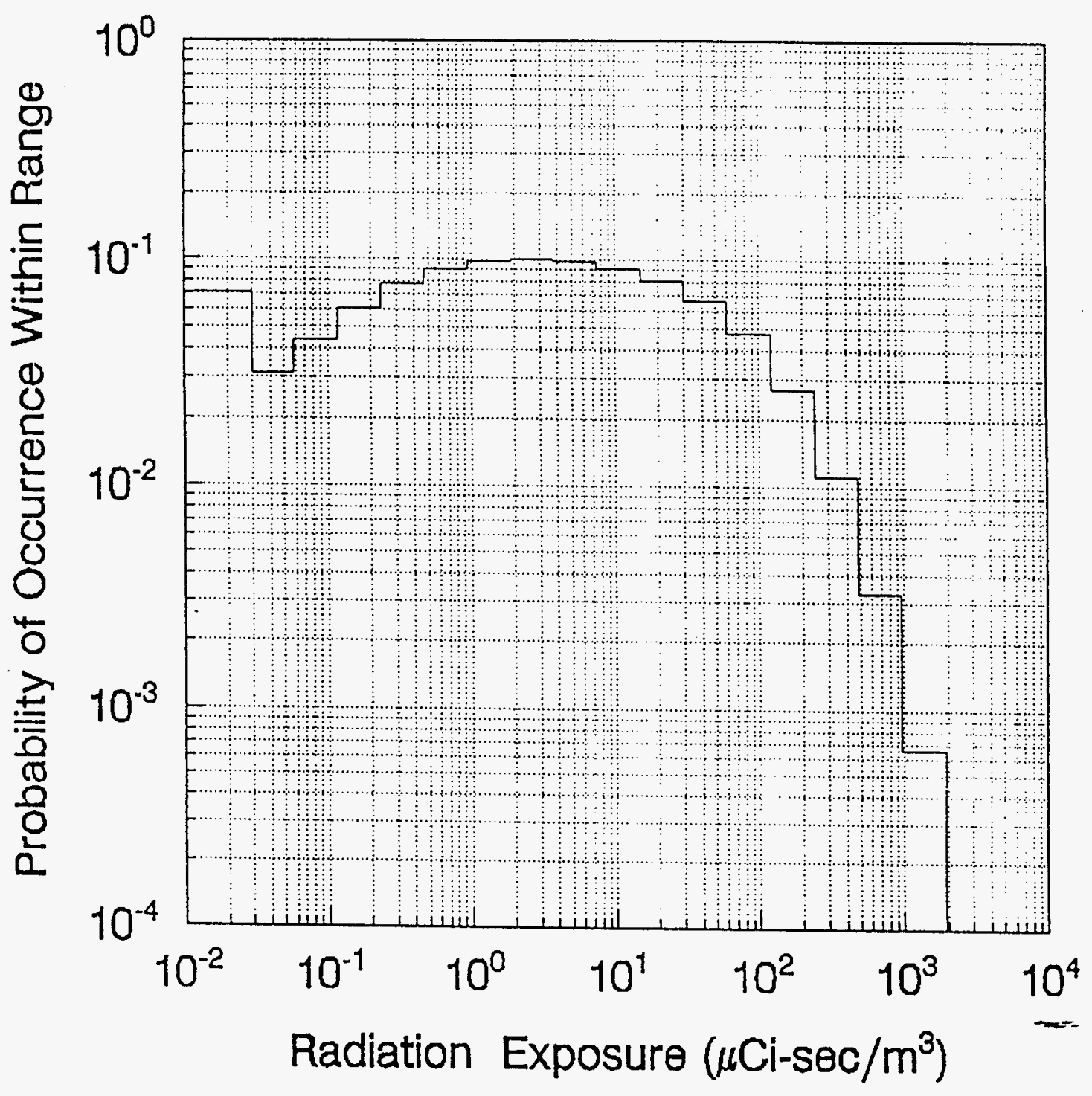

Figure ULY-C5-1b

Integrated Radiation Exposure Probability State Vector

(1000 $\mathrm{m}$ distance) 


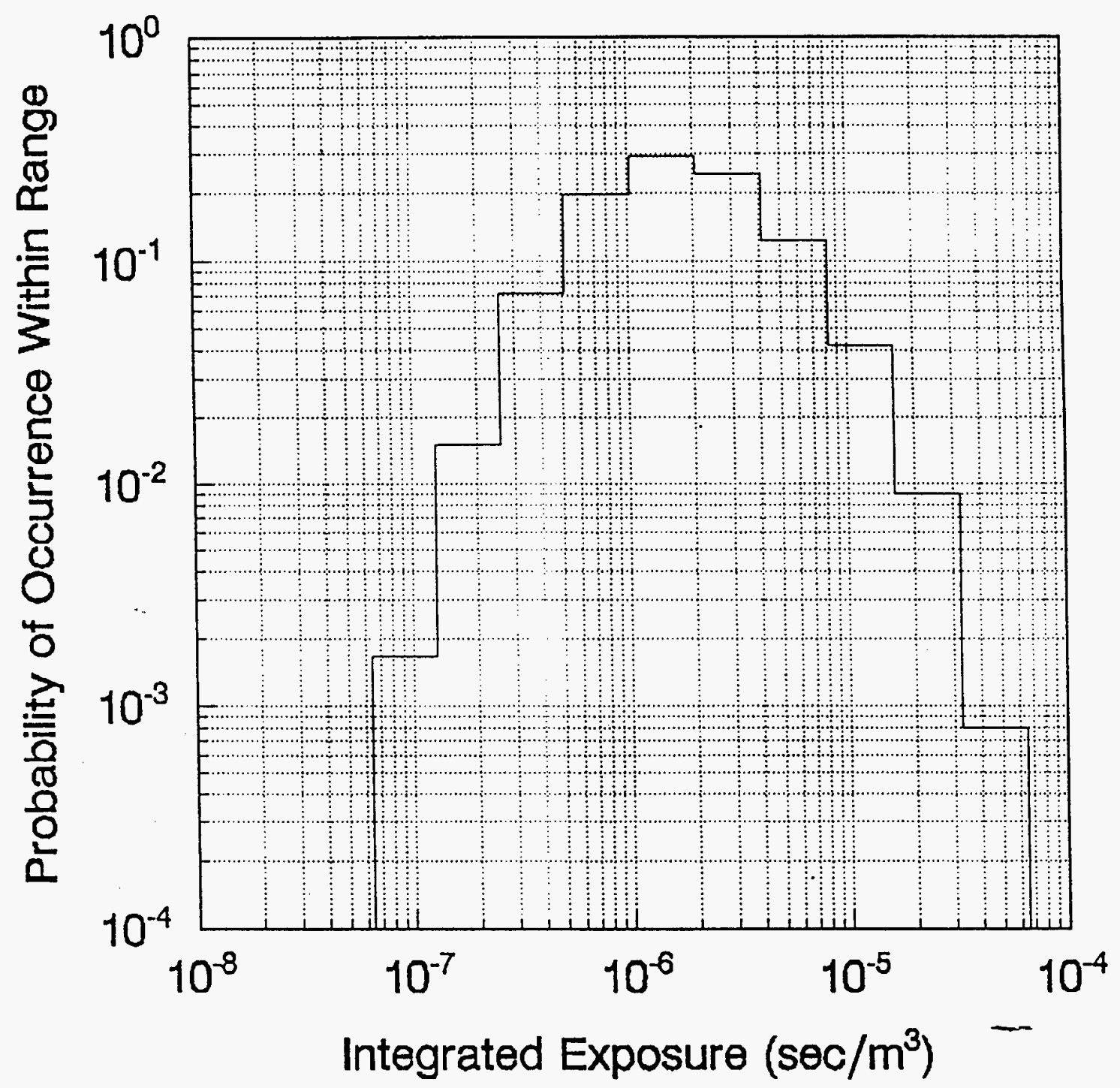

Figure ULY-C5-2a

Integrated Exposure Probability State Vector

(3500 $\mathrm{m}$ distance) 


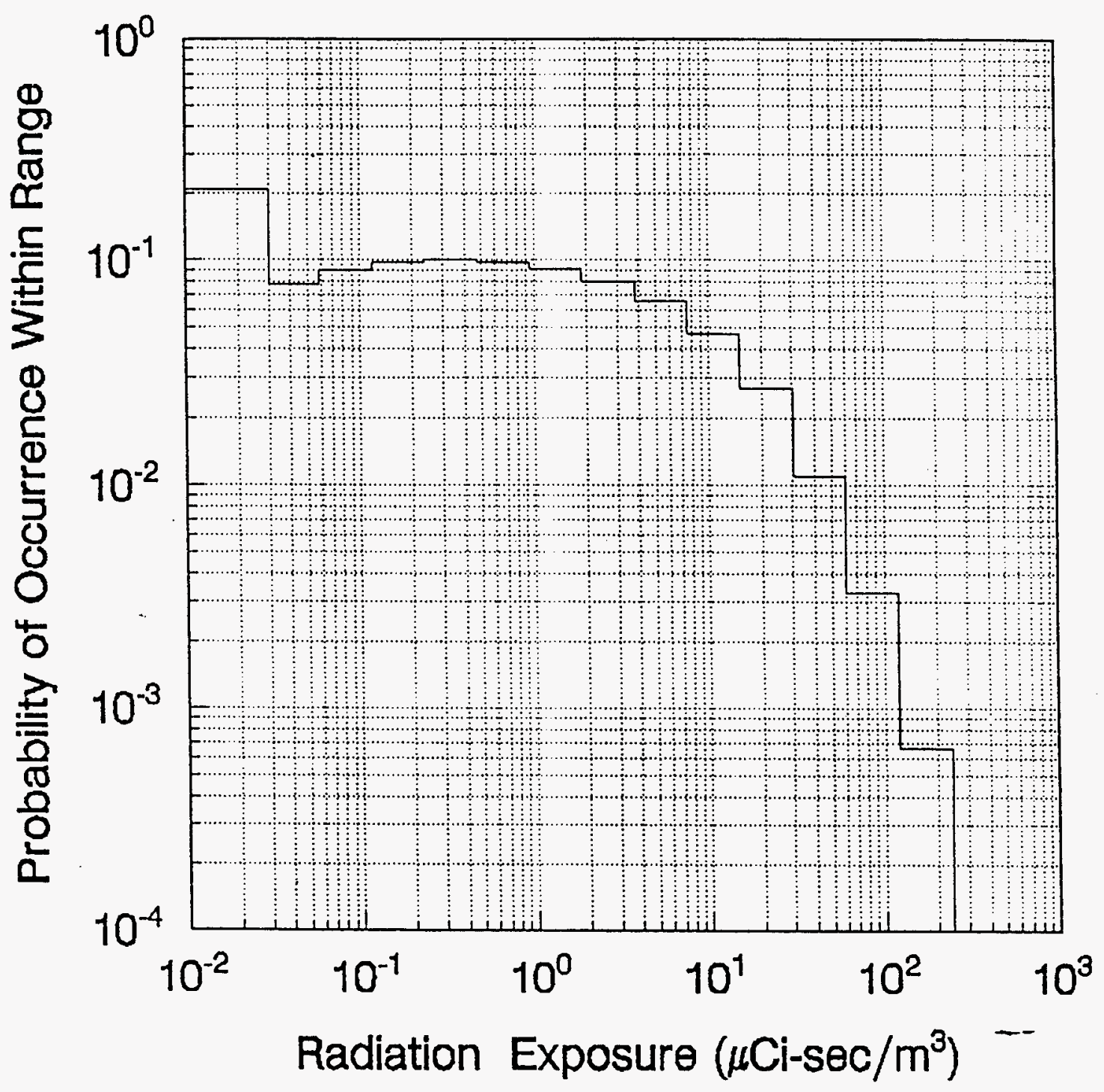

Figure ULY-C5-2b

Integrated Radiation Exposure Probability State Vector (3500 $\mathrm{m}$ distance) 


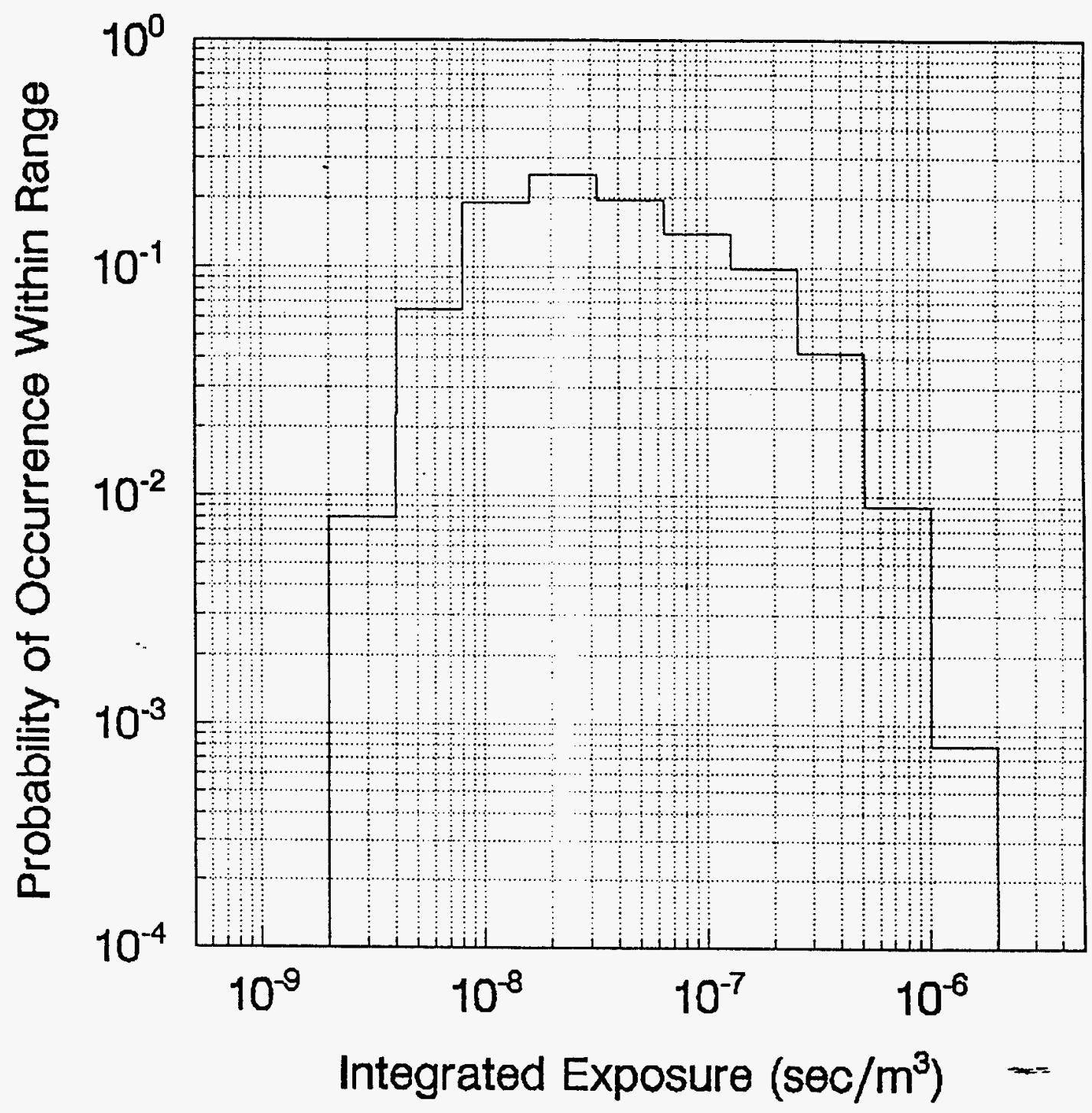

Figure ULY-C5-3a

Integrated Exposure Probability State Vector

(45000 m distance) 


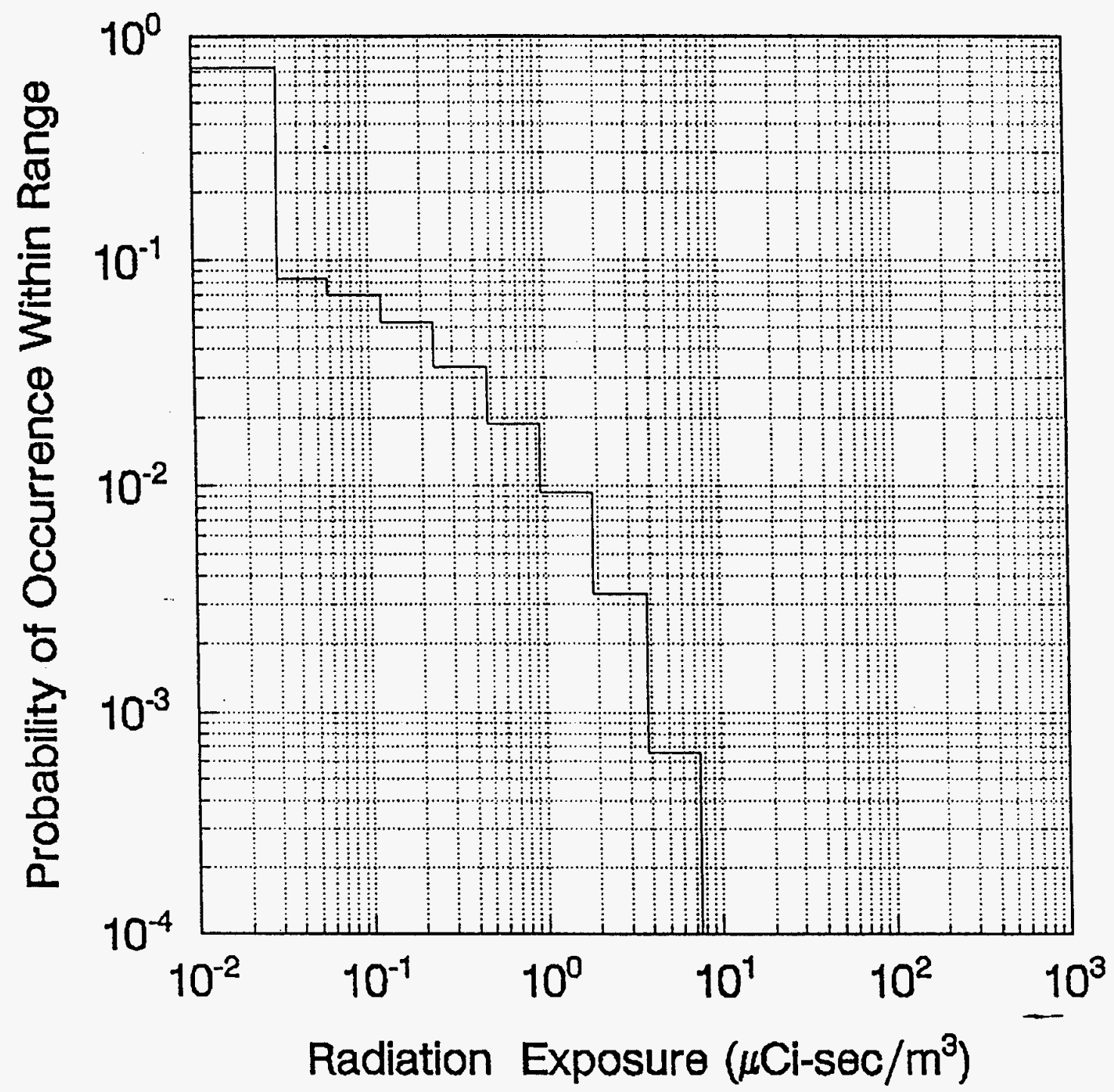

Figure ULY-C5-3b

Integrated Radiation Exposure Probability State Vector

(45000 $\mathrm{m}$ distance) 


\section{F. Biological Interaction (Cell \#6).}

The goal of the biological interaction cell is to describe the probability distribution of radiation dose to humans resulting from exposure to released radioactive materials. Thus, the biological interaction cell consists of those analytical steps necessary to describe the probability distribution of human dose associated with the exposures states output from the previous cell (Cell \#5).

In general, the biological interaction cell can use the calculated exposure states from cell \#5 together with biological models (lung, GI tract, external exposure etc.), diet and/or intake assumptions, and population demographics to estimate the distribution of human insult expressed as dose states. However for this illustration, exposure has been limited to first-flight inhalation, thus the complexity of this cell is dramatically reduced. For the case at hand, the radiation dose conversion factor was taken from the Biomedical and Environmental Effects Subpanel report for the 0.1 to $3.0 \mu \mathrm{m}$ diameter particle size group $\left[6: 81 \times 10^{-2} \mathrm{rem} / \mu \mathrm{Ci}-\mathrm{s} / \mathrm{m}^{3}\right]$. Thus the radiation dose states are taken to be the simple scaler multiplication of this factor times the exposure states $\left(\mu \mathrm{Ci}-\mathrm{s} / \mathrm{m}^{3}\right)$ from the previous cell. The dose distributions, as probability state vectors, for the three example distances used in Cell \#5 are shown in Figures ULY-C6-1, ULY-C6-2, and ULYC6-3, (1000, 3500, and 45000 meters respectively).

Although the calculations made in this cell are extremely simple, the simplification is not a constraint of the framework of analysis. The simplifications are made solely to facilitate illustrating the overall approach. In an actual analysis, where the description of dose distributions by populations (and later dose effects) may be very important to the evaluation of safety, two additional types of considerations could be added without serious difficulty. First, one could have included other exposure pathways (resuspension, food, external dose, etc.), and second one could have included a series of dose factors. Either of these additional considerations could be included as single factors with a range characterizing the uncertainty, or could, in fact, be introduced with population dependence. The mechanics of the analysis would be more cumbersome but the fundamental approach would be no different. 


\section{$\infty$}

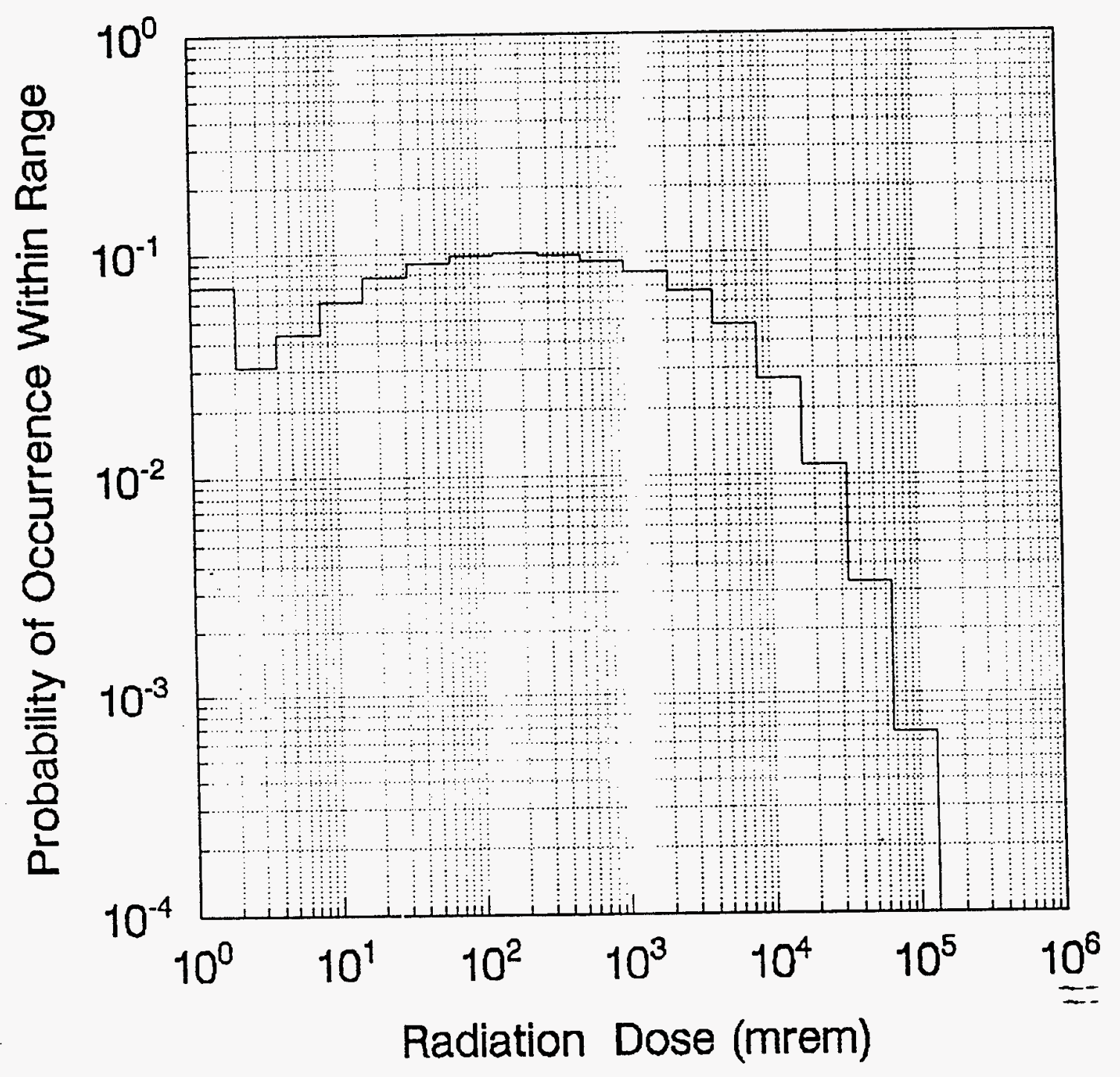

Figure ULY-C6-1

Radiation Dose Probability State Vector

(1000 $\mathrm{m}$ distance) 


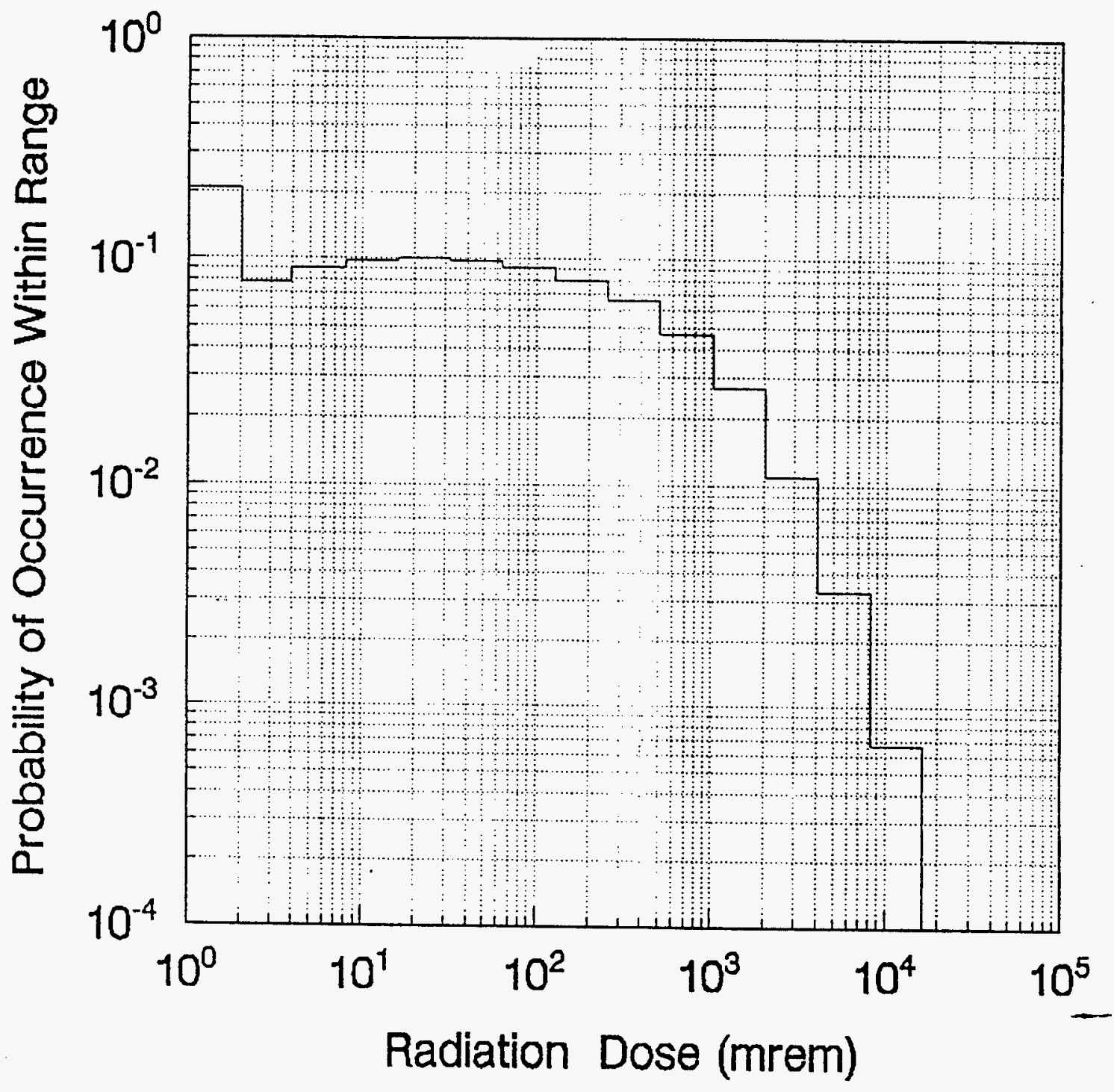

Figure ULY-C6-2

Radiation Dose Probability State Vector

(3500 $\mathrm{m}$ distance) 


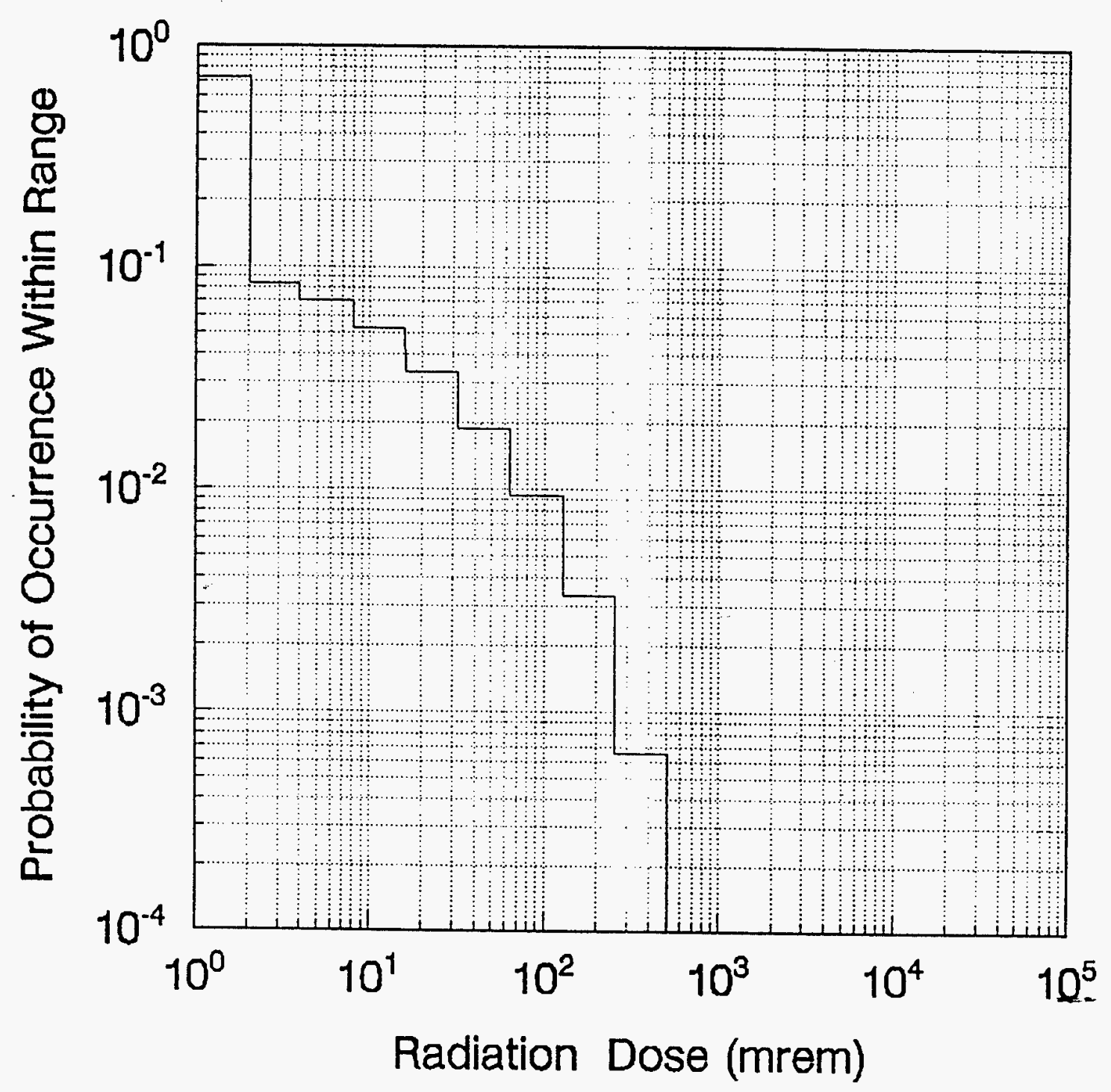

Figure ULY-C6-3

Radiation Dose Probability State Vector (45000 meters) 


\section{G. Risk Valuation (Cell \#7).}

The final step is to combine the radiation dose probability state vectors with local population (to give person-rem) and apply a risk factor to calculate potential cancer fatalities (as was done in the existing Ulysses documentation).

The population data used are those reported in the SAR (Volume III - Book II) and consists of a total population of 844,712 (workers, residents and spectators) out to $70 \mathrm{~km}$ in the nine (9) populated sectors surrounding the launch site. The distance was arbitrarily limited to $70 \mathrm{~km}$ in this analysis because to include the next $20 \mathrm{~km}$ for which population data are provided would more than double the population (adding 947,141 people). This large population would be added at distances where disregarding cloud depletion by deposition would be extremely important and the applicability of the both the dispersion calculation and the uncertainty distribution for dispersion would be clearly inapplicable.

The cancer fatality risk factor used was taken from the INSRP Biological and Environmental Subpanel report (INSRP 90-06) as $3.0 \times 10^{-4}$ cancer deaths/person-rem. This is consistent with the dose factor used, which applies to the calculation of committed (50 year) effective dose equivalent; and is reasonably consistent with the value used by GE/NUS, i.e., $3.5 \times 10^{-4}$ fatalities per person-rem [SAR Volume III (Book 2)].

For the analysis approach taken here, the overall risk (in expected cancers) given an accident, is obtained by weighting the dose probability state vectors of Cell \#6 (see Figures ULY-C6-1, 2 , and 3 ) by population (as a function of distance), multiplying the dose states by the fatality risk factor, and summing the results over all distances.

The value obtained for mission risk in this analysis is 0.39 expected cancer fatalities per mission. This is for the affected population in Florida only and includes only those accident scenarios occurring prior to 88 seconds MET. The GE/NUS SAR arrived at a overall mission risk of 0.11 cancer fatalities per mission. Although these results are similar, the bases of the two calculation are different. The GE/NUS number considers the total mission, while the current analysis includes only the risk to local Florida.

The 0.4 expected cancer fatalities per mission is the point estimate of risk that arises from this analysis. The probability distribution of this risk is a little more complicated to arrive at, and is discussed in the following paragraphs.

A primary benefit of the calculation approach used here is that the distribution of event frequency and the distribution of event consequences are separated in the calculations. Because the calculated state probabilities is normalized to unity at each cell interface (yielding a probability state vector and an occurrence probability), the frequency distribution of "events resulting in a release" is described solely by the frequency distribution of accidents multiplied by the scaler 
event probabilities obtained by the normalization step.

On the other hand, the occurrence distribution of consequences around the mean value of 0.4 is given by the joint distribution formed by the source term state vector and the dispersion state vectors. In this illustration, because both are approximately lognormally distributed the resulting distribution is also lognormal and can be written directly. These two sets of calculations yield a set of curves describing the occurrence frequency related to the expected consequences for any level of uncertainty

The results of these calculations are shown in Figures ULY-C7-1 and ULY-C7-2. The first of these (Figure ULY-C7-1) is the probability density function (as a discrete function) of the expected number of cancer fatalities given an accident (mean event frequency $1.8 \times 10^{-5}$ ). Figure ULY-C7-2 is the transposed cumulative probability function given a launch, which shows the $5^{\text {th }}$ percentile, median, mean, and $95^{\text {th }}$ percentile frequency distributions of cancer fatalities for the mission.

The INSRP presented some point results in their Executive Summary (INSRP 90-01, Volume I, page ES-3) that may be compared (with great care) to the results calculated here. The following tabulation presents two points given by INSRP for the average source term compared to values from the average curve in figure ULY-C7-2.

\begin{tabular}{|c|c|c|}
\hline Fatalities & Prob. INSRP & Prob. This Study \\
\hline 0.00 & $3.5 \times 10^{-5}$ & $6 \times 10$ \\
\hline 2 & $1 \times 10^{-6}$ & $5 \times 10^{-8}$ \\
\hline
\end{tabular}

Although the probabilities are reasonably similar, it must be recognized that they are, in fact, not comparable. The problem is that the INSRP values answer the question, given the average source term what is the probability of a specific fatality value; while the values from this study answer the question, given the distribution of source terms, what is the probability of a specific fatality value. These are clearly not the same questions. 


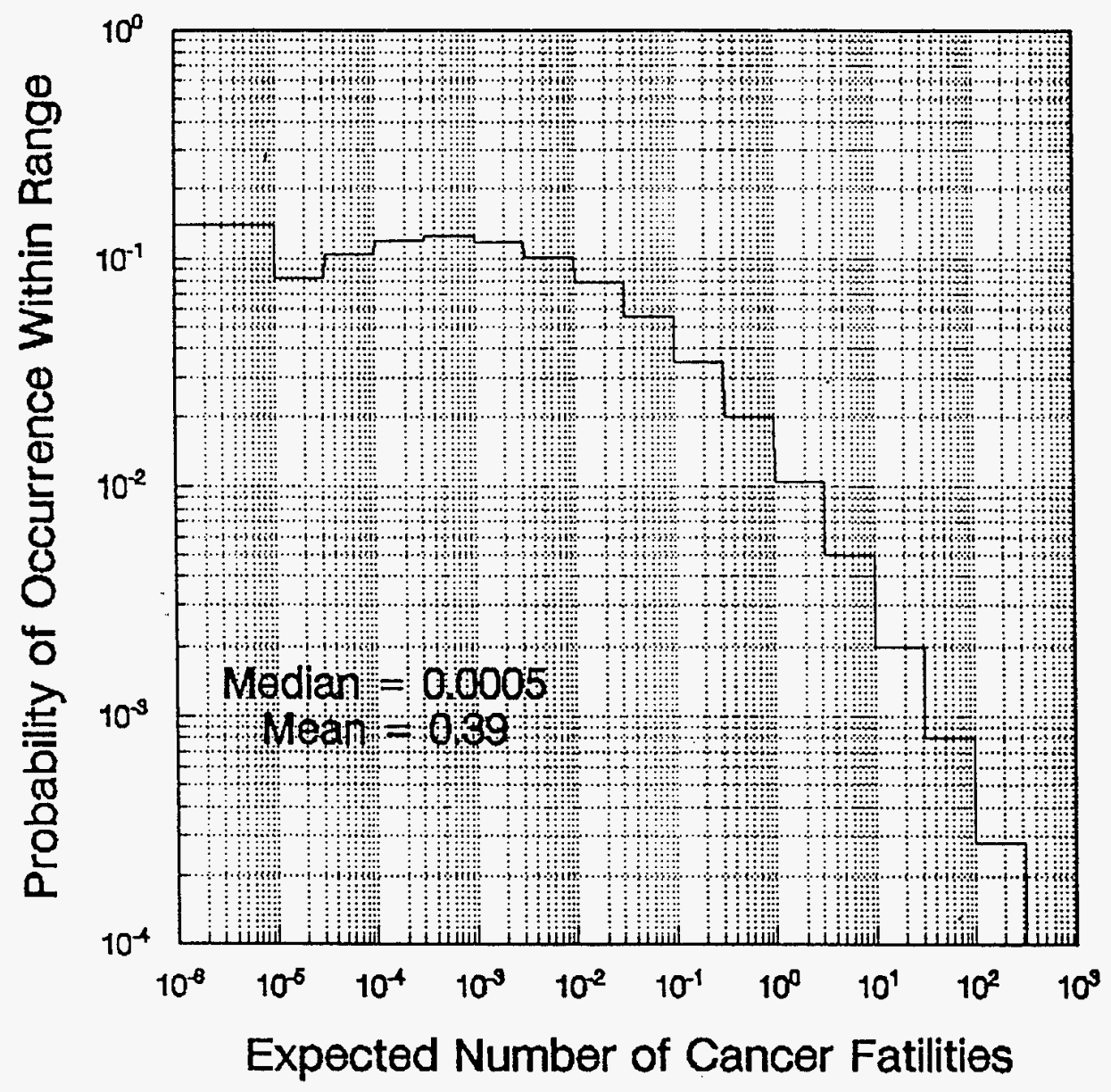

Figure ULY-C7-1

Radiological Risk Density Function

Florida (to $70 \mathrm{~km}$ from launch pad)

Sum of All Scenarios to 87 s MET 


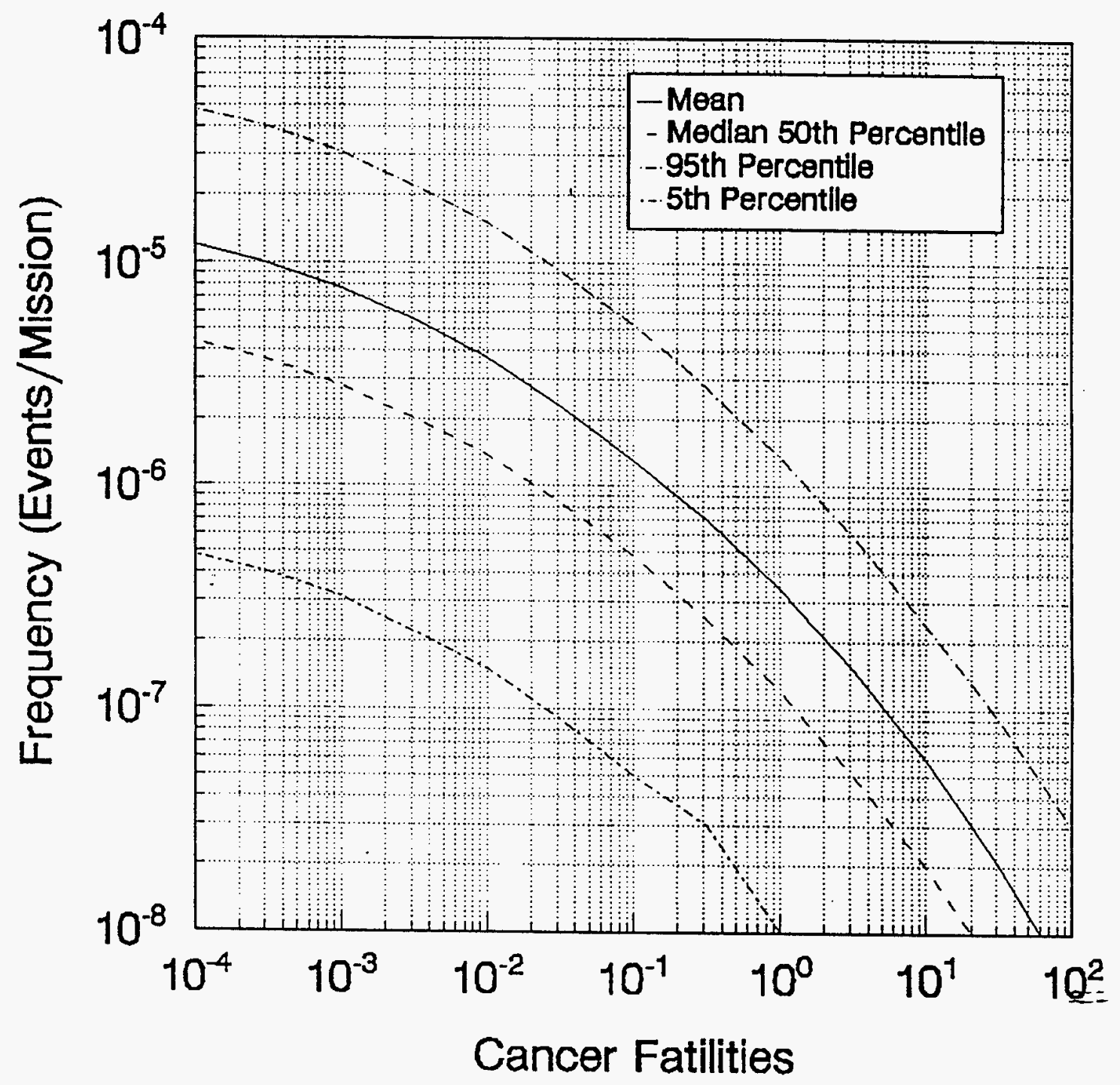

Figure ULY-C7-2

Radiological Risk Distribution

Florida (to $70 \mathrm{~km}$ from launch pad)

Sum of All Scenarios to 87 s MET 


\section{H. Summary Comments.}

This analysis has produced the following results;

1. An accident frequency state vector as output from Cell \#1. Mean accident frequency $=0.01$

2. A fragment velocity state vector (the only environment of interest) as the output from Cell \#2. Fragment hit occurrence probability given accident $=0.145$.

3. A failed clad state vector (giving the probability distribution of clad failure) as the output from Cell \#3. Failure occurrence probability given fragment hit $=0.022$.

4. A source term state vector (giving the probability of fuel releases, both total release and respirable releases) as the outputs from Cell \#4. Source term release occurrence probability given fragment hit and clad failure $=1.0$

5. A set of exposure probability state vectors in $\mathrm{s} / \mathrm{m}^{3}$ and $\mu \mathrm{Ci}-\mathrm{s} / \mathrm{m}^{3}$ for eleven (11) distances from the release point as the output from Cell \#5. Exposure occurrence probability given release $=0.56$

6. A corresponding set of dose probability state vectors in rems for the eleven (11) distances from the release point as the output from Cell \#6. Dose occurrence probability given exposure $=1.0$. A corresponding overall probability of consequences per mission of

$$
0.01 \times 0.145 \times 0.022 \times 1.0 \times 0.56 \times 1.0=1.8 \times 10^{-5} \text { per mission }
$$

for the event characterized as: catastrophic accident -- fragment impact -- clad failure and fuel release -- first flight exposure.

7. And finally, an overall expected mission risk of 0.39 cancers fatâtities and the distribution of risk frequency as the output from Cell \#7.

The mission risk distribution is about an order-of magnitude below the comparable distribution given by the INSRP, and the average case is about the same as the average case for the total mission distribution given by GE/NUS. It is not clear where differences arise (because comparable intermediate data are not clearly given in current documentation) or what these differences imply about the different calculational models.

One obvious difference is that both the GE/NUS and the INSRP environmental transport models include some correction for plume depletion and include doses other than first-flight from the 
cloud. The very simple model used does not include either. This lack of deposition and restricted dose evaluation would tend to give lower doses close-in (as a result of not calculating doses other than first-flight inhalation) and higher doses at great distances (as a result of not depleting the plume). Because the majority of the population is located at greater distances, the lack of these two corrections would probably result in calculating higher risks than if they were included -- thus the risk calculated here should be higher than in the existing documentation. Unfortunately however, because of the lack of comparable intermediate results, it is not possible to ascertain just where difference arise or arrive at truly comparable results.

It is obvious however, that if comparable intermediate results were provided in the existing documentation, it would be very easy to identify the source of differences and to asses the importance of those differences to the calculation of risk.

In summary, as stated above, because of the lack of clear intermediate data in the Ulysses documentation it is not possible to determine where difference arise or what they imply about the various analyses. However, it is clear that the availability of the intermediate data produced here is a significant benefit and clearly illuminates a shortcoming in the current documentation. 


\section{APPLICATION TO A HYDROGEN BURN IN TANK 241-SY-101}

High level radioactive wastes (HLRW) are stored at the Hanford site by the U.S. Department of Energy. Generation of HLRW began in late 1944 and continued periodically until late 1983. The wastes are stored in 149 single-shelled tanks (SSTs) and 28 double-shelled tanks (DSTs). Five of the DSTs and 18 of the SSTs have been identified as generators of combustible gases, particularly hydrogen; and Tank 241-SY-101 has been identified as the tank that produces the greatest quantity of such gases. The combustible gases are generated and accumulated within the non-convecting slurry layer of the stored wastes. The gases may be releases to the dome space above the crust by natural instability due to gas build up, by agitation, or as a result of invasive activities. In the normal course of operations the gases are episodically released due to instability from gas buildup [gas release events (GREs)]. If an ignition source is available during the release of the combustible gases a serious burn can occur. That is the accident considered in this example; specifically a hydrogen burn event initiated by natural causes is considered. The basic accident scenario envisioned is predicated on three fundamental assumptions:

* That the accumulated gases can be released by agitation.

Although information regarding the agitation required to release the gases or of the time response of the gases to that agitation is minimal, it is known that agitation will release the stored gases.

** That an earthquake with an associated ground acceleration of $15 \%$ to $20 \%$ of gravity or greater (about 6.0 on the Richter scale) provides sufficient agitation to release the gases and that the gases are released instantaneously.

The earthquake specified is a serious earthquake (yet less serious than that which might compromise tank integrity -- about $0.25 \mathrm{~g}$ ) with a significant frequency of occurrence when compared to other accidents considered for safety analyses. The frequency range of the $0.15 \mathrm{~g}$ to $0.2 \mathrm{~g}$ earthquake is about $1 \times 10^{-4}$ to $1 \times 10^{-3}$ per year with an estimated median of about 4 $\times 10^{-4}$ per year.

*** That an earthquake with an associated ground acceleration of $15 \%$ to $20 \%$ of gravity or greater can disrupt the internal structure sufficiently to produce sparking and that ignition of the gases will result (it need not result in tank failure).

As mentioned above, it has been estimated by others that tank failure can occur at ground accelerations of greater than about $25 \%$ of gravity. Thus, the intensity of the earthquake assumed here is somewhat less than that estimated for tank failure, but is sufficient to do significant physical damage, which, it is assumed, results in an ignition spark. 
Thus the accident scenario being considered is:

An earthquake yielding a ground acceleration in the range of about $15 \%$ to $20 \%$ of gravity which results in the release of stored gases from the slurry layer and, at the same time, produces an ignition source for the gases in the tank dome. It is assumed that this accident has a frequency (random) of about $4 \times 10^{-4}$ per year.

In order to carry out this analysis a reasonably uniform and consistent description of the tank and its variable contents is required. A number of documents have been produced by the LANL which, to a greater or lesser extent, evaluate the hydrogen burn phenomenon. The two of most interest here are: (1) Reanalysis of the Safety Hazards Associated with a Hydrogen Burn in Hanford High-Level Waste Tank 242-SY-10, LA-UR-92-3225 (N-6-92-R172); and (2) A Safety Assessment for Proposed Pump Mixing Operations to Mitigate Episodic Gas Releases in Tank 241-101-SY, Revision 8. The majority of the descriptive information is obtained from Appendix $\mathrm{T}$ of Revision 8.

Recognizing the that the wastes are dynamic, the system is described for three different conditions: the void free condition (no accumulated gas); the average pre Gas-Release-Event (GRE) or neutral buoyancy condition; and the post GRE or average quiescent condition. The descriptive details of these physical conditions (developed from the information in Appendix $T$ of $\mathrm{SA}$ ) are summarized in Table $\mathrm{H} 2-\mathrm{C} 0-1$.

The goal of the approach proposed here, as was the goal of the Ulysses example, is to describe the physical aspects of the accident consequences in a probabilistic manner. The current documentation does not offer a probabilistic analysis of accident consequences. The analysis model has been described in Section II. It structures the calculations into a stepwise analysis with intermediate output distributions that facilitate understanding and evaluation. In brief, the approach divides the overall problem into the following broad analysis compartments (referred to as analysis cells or just cells) which provide a convenient framework for the analysis.

- Accident Frequencies

- Accident Environments

- System Response

- Source Terms

- Environmental Transport

- Biological Interaction

- Risk Valuation

The following paragraphs summarize the calculational approach, calculations, results, and output of the individual cells. Brief summary comments are offered at the end of the hydrogen presentation. 
TABLE H2-C0-1

SUMMARY OF ASSUMED TANK/WASTE DESCRIPTION AND CONDITIONS

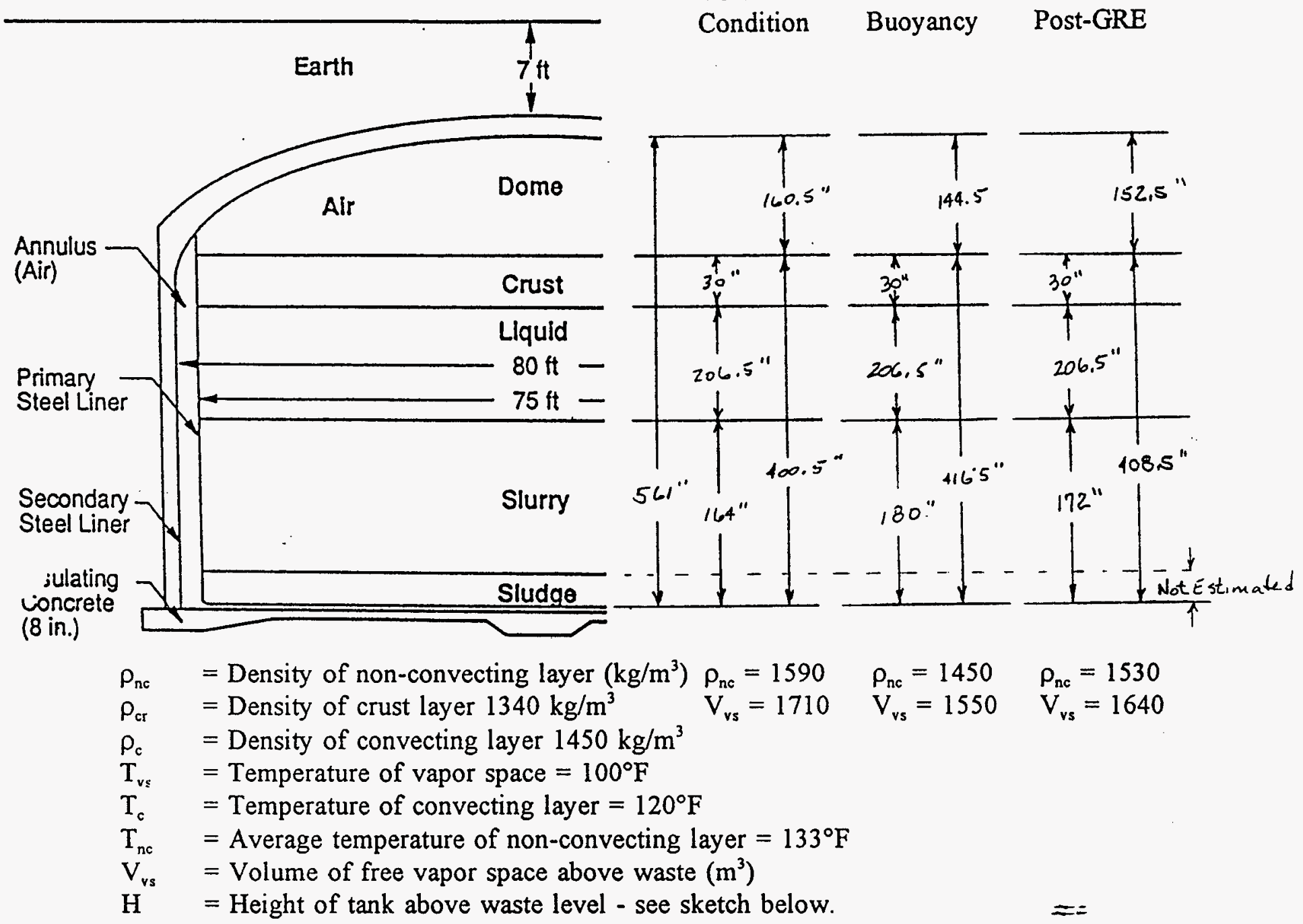

Calculated volume of vapor space $\left(\mathrm{m}^{3}\right)=\pi(11.45)^{2}(\mathrm{H}+0.23 / 3)$

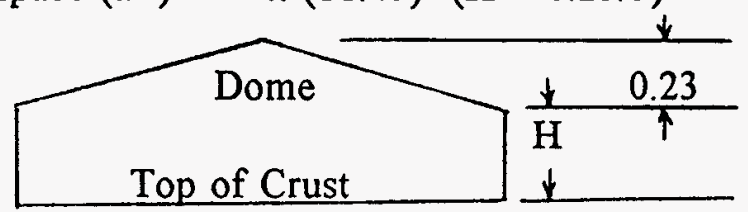

Other definitions:

Standard pressure and temperature conditions: 1 atmosphere and $0^{\circ} \mathrm{C}$

Standard gas conditions (yielding Standard Cubic Feet): 1 atmosphere and $60^{\circ} \mathrm{F}$

Standard WHC pressure and temperature conditions: 1 atmosphere and $100^{\circ} \mathrm{F}$ 


\section{Accident Frequencies (Cell \#1)}

As discussed above, the accident scenario considered here is:

An earthquake yielding a ground acceleration in the range of about $15 \%$ to $20 \%$ of gravity which results in the release of stored gases from the slurry layer and, at the same time, produces an ignition source for the gases in the tank dome. It is assumed that this accident has a frequency (random) of about $4 \times 10^{-4}$ per year.

The substance of the effort in this cell is to describe the probability distribution of the quantity of gases that may be released in this accident scenario. In the following paragraphs this problem is addressed in two parts: (1) the generation of gases in the slurry and (2) the probability for the release of a specific quantity of gas given the random initiating earthquake event.

\section{Gas Generated as a Function of Time.}

The generation and retention of gases in the waste slurry results in the expansion of the slurry and is reflected in a changing level of the liquid height in the tank. As reflected in waste height, gas retention has shown to be a linear function of time following the natural episodic events (GREs). The gas production rate has been relatively constant over the last seven years. This is shown in Figure H2-C1-1, which graphs the "Cumulative Level Drop (in inches)" for all events since August 3, 1986. The rate of accumulation of releasable gases is about 0.0773 inches/day (with a linear correlation coefficient of 0.9995 ). This provides the basis for estimating releasable gas as a function of time following a release event.

\section{Gas Release Probabilities.}

Given that an earthquake is a random event and for the moment disregarding the natural episodic releases, the probability that the sludge will contain a releasable quantity of gas within any given range (a potential release) is directly proportional to the width of the range (the time required to generate the differential gas quantity within that range). Thus the probability density function (expressed as probability per unit time as a function of source quantity) and the sfate vector for this cell would be a single value (a uniform distribution) if it were not for episodic releases. However, because the maximum size of potential releases is limited by the natural episodic events (GREs) the state vector for earthquake induced events must be modified by this natural limitation. For this analysis an empirical distribution, obtained from GRE observations, is developed for that purpose.

In the following paragraphs a simple mathematical approach is proposed to describes the time between observed events. This yields a probability distribution that appears more reasonable than simply fitting on arbitrary distributions -- and which appears to provides a reasonable description of the waste GRE dynamics. 
Start with the assumptions: (1) that the differential change in the probability of observing a new GRE in some time interval following a previous GRE is proportional to the gas accumulation within the slurry and the probability of surviving to that interval; and (2) that there is some minimum gas accumulation that is required for a GRE. Given these two assumptions, the differential equation of the probability of experiencing a GRE as a function of time (the probability density function) can be written as:

$$
\frac{d P}{d t}=[1-P(t)] \propto\left[G(t)-G_{*}\right] \quad \begin{aligned}
& \text { Where } \mathrm{G}(\mathrm{t}) \text { is the time dependent gas accumulation, } \mathrm{G}_{*} \text { is } \\
& \text { the minimum gas accumulation required for a GRE, } \alpha \text { a } \\
& \text { proportionality factor, and } \mathrm{P}(\mathrm{t}) \text { the cumulative probability } \\
& \text { distribution of a GRE. }
\end{aligned}
$$

Before solving this differential equation, some additional considerations can be included In the previous subsection a graph is provided showing that the average slurry growth rate for tank 241 SY-101 is 0.0773 inches per day. Recognize that this can be stated as 0.0773 in $^{3}$ of expansion per in ${ }^{3}$ of slurry per day (thus having the dimension of days ${ }^{-1}$ ) by simply dividing by the depth of the slurry layer. In this way $\mathrm{G}(\mathrm{t})$ is given by $0.0773 * \mathrm{t} / \mathrm{H}$. Also, it can show that $\mathrm{G}_{*}$ may be stated in terms of a minimum time $\left(\mathrm{T}_{0}\right)$ rather than in terms of a minimum gas accumulation, thus $\mathrm{G}_{*}=0.0773 * \mathrm{~T}_{0} / 2 \mathrm{H}$. With these additional considerations the solution of the differential equation takes the form:

$$
P=1-e^{-\frac{0.0773 \alpha}{2 H}\left[t^{2}-\mathrm{T}_{0} t\right]}
$$

The application of this equation can be approached in two ways: (1) one by simply fitting the data to the equation form; and (2) two by using the form of the equation, specifying the minimum time to GRE as one day less than actually observed in the data $\left(T_{0}=68\right)$ and maintaining the median time from the fitted case (thus in both cases a median of 100.2 days is maintained). If subscripts are added to identify the specific approach, the general equation can be written as follows:

Then $a_{1}=0.0002573$ and $b_{1}=0.01919 ;$ and $a_{2}=0.0002063$ and $P=1-e^{-\left[a t^{2}-b t\right]} \quad \begin{aligned} & \mathrm{b}_{2}=0.01403 \text {. Where the subscripts refer to the first or second } \\ & \text { approach described above. Note that the ratio } \mathrm{a} / \mathrm{b}=-\mathrm{T}_{0} \text { in either }\end{aligned}$ case.

The first approach yields a $\mathrm{T}_{0}$ of 74.58 days, somewhat longer than the actual 69 days observed. But, in any event, the form of the equation fits the data quite well in either case (a correlation coefficient of 0.987 for the first approach -- simple fitting). The results for the two approaches are shown graphically in Figure $\mathrm{H} 2-\mathrm{Cl}-2$. The probability density function for the fitted parameters approach is shown in Figure $\mathrm{H} 2-\mathrm{Cl}-3$.

The fitted form ( $\mathrm{T}_{0}=74.58$ days) will be used in this analysis because it is derived from the data. This equation has a median of 100.2 days and a mean of 106.0 days. It is interesting to note that 
the probability of having a Maximum Expected Burp [(MEB) -- $296 \mathrm{~m}^{3}$ at WHC standard conditions] as defined in the two reference documents is approximately $1 \%$ per event or about 0.0026 per year; and of having a Maximum Allowable Burp [(MAB) $-354 \mathrm{~m}^{3}$ at WHC standard conditions] approximately $0.05 \%$ per event or about 0.0014 per year.

To arrive at the state vector for this cell the uniform distribution described previously is modified, at the upper end, by the empirical distribution and then normalized to one. That is, the normalized probability density function for the state vector is given by:

$$
\begin{aligned}
& \text { For } \mathrm{t}<\mathrm{T}_{0} \\
& \text { For } \mathrm{t}>\mathrm{T}_{0} \\
& \frac{d P}{d t}=0.00945 \quad \frac{d P}{d t}=0.000945 e^{-\left(0.0002573 t^{2}-0.01919 t\right)}
\end{aligned}
$$

And the probability within the state vector range is defined by:

$$
\begin{array}{cc}
\text { For } \mathrm{t}<\mathrm{T}_{0} & \text { For } \mathrm{t}>\mathrm{T}_{0} \\
P=0.00945 \Delta t & P=0.00945 \int_{-t_{4}}^{t_{2}} e^{-\left(0.0002573 t^{2}-0.01919 t\right)} d t
\end{array}
$$

Where the time included within the range is defined by the range of the releases in inches of slurry growth.

The range of releases has been selected to extend from releases associated with slurry expansion of $<0.60$ inches (about 8 days) to $>12.6$ inches of expansion (about 160 days). Twenty-two states are defined to encompasses $100 \%$ of all possible releases. The minimum release state $(<$ 0.6 inches) comprises $7.3 \%$ of the total distribution and the maximum release state $(>12.6$ inches) constitutes about $0.1 \%$ of the total distribution. The release states and the probability state vector are shown in tabular form in Table H2-Cl-1 and graphically in Figure H2-C1-4.

The event probability for this cell is $4 \times 10^{-4}$ per year.

$$
==
$$


Table $\mathrm{H} 2-\mathrm{Cl}-\mathrm{l}$

Release States and Probability State Vector Assuming Random Initiating Event

\begin{tabular}{|c|c|c|c|}
\hline \multicolumn{2}{|c|}{$\begin{array}{l}\text { Range of Release } \\
\text { Expressed as Inches of Slurry Expansion }\end{array}$} & \multicolumn{2}{|c|}{$\begin{array}{l}\text { Occurrence Probability and } \\
\left.\text { Probability Density (day }{ }^{-1}\right)\end{array}$} \\
\hline Lower Limit & Upper Limit & Event Probability & Probability Density \\
\hline 0.0 & 0.60 & 0.0073 & 0.00945 \\
\hline 0.60 & 1.20 & 0.0073 & 0.00945 \\
\hline 1.20 & 1.80 & 0.0073 & 0.00945 \\
\hline 1.80 & 2.40 & 0.0073 & 0.00945 \\
\hline 2.40 & 3.00 & 0.073 & 0.00945 \\
\hline 3.00 & 3.60 & 0.073 & 0.00945 \\
\hline 3.60 & 4.20 & 0.073 & 0.00945 \\
\hline 4.20. & 4.80 & 0.073 & 0.00945 \\
\hline 4.80 & 5.40 & 0.073 & 0.00945 \\
\hline 5.40 & 6.00 & 0.073 & 0.00945 \\
\hline 6.00 & 6.60 & 0.063 & 0.00817 \\
\hline 6.60 & 7.20 & 0.052 & 0.00674 \\
\hline 7.20 & 7.80 & 0.042 & 0.00540 \\
\hline 7.80 & 8.40 & 0.032 & 0.00418 \\
\hline 8.40 & 9.00 & 0.024 & 0.00315 \\
\hline 9.00 & 9.60 & 0.018 & $0 . \overline{00} \overline{2} 29$ \\
\hline 9.60 & 10.20 & 0.013 & 0.00162 \\
\hline 10.20 & 10.80 & 0.009 & 0.00111 \\
\hline 10.80 & 11.40 & 0.006 & 0.00074 \\
\hline 11.40 & 12.00 & 0.004 & 0.00048 \\
\hline 12.00 & 12.60 & 0.002 & 0.00030 \\
\hline$>12.60$ & & 0.001 & 0.00018 \\
\hline
\end{tabular}




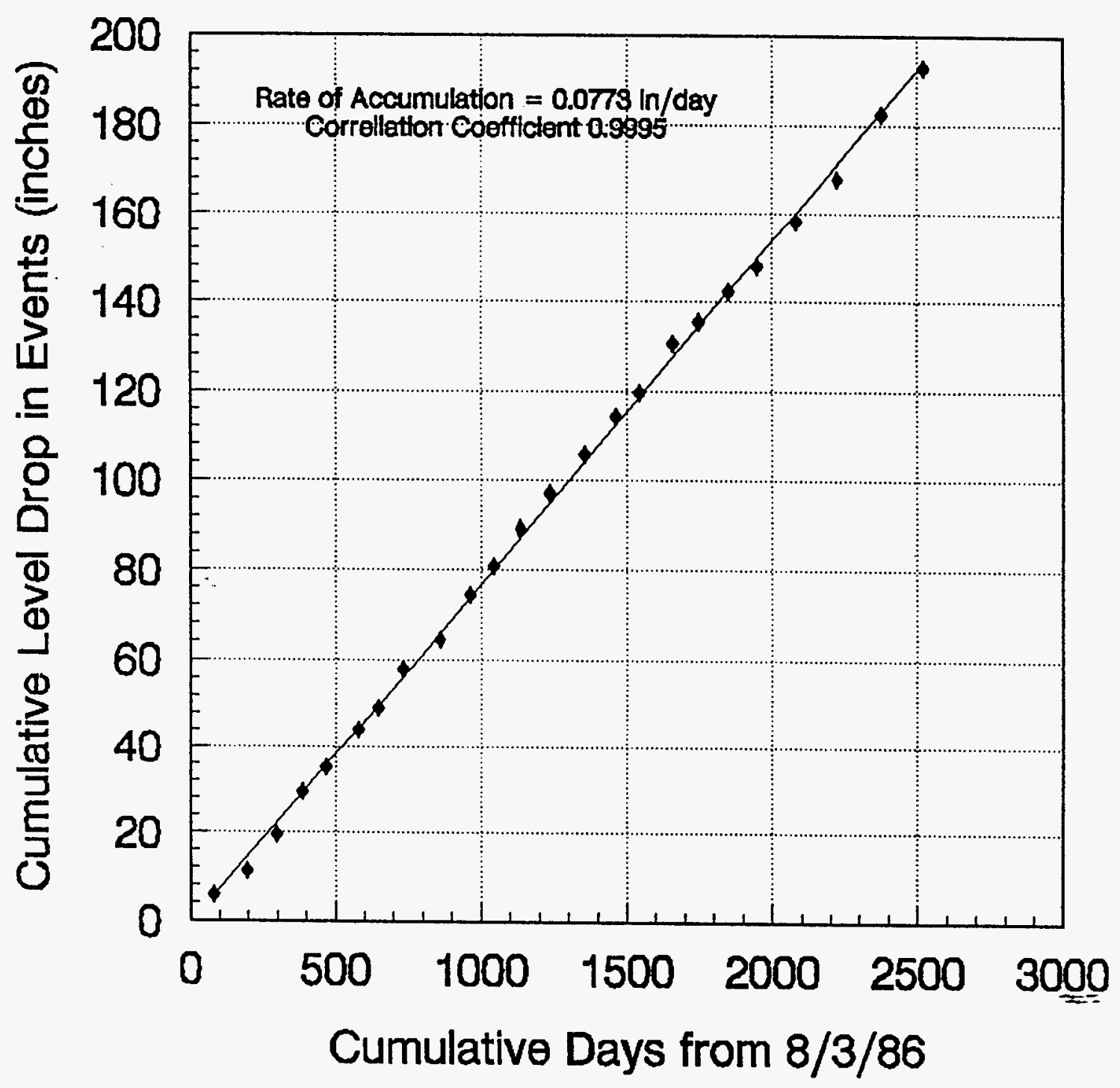

Figure $\mathrm{H} 2-\mathrm{Cl}-1$

Cumulative Level Drop (in inches)

All Episodic GREs from 8/3/86 
Probability - That time to next GRE will be equal to or less than indicated value
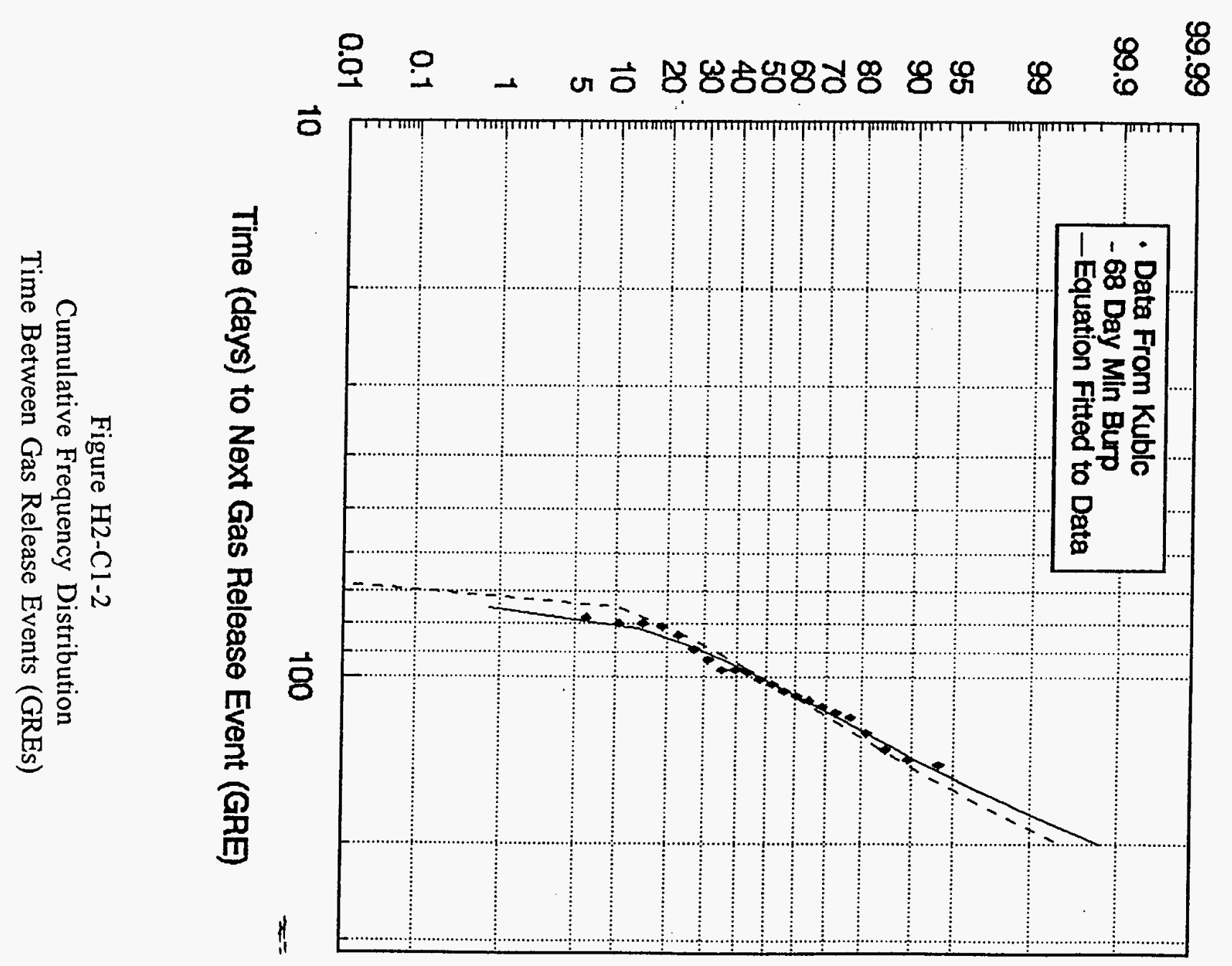
(

6625K0014-96, Task-2

Draft 01-JRC-6/01/94

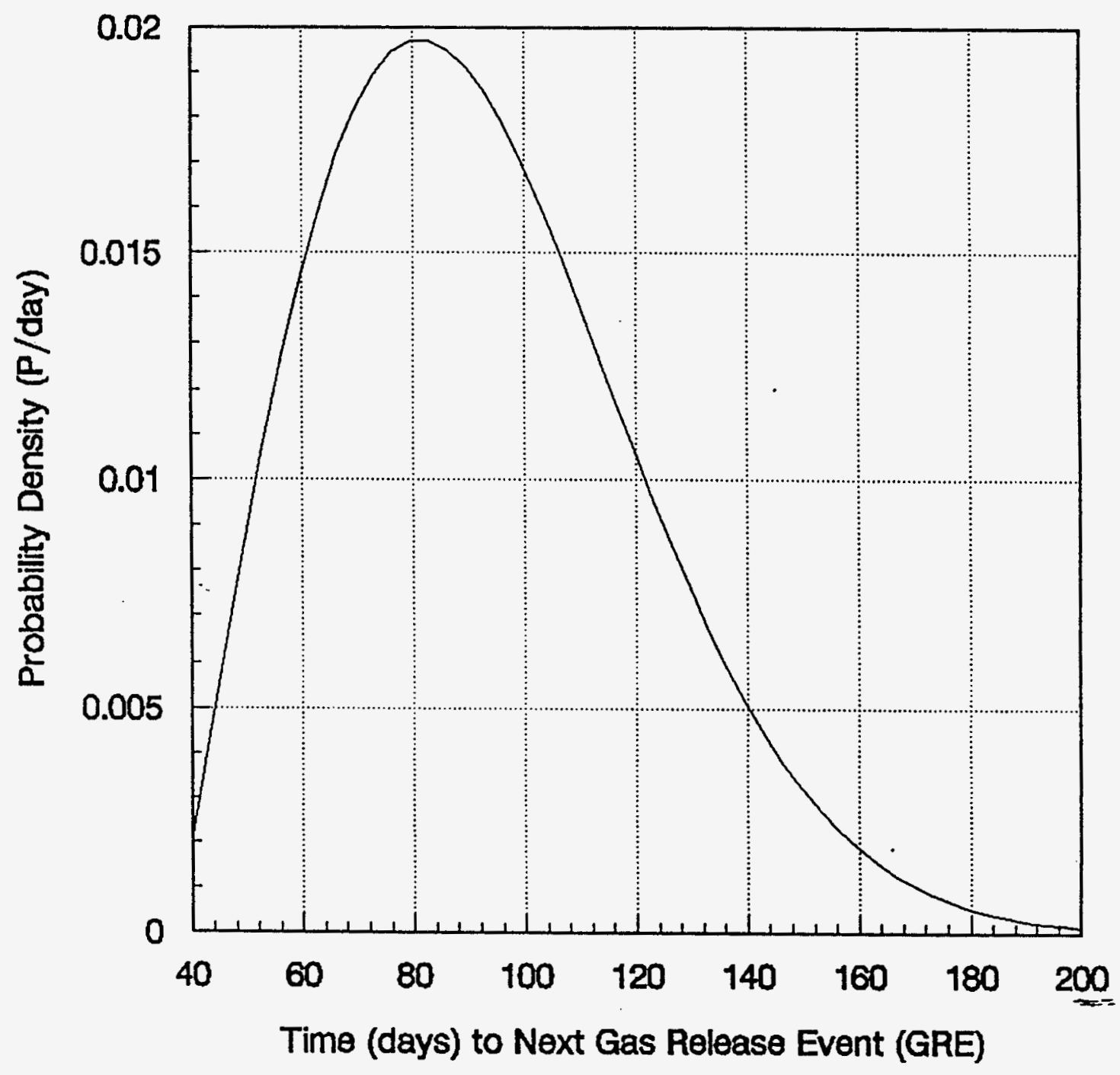

Figure $\mathrm{H} 2-\mathrm{Cl}-3$

Probability Density Function

Fitted Equation for Time Between Gas Release Events (GREs) 


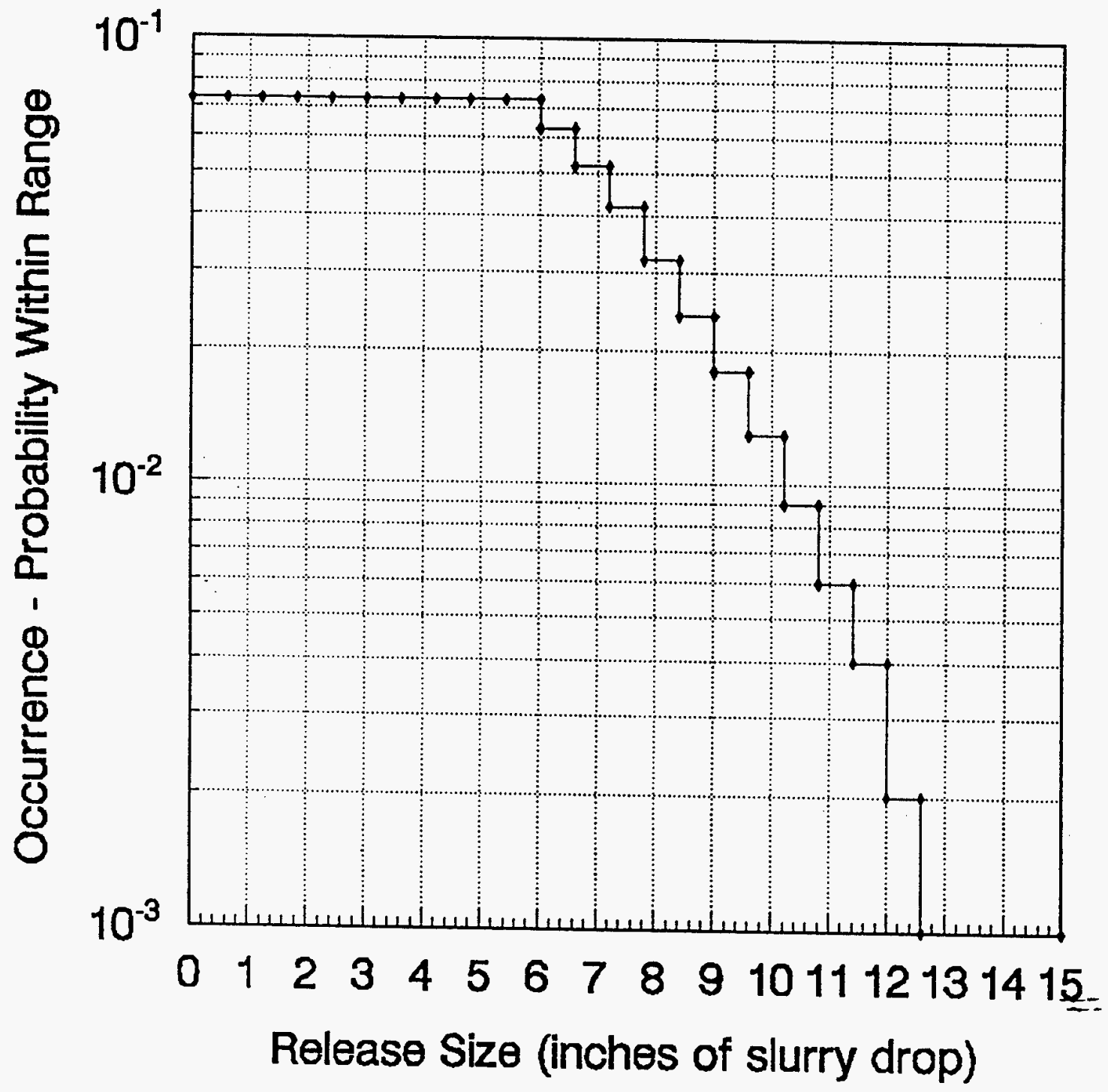

Figure $\mathrm{H} 2-\mathrm{Cl}-4$

Cell \#1 State Probability Vector

Probability of Occurrence vs Release Size (inches of drop) 


\section{Accident Environments (Cell \#2)}

The accident environment of interest is the initial pressure/temperature in the tank dome following gas ignition and is related to the quantity of released gases and their composition. A number of initial values or calculations are required in order to calculate those environments: the moles of gas released; the initial mole content of the free-space; and the heat of reaction. The following paragraphs present the method of calculation used here. The initial temperatures, densities, and dimensions used to describe the tank and its contents for these calculations are those provided in the Table $\mathrm{H} 2-\mathrm{C} 0-1$ presented earlier.

\section{Gas Moles per Inch of Expansion.}

The density and thickness data for the waste layers listed in the descriptive table (Table $\mathrm{H} 2-\mathrm{C} 0-1$ ) provide the information needed to calculate the moles of gas represented by one inch expansion of the slurry layer. The data used are:

Thickness and density of crust: $0.762 \mathrm{~m}\left(30^{\prime \prime}\right)$ and $1340 \mathrm{~kg} / \mathrm{m}^{3}$

Thickness and density of convective liquid layer: $5.245 \mathrm{~m}\left(206.5^{\prime \prime}\right)$ and $1450 \mathrm{~kg} / \mathrm{m}^{3}$

Thickness and density of non-convective slurry layer: $4.572 \mathrm{~m} \mathrm{(180")} \mathrm{and} 1450 \mathrm{~kg} / \mathrm{m}^{3}$ Ambient pressure: $14.7 \mathrm{psi}$.

Temperature of the non-convecting slurry layer $329^{\circ} \mathrm{K}\left(133^{\circ} \mathrm{F}\right.$, or $\left.56^{\circ} \mathrm{C}\right)$.

The gas is assumed to behave as an ideal gas.

Therefore the average pressure in the slurry (because the pressure is linear with depth, the average is simply the pressure at half-depth) is:

$$
14.7+[0.762 * 1340+5.245 * 1450+2.286 * 1450]^{*} 2.2 /(39.37)^{2}=31.65 \mathrm{psi}
$$

The volume of one mole of gas at slurry conditions (assuming the ideal gas law):

$$
22.4 *(329 / 273) * 14.7 / 31.65=12.54 \text { liters } / g-m o l e
$$

Volume per inch of expansion:

$$
\pi^{*}(11.45)^{2 *}(1000 / 39.4)=1.045 \times 10^{4} \text { liters/inch }
$$

Therefore each inch of expansion (or collapse) represents $833 \mathrm{~g}$-moles of gas $\left(1.045 \times 10^{4} / 12.54\right)$.

\section{Volume of Free Dome-Space and Initial Moles of Air.}

The geometry for calculating the free-space volume and the values for the three conditions of interest are given in Table $\mathrm{H} 2-\mathrm{CO}-\mathrm{l}$ of this report. The volumes of interest here are the values 
of $1550 \mathrm{~m}^{3}$ and $1640 \mathrm{~m}^{3}$ [the estimated free vapor space volume at the neutral buoyancy condition (pre-GRE) and the post-GRE condition respectively]. The ambient conditions in the free vapor space is taken to be $14.7 \mathrm{psi}$ and $311^{\circ} \mathrm{K}\left(100^{\circ} \mathrm{F}\right.$, or $\left.38^{\circ} \mathrm{C}\right)$. Therefore, the two volumes $\left(1550 \mathrm{~m}^{3} \& 1640 \mathrm{~m}^{3}\right)$ and the ambient dome conditions relate to $6.09 \times 10^{4}$ and 6.44 $\times 10^{4} \mathrm{~g}$-moles of air respectively. For the purposes of calculating the initial peak pressure in the dome space the pre-GRE quantity of air in the dome space $\left(8.66 \times 10^{4}\right.$ moles $)$ is assumed to be present in the post-GRE volume $\left(1640 \mathrm{~m}^{3}\right)$. The effect of expelling air during the GRE is relatively unimportant.

\section{Gas Composition \& Thermodynamic Parameters.}

The gas composition used is the "best estimate" composition from table C-3 in Appendix C of the Tank SA (Rev. 8). The uncertainty illustrated by the "conservative estimate" is not included for this illustration, but could easily be included later as an uncertainty. The gas composition of the best estimate is given below:

$\begin{array}{lll}\mathrm{H}_{2} & = & 0.2877 \\ \mathrm{~N}_{2} \mathrm{O} & =0.2445 \\ \mathrm{NH}_{2} & =0.1095 \\ \mathrm{~N}_{2} & =0.3282 \\ \mathrm{CH}_{4} & =0.0035 \\ \mathrm{CO}_{2} & =0.0025 \\ \mathrm{H}_{2} \mathrm{O} & =0.0241\end{array}$

The chemical reactions assumed comprise two groups (those wherein the oxidation is by $\mathrm{N}_{2} \mathrm{O}$ an those oxidized by $\mathrm{O}_{2}$ ) which are shown below.

Oxidized by $\mathrm{N}_{2} \mathrm{O}$ :

$$
\begin{array}{ll}
\mathrm{H}_{2}+\mathrm{N}_{2} \mathrm{O} \rightarrow \mathrm{H}_{2} \mathrm{O}+\mathrm{N}_{2} & -73.3 \mathrm{kcal} / \mathrm{g}-\mathrm{mole} \\
\mathrm{NH}_{3}+1.5 \mathrm{~N}_{2} \mathrm{O} \rightarrow 1.5 \mathrm{H}_{2} \mathrm{O}+2 \mathrm{~N}_{2} & -105.7 \mathrm{kcal} / \mathrm{g}-\mathrm{mole} \\
\mathrm{CH}_{4}+4 \mathrm{~N}_{2} \mathrm{O} \rightarrow 2 \mathrm{H}_{2} \mathrm{O}+4 \mathrm{~N}_{2}+\mathrm{CO}_{2} & -270.4 \mathrm{keal} / \mathrm{g}-\mathrm{mole} \\
\mathrm{CO}+\mathrm{N}_{2} \mathrm{O} \rightarrow \mathrm{CO}_{2}+\mathrm{N}_{2} & -87.2 \mathrm{kcal} / \mathrm{g}-\text { mole }
\end{array}
$$

Oxidized by $\mathrm{O}_{2}$ :

$$
\begin{aligned}
& \mathrm{H}_{2}+0.5 \mathrm{O}_{2} \rightarrow \mathrm{H}_{2} \mathrm{O} \\
& \mathrm{NH}_{3}+0.75 \mathrm{O}_{2} \rightarrow 1.5 \mathrm{H}_{2} \mathrm{O}+0.5 \mathrm{~N}_{2} \\
& \mathrm{CH}_{4}+2 \mathrm{O}_{2} \rightarrow 2 \mathrm{H}_{2} \mathrm{O}+\mathrm{CO}_{2} \\
& \mathrm{CO}+0.5 \mathrm{O}_{2} \rightarrow \mathrm{CO}_{2}
\end{aligned}
$$

- $56.7 \mathrm{kcal} / \mathrm{g}-\mathrm{mole}$

- $75.8 \mathrm{kcal} / \mathrm{g}-\mathrm{mole}$

- $190.7 \mathrm{kcal} / \mathrm{g}$-mole

- $67.2 \mathrm{kcal} / \mathrm{g}$-mole 
The SA assumes that the proportion of oxidation by $\mathrm{N}_{2} \mathrm{O}$ can be calculated by the following relationship (where the Fs relate to mole fractions):

$$
\eta=\mathrm{F}\left(\mathrm{N}_{2} \mathrm{O}\right) /\left[\mathrm{F}\left(\mathrm{H}_{2}\right)+1.5 \mathrm{~F}\left(\mathrm{NH}_{3}\right)+4 \mathrm{~F}\left(\mathrm{CH}_{4}\right)+\mathrm{F}(\mathrm{CO})\right.
$$

This approach is also used here, but it must be understood that this approach contains the implicit assumption that there is no mixing of the released gases with the tank air. This relationship can be used to adjust the mole quantities in the tank free-space by the loss of reactants and the gain of products due to the chemical reactions. This is summarized as follows for the best estimate GRE composition (on a per mole GRE input basis).

\section{INPUT MOLES}

$\begin{array}{lll}\mathrm{H}_{2} & = & 0.2877 \\ \mathrm{~N}_{2} \mathrm{O} & =0.2445 \\ \mathrm{NH}_{2} & = & 0.1095 \\ \mathrm{~N}_{2} & = & 0.3282 \\ \mathrm{CH}_{4} & = & 0.0035 \\ \mathrm{CO} & =0.0025 \\ \mathrm{H}_{2} \mathrm{O} & =0.0241 \\ \text { Total } & =\end{array}$

\section{OUTPUT MOLES}

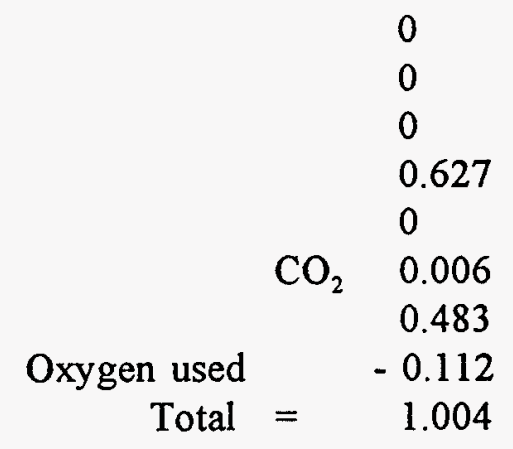

Thus, the best estimate gas composition results in roughly one mole of gaseous products per mole of gas input.

It was mentioned above that the method of calculating the oxidation by $\mathrm{N}_{2} \mathrm{O}$ contains the implicit assumption that there is no mixing. That is, it assumes that all of the $\mathrm{N}_{2} \mathrm{O}$ is consumed and only then is the oxygen consumed. This is important because it defines a different situation than that discussed in Section 4.3.2. of the SA (complete mixing), and is inconsistent with invoking a Lower Flammability Limit (LFL) based on dilution within the existing free-space air. Thus an important question is to decide which case to use. If one assumes that there is no mixing then the released gas mixture is flammable, the heat release is biased toward the $\mathrm{N}_{2} \mathrm{O}$ equations (a release of $30.6 \mathrm{kcal} / \mathrm{g}$-mole of gas), and one cannot invoke the LFL; if, on the other hand, one assumes essentially complete mixing then the nitrous oxide will be burned (in the most elementary view) at a rate proportional to its relative mole fraction related to oxygen, the heat release would be biased toward the $\mathrm{O}_{2}$ equations (about $75 \%$ of that for $\mathrm{N}_{2} \mathrm{O}$ ), and a LFL can be invoked. This complicates the algebra somewhat but is not really difficult.

For the purposes here (which are somewhat different than the SA) the "no mixing" case will be assumed. The reason for this is that the accident scenario described assumes that the initiating event causes both the gas release and provides an ignition source. Thus, because the gas will be 
ignited as released the nitrous oxide would be consumed first; yielding $29.9 \mathrm{kcal} / \mathrm{g}$-mole of gas as is implied by the above equation for $\eta$. And, in this case the LFL cannot be invoked on the basis of dilution. This is conservative in terms of accident probability as well as heat release. The use of an LFL does not appear to be highly significant. From the state vector in Cell \#l a $2 \%$ hydrogen LFL would reduce the accident probability by about $60 \%$ and the effect on heat release is relatively minor. If one considers only naturel GREs rather than induced GREs the LFL has essentially no effect.

The final parameters necessary to calculate the temperature and pressure in the vapor space are the heat capacities of the product gases and air. These are calculated from the following approximating equations.

$$
\begin{aligned}
& \mathrm{c}_{\mathrm{v}}\left(\mathrm{H}_{2} \mathrm{O}\right)=6.233+0.00015 \mathrm{~T}+0.00000134 \mathrm{~T}^{2} \quad \mathrm{cal} / \mathrm{g}-\mathrm{mole}-^{\circ} \mathrm{K} \\
& c_{v}\left(N_{2}, O_{2} \text { or dry air }\right) \\
& =4.773+0.000606 \mathrm{~T}+0.00000013 \mathrm{~T}^{2} \quad \mathrm{cal} / \mathrm{g}-\mathrm{mole}-^{\circ} \mathrm{K} \\
& c_{v}\left(\mathrm{CO}_{2}\right)=5.713+0.00530 \mathrm{~T}-0.00000083 \mathrm{~T}^{2} \quad \mathrm{cal} / \mathrm{g}-\mathrm{mole}^{\circ}{ }^{\circ} \mathrm{K}
\end{aligned}
$$

The approach taken in this application involves three steps: (1) to integrate each of these equations from the initial dome condition $\left(\mathrm{T}_{0}=311^{\circ} \mathrm{K}\right)$ to a variable $\mathrm{T}_{1}$ to get an average value of $c_{v}$ over the range $T_{0}$ to $T_{1}$, (2) fitting an equation to the results so that one now has $c_{v}$ (ave) as a function of the end point temperature and (3) using that equation in a simple iteration procedure to calculate final temperatures.

On the basis of all of the foregoing information the resulting temperature of the gases and the associated pressure in the free-space can be calculated.

\section{Cell \#2 Initial Pressure States and State Vector.}

The results of calculations of the initial pressure states, the upper limit temperature, the percent hydrogen in the gas mixture (even though no LFL will be invoked) and the occurrence probabilities (probability state vector) are shown in Table H2-C2-1 (the probability state vector is shown graphically in Figure H2-C2-1).

The calculations use; a constant volume vapor space of $1640 \mathrm{~m}^{3}$ (initial content $64,400 \mathrm{~g}$-moles of air) with no leakage, the best estimate composition of released gases, and a heat release of $29.9 \mathrm{kcal} / \mathrm{g}$-mole of gas released in the event. The method of calculation (using the appropriate gas composition) was compared with the results in Table 4-III of the LA-UR-92-3225 and gave temperatures within one percent and a pressure within about $7 \%$ of those values. 
In order to get a basis for comparison, several calculations in the SA (Rev. 8) source document have been reproduced (as close as possible). For the Maximum Expected Release (MER) in Rev. 8 with the ventilation system closed ( $\$ 5.3 .1$ page 5-16) the SA gives 60 psia and $1480^{\circ} \mathrm{K}$. For the MER with a closed system and the same conditions the approach used here yields 80 psia and $1395^{\circ} \mathrm{K}$. For the Maximum Allowable Release (MAR) in Rev. 8 with the ventilation system closed ( $\$ 5.3 .1$ page 5-16) the SA gives 68 psia and $1650^{\circ} \mathrm{K}$. For the MAR with a closed system and the same conditions the approach used here yields 90 psia and $1530^{\circ} \mathrm{K}$. The difference in pressure may be the result of the riser cover lifting in the SA analysis. The differences in temperature, while somewhat disturbing, are not significant. In any event, in the end, the differences are not important to illustrating this approach to the analysis.

Summary of pertinent initial conditions:

Dome free space volume:

Initial quantity of air:

Dome free space temperature

Gram-moles of gas per inch of slurry swelling:

Best Estimate gas composition:

Heat release:
$1640 \mathrm{~m}^{3}$

64400 gram-moles

$311^{\circ} \mathrm{K}$

833 gram-moles/inch

Table C-5, Appendix C, SA (Rev.8) $29.9 \mathrm{kcal} / \mathrm{mole}$ released gas.

The event occurrence probability for this cell is 1.0 . 
Table H2-C2-1

Pressure and Probability State Vector for Cell \#2

Assuming $1640 \mathrm{~m}^{3}$ Vapor Space Volume

\begin{tabular}{|c|c|c|c|c|}
\hline \multicolumn{2}{|c|}{$\begin{array}{l}\text { Range of Pressure } \\
\text { (psi) }\end{array}$} & \multirow{2}{*}{$\begin{array}{c}\begin{array}{c}\text { Occurrence } \\
\text { Probability }\end{array} \\
0.073\end{array}$} & \multirow{2}{*}{$\begin{array}{c}\begin{array}{c}\text { Mole \% } \\
\text { Hydrogen }\end{array} \\
0.22\end{array}$} & \multirow{2}{*}{$\begin{array}{c}\begin{array}{c}\text { Temperature } \\
{ }^{\circ} \mathrm{K}\end{array} \\
357\end{array}$} \\
\hline 0 & 17.0 & & & \\
\hline 17.0 & 19.3 & 0.073 & 0.44 & 402 \\
\hline 19.3 & 21.6 & 0.073 & 0.66 & 446 \\
\hline 21.6 & 23.8 & 0.073 & 0.87 & 489 \\
\hline 23.8 & 26.0 & 0.073 & 1.08 & 532 \\
\hline 26.1 & 28.2 & 0.073 & 1.29 & 573 \\
\hline 28.3 & 30.4 & 0.073 & 1.49 & 614 \\
\hline 30.5 & 32.6 & 0.073 & 1.69 & 653 \\
\hline 32.6 & 34.7 & 0.073 & 1.89 & 692 \\
\hline 34.7 & 36.9 & 0.073 & 2.09 & 731 \\
\hline 36.9 & 39.0 & 0.063 & 2.28 & 768 \\
\hline 39.0 & 41.2 & 0.052 & 2.47 & 805 \\
\hline 41.2 & 43.3 & 0.042 & 2.66 & 841 \\
\hline 43.3 & 45.4 & 0.032 & 2.85 & 876 \\
\hline 45.4 & 47.5 & 0.024 & 3.04 & 911 \\
\hline 47.5 & 49.6 & 0.018 & 3.22 & $=245$ \\
\hline 49.6 & 51.6 & 0.013 & 3.40 & 979 \\
\hline 51.6 & 53.7 & 0.009 & 3.58 & 1012 \\
\hline 53.7 & 55.8 & 0.006 & 3.75 & 1044 \\
\hline 55.8 & 57.8 & 0.004 & 3.93 & 1076 \\
\hline 57.8 & 59.8 & 0.002 & 4.10 & 1107 \\
\hline$>59.8$ & & 0.001 & 4.20 & 1138 \\
\hline
\end{tabular}




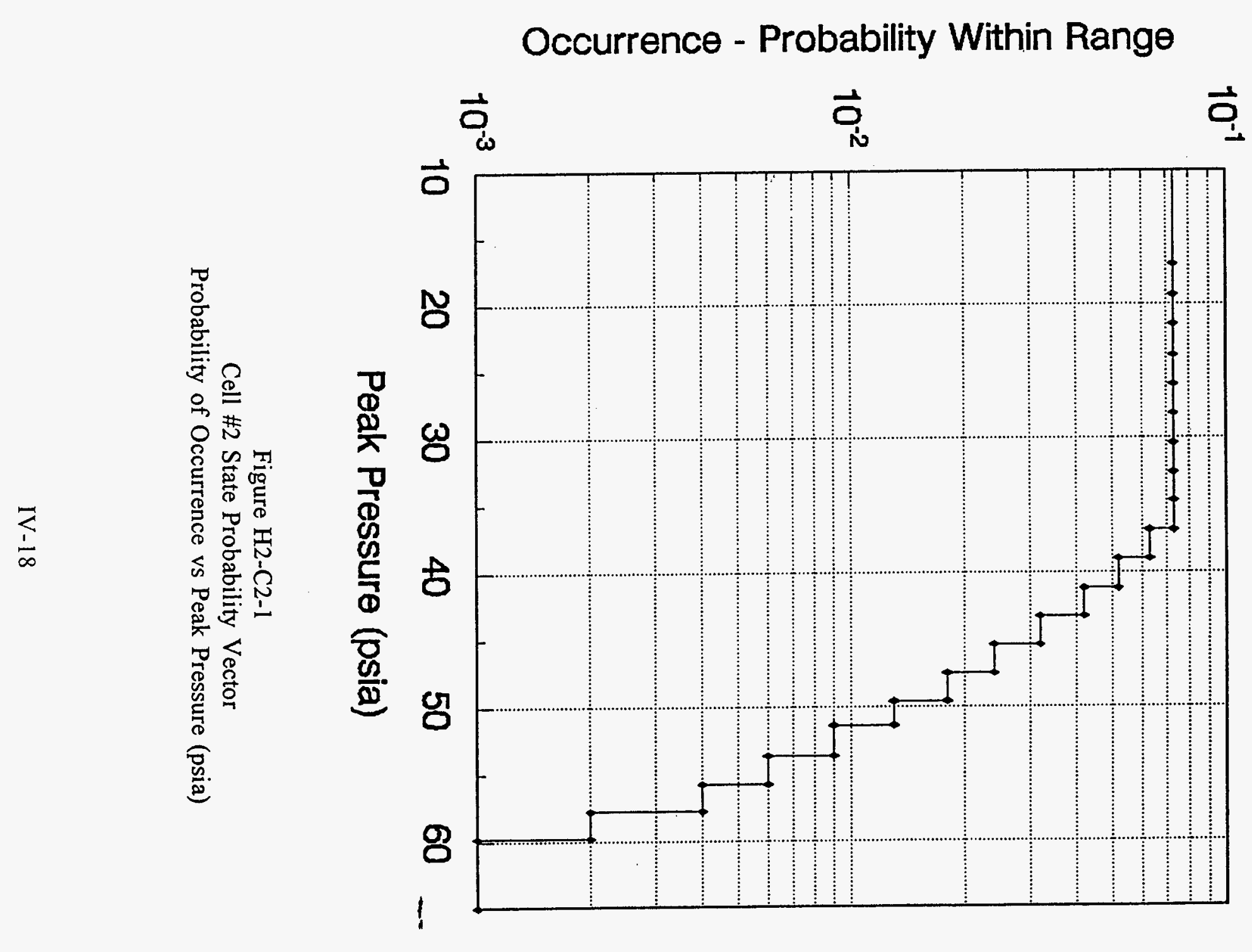

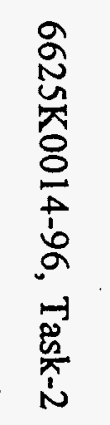

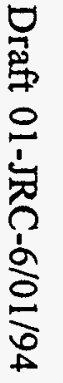




\section{System Response (Cell \#3)}

The system response cell consists of those analytical steps necessary to describe the distribution of physical damage to the system as a result of the environment states defined in the previous cell and the associated probabilities of those damage states occurring. This cell utilizes the accident environments described in the previous cell together with engineering judgement, data, and analyses to develop a set of system response states (e.g., ruptured tank, vented leaks, ruptured HEPA) and the associated transition probabilities to those states from the previously defined environment states. Figure H2-C3-1 shows the physical description of the tanking system assumed here -- an exhaust system interconnecting the three tanks by an exhaust header duct culminating in an exhaust HEPA, and an inlet HEPA but with no interconnected inlet system. Both exhaust and an inlet systems are assumed to be 12" pipes (after Figure A-1 of SA Rev. 8, Appendix A).

In general, HEPA filters exhibit structural failure at pressure differentials of about 2 psi. In this light, the inlet HEPA is assumed to fail in any event resulting in an internal tank pressure of 17 psia -- providing a 12 inch leakage path to the environment. Thus, any event exhibiting pressures greater than 17 psia will release the pressurized gases to the environment through the tank inlet HEPA as well as any other vents.

The failure of the exhaust HEPA is also important in that this will provide a second route for release of waste gases to the environment. As mentioned above, the system is taken to be that illustrated in Figure A-1 of SA Appendix A and included here as Figure H2-C3-1. That is, an interconnection among the three tanks through the exhaust system and an exhaust HEPA in addition to the individual intake HEPA on tank 101-SY. This view of the system presents the possibility that the unloading of the tank pressure into the exhaust system may also challenge the exhaust HEPA. This problem has been reduced to a simple three compartment model to calculate the pressure-time relationship in the tank system considering these two exhaust pathways and is described in the discussion of Cell \#4 that follows.

In any event, the result of this analysis is, that any event producing a peak pressure of greater than 17 psia ( 2.3 psig or 64 inches of $\mathrm{H}_{2} \mathrm{O}$, gage) in Tank 101-SY will result in the structural failure of the inlet HEPA and subsequent venting to the environment through the 12" inlet. In addition, any event producing a peak tank pressure of greater than about 30 psia in Tank 101-SY will also result in the structural failure of the exhaust HEPA resulting in a second 12" venting pathway. Because the HEPAs fail at relatively low pressure differentials other failure pathways are not of great significance in-so-far-as airborne source terms are concerned.

The output of this cell is, in the general case, the product of the environment probability state vector from the previous cell and the derived transition matrix from this cell. However, in this instance, no transition matrix, per se, has been devised. That is, it is simply assumed that failure occurs at point pressures and thus no distributions of failure probabilities is proposed. Thus the 
probability state vector for this cell is just the probability state vector from the previous cell modified slightly and assigned new states, i.e., the failure states. The pressure states have already been selected in the previous cell so that the first state includes all event that yield peak pressures less than 17 psi. For this cell we need only use the complement of the $<17$ psia state probability as an event probability for failure, and renormalize the remaining state probabilities to one.

Thus the failure event probability is 0.927 and the state vector that consists of the upper 21 states in Table H2-C2-1 normalized to one. The response states are either one or both HEPAs failed and venting to the environment. This state vector is tabulated in Table H2-C3-1. 
Table H2-C3-1

Pressure and Probability State Vector (Damage State) for Cell \#3 Assuming $1640 \mathrm{~m}^{3}$ Vapor Space Volume

\begin{tabular}{|c|c|c|c|}
\hline \multicolumn{2}{|c|}{$\begin{array}{l}\text { Range of Pressure } \\
\text { (psia) }\end{array}$} & \multirow{2}{*}{$\begin{array}{c}\text { Occurrence } \\
\text { Probability } \\
0.079 \\
\end{array}$} & \multirow{2}{*}{$\begin{array}{c}\text { Damage State } \\
\text { Inlet HEPA failed - one } 12^{\prime \prime} \text { vent }\end{array}$} \\
\hline 17.0 & 19.3 & & \\
\hline 19.3 & 21.6 & 0.079 & $"$ \\
\hline 21.6 & 23.8 & 0.079 & $"$ \\
\hline 23.8 & 26.0 & 0.079 & $"$ \\
\hline 26.1 & 28.2 & 0.079 & $"$ \\
\hline 28.3 & 30.4 & 0.079 & Inlet/exhaust failed - two 12" vent \\
\hline 30.5 & 32.6 & 0.079 & $"$ \\
\hline 32.6 & 34.7 & 0.079 & $"$ \\
\hline 34.7 & 36.9 & 0.079 & $"$ \\
\hline 36.9 & 39.0 & 0.068 & $"$ \\
\hline 39.0 & 41.2 & 0.056 & $"$ \\
\hline 41.2 & 43.3 & 0.045 & $"$ \\
\hline 43.3 & 45.4 & 0.034 & $"$ \\
\hline 45.4 & 47.5 & 0.026 & $"$ \\
\hline 47.5 & 49.6 & 0.019 & $"$ \\
\hline 49.6 & 51.6 & 0.014 & $" \quad=$ \\
\hline 51.6 & 53.7 & 0.010 & $"$ \\
\hline 53.7 & 55.8 & 0.006 & $"$ \\
\hline 55.8 & 57.8 & 0.004 & $"$ \\
\hline 57.8 & 59.8 & 0.002 & $"$ \\
\hline$>59.8$ & & 0.001 & $"$ \\
\hline
\end{tabular}




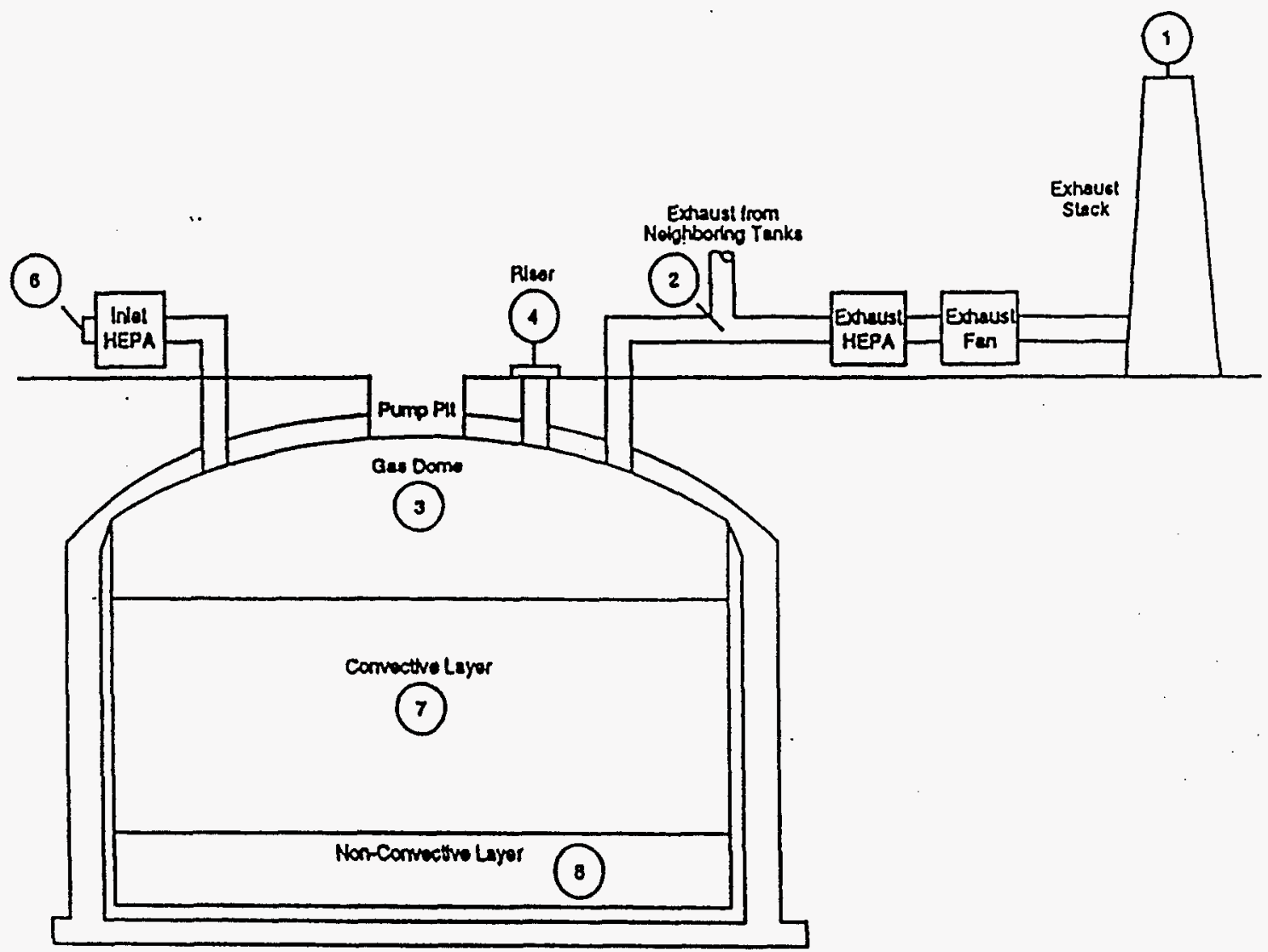

Tank 101-SY HazOp analysis node diagram tank and HVAC system

$\operatorname{Rev} .8$

Figure H2-C3-1

Diagram of Tank 101-SY Intake and Exhaust System

Taken From Figure A-1 of Pump SA (Rev. 8) 


\section{Source Terms (Cell \#4).}

The source term cell consists of those analytical steps necessary to describe the probability distribution of releases associated with the damage states defined in the previous cell. This cell utilizes the system response states and the accident environments from the previous cell together with engineering judgement, data, and analyses to estimate the quantity and characteristics of potentially released hazardous materials.

The SA is not definitive in its description of the calculation of source terms but the general process is described on page 4-11 as follows.

The radioactive source term in the dome space atmosphere considers the convective entrainment of waste particles from the surface. In analyzing leakage to the atmosphere, three paths were considered: (I) leakage through tank penetrations that are inlets under normal conditions, (2) flow through the ventilation system with a HEPA filter (assumed to have failed during the hydrogen combustion cases), and (3) releases from any potential failures in risers or in the tank itself and from risers that could be open during the window activities. The release of radionuclides to the atmosphere were determined with HMS by integrating the mass flow rate leaving the tank, as determined by TRAC.

Because the details of the "convective entrainment of waste particles" are not provided nor is HMS-TRAC, a simple approach based on the experiments of Sutter (Aerosols Generated by Releases of Pressurized Powders and Solutions in Static, Air (NUREG/CR-3039), and the discussion of adiabatic flow in horizontal ducts in Perry (Chemical Engineering Handbook, $6^{\text {th }}$ Edition, pages 5-28 et seq.) has been devised for this illustration. The approach to each of these problems is discussed separately in the following paragraphs.

\section{Aerosol Production}

In one set of experiments carried out by Sutter the physical set-up is very similar to that obtained with a hydrogen ignition in the tank free-space. For these tests the free-space above the liquid sample surface was pressurized to the test pressure and then quickly released (see Figure H2-C41, Test Configuration for Pressurized Release Experiments). The subsequent quantity and character of the airborne aerosol was investigated (mass and some particle size information). The similarity with the pressurization of the tank free-space by hydrogen ignition is obvious. However, clear and significant difference must also be recognized, in particular the rate of depressurization and the temperature. It would be extremely valuable to test the models used in the SA by modeling the several sets of experiments by Sutter.

In any event the Sutter experiments provide a simple (unfortunately probably not conservative) basis for estimating the aerosolized source term in the tank free-space as a function of the peak pressure resulting from a hydrogen burn. In order to use these data the first step is to devise a 
general mathematical form for the expected aerosolized source term so that extrapolation beyond the experimental observations is defensible. For this purpose the following approach is taken:

a. Assume that the airborne source term [taken to be $<10 \mu \mathrm{m}$ aerodynamic equivalent diameter (AED)] is linearly proportional to the energy stored in the liquid volume as a result of pressurized compression (that is $S=c_{0} E$ ).

b. Assume that the energy can be stated as $P \Delta V$ and that $\Delta V$ can be stated as $c_{1} \Delta h$ (where $h$ is the height of the liquid under compression).

c. Finally assume that $\Delta h$ over the range of interest is a linear function of the pressure $\mathrm{P}$ (that is $\Delta h=\mathrm{c}_{2} \mathrm{P}$ ).

Under these assumptions the airborne source would be expected to be proportional to the square of the pressure (that is $S=c_{1} c_{2} P^{2}$ ). The observed data are reasonably consistent with such a function but the statistics are not very good. Although a better fit to the data can be obtained by adding more terms in a power series it is better to stay with the equation form rather than simply fitting by an arbitrary function, because the purpose is extrapolation. Also because the interest here is in the lower limit of the experimental data (in the range from 0 to $50 \mathrm{psig}$ ) the 50 psig data are the most important. Thus for this effort the equation form has been fitted only to the 50 psig data.

All of the data and the $\mathrm{P}^{2}$ function fitted only to the 50 psig data are shown in Figure H2-C4-2. The equation for this curve, reduced to an inhalable source term (less than $10 \mu \mathrm{m}$ AED) per unit area as a function of $\mathrm{P}^{2}$, is :

$$
\mathrm{S}\left(\mathrm{g} / \mathrm{cm}^{2}<10 \mu \mathrm{m} \mathrm{AED}\right)=1.8 \times 10^{-8} \mathrm{P}^{2} \text {, where } \mathrm{P} \text { is in psig. }
$$

This equation and the cross-sectional area of the tank are used to calculate the source term (in grams) as a function of the event pressure. However, it is recognized that this approach overlooks a host of difference between the tests carried out by Sutter and the events being considered here.

It is difficult to make a comparison with the source terns used in the SA Rev. 8, because they are not explicitly presented. However, a comparison can be made with the information in LAUR-92-3225. In that report, the generation of aerosols is discussed in Appendix A and a graph of the mass of aerosol produced as a function of initial burn product volume is provided (Figure A-11, page A-16). It is assumed that the particle sizes used in this figure are physical diameters. The $<10 \mu \mathrm{m}$ AED used here relates to (roughly) an $<8 \mu \mathrm{m}$ physical diameter and a comparison can be made on that basis. Thus, although quite rough, it appears that the source terms calculated here are about a factor of 30 below those calculated in Appendix A of LA-UR-923225. This is a sizable difference but, because the Appendix deals with under-the-crust burns 
rather than above-the-crust burns, significantly higher source terms would be expected. It appears that the SA Rev. 8 uses the same methodology as used in Appendix A of LA-UR-92-3225, thus the source terms calculated here may be about a factor of 30 below those in Rev. 8 .

\section{Venting of Tank Under Pressure}

In order to calculate the release source term one must calculate the fraction of the material made airborne in the tank free-space that is vented to the environment. To do a pressure-time relationship for the tank venting through one or more of the failed HEPA filters must be devised. As mentioned previously, the SA uses the HMS-TRAC model for these calculations. For the purposes of this report, the graphical approach described by Perry (Chemical Engineer's Handbook, Sixth Edition, Pages 5-28 to 5-30) based on the work of Levenspiel (AIChE Journal, Vol. 23, No. 3) is used. The approach is described in the following paragraphs.

Start by defining the following.

$\mathrm{V}_{1}=$ Volume of free-space in the pressurized tank $\left(1640 \mathrm{~m}^{3}\right)$.

$\mathrm{V}_{2}=$ Volume of free-space in remaining system including the piping $\left(3280 \mathrm{~m}^{3}\right)$.

$\mathrm{P}_{1}=$ Pressure in volume $\mathrm{V}_{1}$ (the pressurized tank).

$\mathrm{P}_{2}=$ Pressure in volume $\mathrm{V}_{2}$ (the remainder of the interconnected system).

$\mathrm{w}_{2}=$ Mole flow rate out of volume $\mathrm{V}_{1}$ into volume $\mathrm{V}_{2}$.

$\mathrm{w}_{\text {out }}=$ Mole flow rate out of volume $\mathrm{V}_{1}$ into environment.

$\mathrm{S}=\quad$ Moles released to the environment.

With these definitions, together with $T$ (absolute temperature), $R$ (gas constant) and the assumption of ideal gases, the following simple differential equations can be written for the pressure relationships between the two volumes of the system and the discharge to the environment.

$$
\frac{d P_{1}}{d t}=-\frac{R T}{V_{1}}\left[w_{2}+w_{\text {out }}\right] \quad \frac{d P_{2}}{d t}=\frac{R T}{V_{2}} w_{2} \quad \frac{d S}{d t}=w_{\text {out }}
$$

The problem at this point is to determine the pressure dependent values of the flow rates $w_{2}$ and $\mathrm{w}_{\text {out }}$ which may be done by considering the flow through a nozzle (based on Perry). The governing equation is the mechanical energy balance. For horizontal flow the differential equation is:

$$
V d P+\frac{u}{g_{c}} d u=-\frac{f u^{2}}{2 g_{c}} d x \quad \text { Where: } \quad \begin{aligned}
& \mathrm{u}=\text { velocity } \\
& \mathrm{F}=\text { Fanning friction factor } \\
& \mathrm{x}=\text { distance from nozzle inlet } \\
& \mathrm{g}_{\mathrm{c}}=\text { dimensional constant }
\end{aligned}
$$

Perry presents a graphical method for integrating this equation for adiabatic horizontal flow as 
a function of the pressure ratio, pipe size, friction resistance, length, gas, and existing conditions. The method provides graphical results relating the pressure ratio (outlet/inlet) to a mass discharge ratio (mass velocity/maximum mass velocity) for various values of $k$ (ratio of specific heats) and of $\mathrm{N}$ ( $\mathrm{fL} / \mathrm{R}_{\mathrm{H}}$ the friction resistance in velocity heads). The curves presented in Perry have been reduced to a set of fitting equations to facilitate calculations and the use of the method (the equations generally fit the data within the error of reading the graph -- roughly 10 percent for reading flow rate from pressure ratio). The graphical data are approximated by the following equations.

$$
\begin{aligned}
\left(\frac{G}{G^{*}}\right)^{2} & =\left(N^{2}\right)^{2}\left[1-\left(\frac{P_{0}}{P_{i}}\right)^{\frac{1}{n}}\right] \\
N^{*} & =\left[\frac{1}{1+N}\right]^{0.412}
\end{aligned}
$$

and

$$
G^{*}=P_{i} \sqrt{\frac{g_{c} k}{R T_{i} M}\left[\frac{2}{k+1}\right]^{\left(\frac{k+1}{k-1}\right)}}
$$

Where:

$$
\begin{array}{ll}
\mathrm{G} & =\text { Mole velocity (moles/sec-unit area } \\
\mathrm{P}_{0} & =\text { Outlet pressure } \\
\mathrm{P}_{\mathrm{i}} & =\text { Inlet pressure } \\
\mathrm{N} & =\text { Friction resistance in velocity heads }
\end{array}
$$

$$
\begin{array}{ll}
\mathrm{g}_{\mathrm{c}} & =\text { Dimensional constant } \\
\mathrm{k} & =\text { Ratio of specific heats } \\
\mathrm{M} & =\text { Molecular weight } \\
\mathrm{R} & =\text { Gas constant }
\end{array}
$$

This model approach has been incorporated into a short Basic program that predicts the pressuretime history as a function of the several variables. The initial conditions are those identified in Table $\mathrm{H} 2-\mathrm{C} 0-1$ and the state vector from the previous cell.

The model has been checked by comparison with several existing calculations. The results derived from this model compare quite well (although about $10 \%$ to $15 \%$ high) with Figures $5-5$ and 5-6 of the SA (Rev. 8 page 5-16 and 5-20 respectively) when using a 42" diameter exhaust (the open riser). The model also compares quite well (within a few percent) with Figure 4-31 in LA-UR-92-3225 (page 4-28) using a single 12 inch discharge.

However, the pressure-time exhaust relationship is not the major point of interest (the total time of release is a maximum of about 80 seconds). What is important is the fraction of the material made airborne in the tank free-space that is exhausted to the environment. In this regard, it is assumed that once the ignition takes place, the airborne source term is uniformly mixed in the dome space and then discharged proportionally with the mixed gases. Thus to determine the fraction of source material exhausted, one need only calculate the fraction of the pressurized material that is exhausted. This is done in the calculational program. 
The results are summarized in Table H2-C4-1 for a set of selected environment states (pressure ranges). This table presents: (1) the top of the pressure range, (2) the associated material made airborne in the burn (grams $<10 \mu \mathrm{m} \mathrm{AED),} \mathrm{(3)} \mathrm{the} \mathrm{fraction} \mathrm{of} \mathrm{that} \mathrm{material} \mathrm{released} \mathrm{through}$ venting, and (4) the appropriate released source material in grams. This constitutes an intermediate state vector.

\section{Uncertainty}

The source term data show considerable spread around the approximating equation presented in Section 1 above (see Figure H2-C4-2). This scatter can be treated as an uncertainty in the source term calculation by devising a new set of "source term states" and constructing a probability transition matrix to those states. This has been done by fitting a lognormal distribution to the airborne source around the best fit value (a geometric standard deviation of 1.72, giving an effective range of about a factor of 7 in each direction) and using this distribution to develop the row vectors for a probability state transition matrix. This probability state transition matrix (the transitions matrix for this cell) is shown in Table H2-C4-2. The initial probability state vector for the new states (a new Cell \#3 state vector) together with the calculated output state vector from this cell (Cell \#4 output) are tabulated on the following page. The Cell \#4 output, as the probability state vector, is also shown in Figure $\mathrm{H} 2-\mathrm{C} 4-3$ and as a cumulative probability distribution in Figure H2-C4-4.

The event occurrence probability for this cell is 1.0 . 


$\begin{array}{ccc}\text { ID\# } & \begin{array}{c}\text { Source Term Range } \\ \text { (grams) }\end{array} \\ 1 & \quad 0 \text { to } 0.78 \\ 2 & 0.78 \text { to } 2.82 \\ 3 & 2.82 \text { to } 6.93 \\ 4 & 6.93 \text { to } 11.8 \\ 5 & 11.8 \text { to } 18.6 \\ 6 & 18.6 \text { to } 27.0 \\ 7 & 27.0 \text { to } 36.8 \\ 8 & 36.8 \text { to } 48.7 \\ 9 & 48.7 & \text { to } 62.2 \\ 10 & 62.2 & \text { to } 76.6 \\ 11 & 76.7 \text { to } 92.0 \\ 12 & 92.0 \text { to } 107 \\ 13 & 107 & \text { to } 122 \\ 14 & 122 & \text { to } 137 \\ 15 & 137 & \text { to } 152 \\ 16 & 152 & \text { to } 167 \\ 17 & 167 & \text { to } 182 \\ 18 & 182 & \text { to } 197 \\ 19 & 197 & \text { to } 212 \\ 20 & 212 & \text { to } 227 \\ 21 & 227 & \text { to } 242 \\ 22 & >242 & \end{array}$

Input Probability State Vector

0.159
0.159
0.159
0.159
0.147
0.101
0.060
0.033
0.016
0.006
0.001
0
0
0
0
0
0
0
0
0
0
0

Output Probability

State Vector (Cell \#4)

0.1618
0.1723
0.1733
0.1375
0.1229
0.0881
0.0570
0.0370
0.0218
0.0121
0.0069
0.0037
0.0021
0.0013
0.0008
0.0005
0.0003
0.0002
0.0001
0.0001
0.0001
0.0002


Table H2-C4-1

Pressure, Airborne Mass, Fraction Release \& Release Mass for Cell \#4

Following Hydrogen Ignition in the Vapor Space

\begin{tabular}{|c|c|c|c|}
\hline $\begin{array}{l}\text { Top of Pressure } \\
\text { Range (psia) }\end{array}$ & $\begin{array}{l}\text { Airborne Material } \\
(\mathrm{g}<10 \mu \mathrm{m} \text { AED) }\end{array}$ & Fraction Released & $\begin{array}{l}\text { Released Source } \\
(\mathrm{g}<10 \mu \mathrm{m} \text { AED })\end{array}$ \\
\hline 19.3 & 1.6 & 0.169 & 0.27 \\
\hline 21.5 & 3.5 & 0.223 & 0.78 \\
\hline 23.8 & 6.1 & 0.267 & 1.63 \\
\hline 26.0 & 9.4 & 0.303 & 2.82 \\
\hline 28.2 & 13.4 & 0.331 & 4.42 \\
\hline 30.4 & 18.1 & 0.357 & 6.93 \\
\hline 32.6 & 23.5 & 0.383 & 9.00 \\
\hline 34.7 & 29.4 & 0.402 & 11.8 \\
\hline 36.9 & 36.2 & 0.415 & 15.0 \\
\hline 39.0 & 43.4 & 0.428 & 18.6 \\
\hline 41.2 & 51.6 & 0.439 & 22.7 \\
\hline 43.3 & 60.1 & 0.449 & 27.0 \\
\hline 45.4 & 69.2 & 0.458 & 31.7 \\
\hline 47.5 & 79.0 & 0.466 & 36.8 \\
\hline 49.6 & 89.5 & 0.478 & 42.8 \\
\hline 51.6 & 100 & 0.487 & 48.7 \\
\hline 53.7 & 112 & 0.495 & 55.4 \\
\hline 55.8 & 124 & 0.502 & 62.2 \\
\hline 57.8 & 137 & 0.508 & 69.6 \\
\hline 59.8 & 149 & 0.514 & 76.6 \\
\hline$>59.8$ & $>149$ & 0.519 & $>77.3$ \\
\hline
\end{tabular}


Table H2-C4-2

Probability Transition Matrix -- Cell \#4

\begin{tabular}{|c|c|c|c|c|c|c|c|c|c|c|c|c|c|c|c|c|c|c|c|c|c|c|c|}
\hline & 1 & 2 & 3 & 4 & 5 & 6 & 7 & ${ }_{8}^{\text {So }}$ & $e^{T}$ & & $\begin{array}{l}\text { Proba } \\
10\end{array}$ & $\begin{array}{l}\text { ity } \mathrm{St} \\
11\end{array}$ & $\begin{array}{l}\text { Identi } \\
12\end{array}$ & $\begin{array}{c}\text { ation } \\
13 \\
\end{array}$ & $\begin{array}{l}\text { Iumber } \\
14\end{array}$ & 15 & 16 & 17 & 18 & 19 & 20 & 21 & 22 \\
\hline 1 & .900 & .099 & .001 & & & & & & & & & & & & & & & & & & & & \\
\hline 2 & .117 & .766 & .115 & .002 & .0001 & & & & & & & & & & & & & & & & & & \\
\hline 3 & .0007 & .2019 & .5949 & .1680 & .0306 & .0035 & .0004 & & & & & & & & & & & & & & & & \\
\hline 4 & & .0155 & .2956 & .3779 & .2202 & .0695 & .0167 & .003 & & 007 & .0001 & & & & & & & & & & & & \\
\hline 3 & & .0011 & .0787 & .2570 & .3265 & .2036 & .0872 & .032 & & 098 & .0028 & .0008 & .0002 & .0001 & & & & & & & & & \\
\hline 6 & & .0001 & .0148 & .1026 & .2476 & .2700 & .1858 & .103 & .04 & 46 & .0179 & .0070 & .0026 & .0010 & .0005 & .0002 & .0001 & & & & & & \\
\hline 7 & & & .0025 & .0319 & .1299 & .2228 & .2257 & .1765 & & 062 & .0540 & .0264 & .0118 & .0057 & .0028 & .0015 & .0008 & .0004 & .0002 & .0001 & .0001 & & .0001 \\
\hline 8 & & & .0004 & .0086 & .0549 & .1386 & .1952 & .204 & & 596 & .1020 & .0608 & .0323 & .0180 & .0102 & .0059 & .0034 & .0021 & .0013 & .0008 & .0005 & .0003 & .0006 \\
\hline 9 & & & .0001 & .0021 & .0201 & .0713 & .1344 & .182 & & 792 & .1402 & .0995 & .0616 & .0389 & .0246 & .0157 & .0101 & .0065 & .0043 & .0028 & .0019 & .0013 & .0030 \\
\hline 10 & & & & .0005 & .0070 & .0335 & .0810 & .137 & & 644 & .1529 & .1262 & .0889 & .0627 & .0436 & .0302 & .0210 & .0146 & .0102 & .0072 & .0051 & .0037 & .0101 \\
\hline 11 & & & & .0001 & .0025 & .0152 & .0455 & .093 & & 327 & .1433 & .1347 & .1061 & .0822 & .0622 & .0464 & .0344 & .0255 & .0188 & .0140 & .0104 & .0078 & .0250 \\
\hline
\end{tabular}




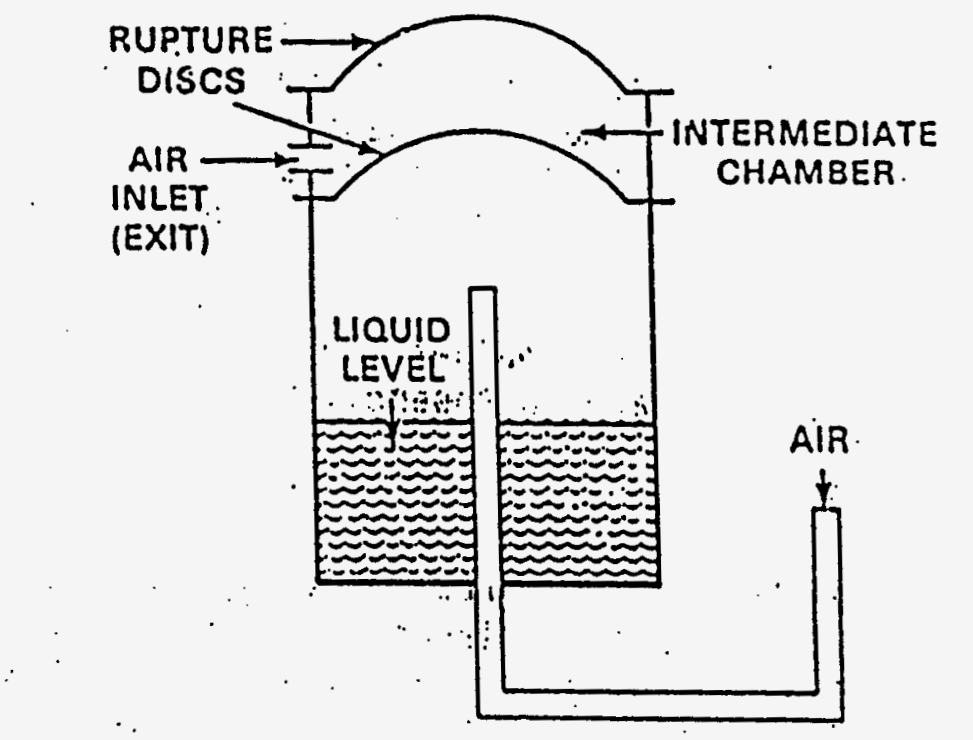

FIGURE 5. PARE. Modification for Pressurized Liquid Release Experiments

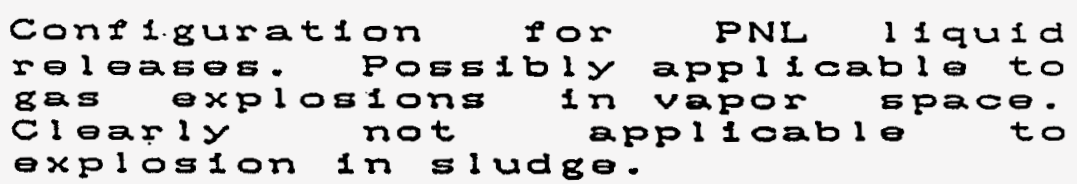

oxplosion in sludge.

Figure H2-C4-1

Experimental Configuration for PNL (Sutter) Pressurized Liquid Releases Used an Approximation to a Gas Ignition in the Tank Vapor Space 


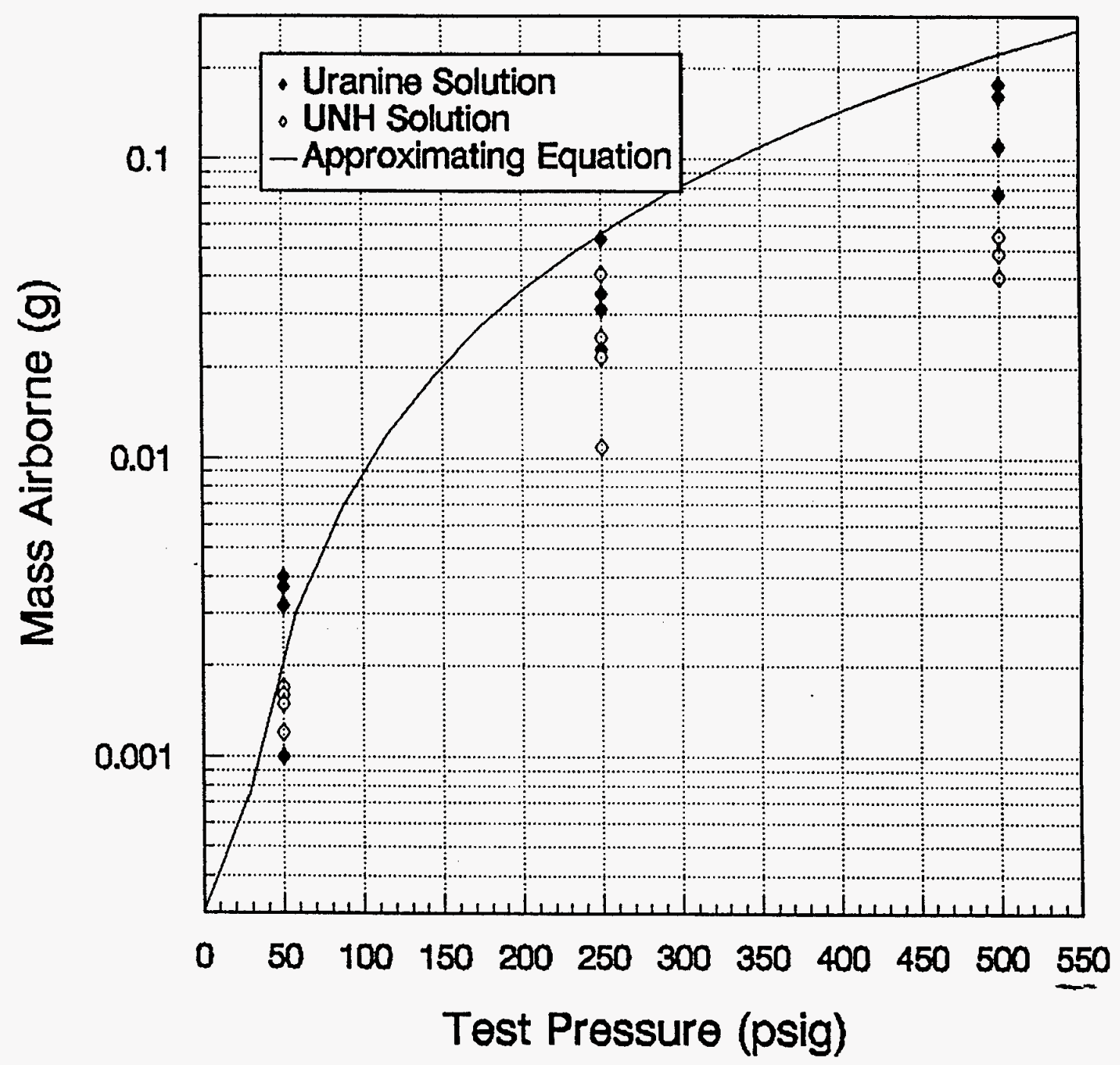

Figure $\mathrm{H} 2-\mathrm{C} 4-2$

Mass of Liquid Made Airborne (aerosols $<10 \mu \mathrm{m}$ AED)

Pressurized Liquid Experiments for PNL (Sutter) 


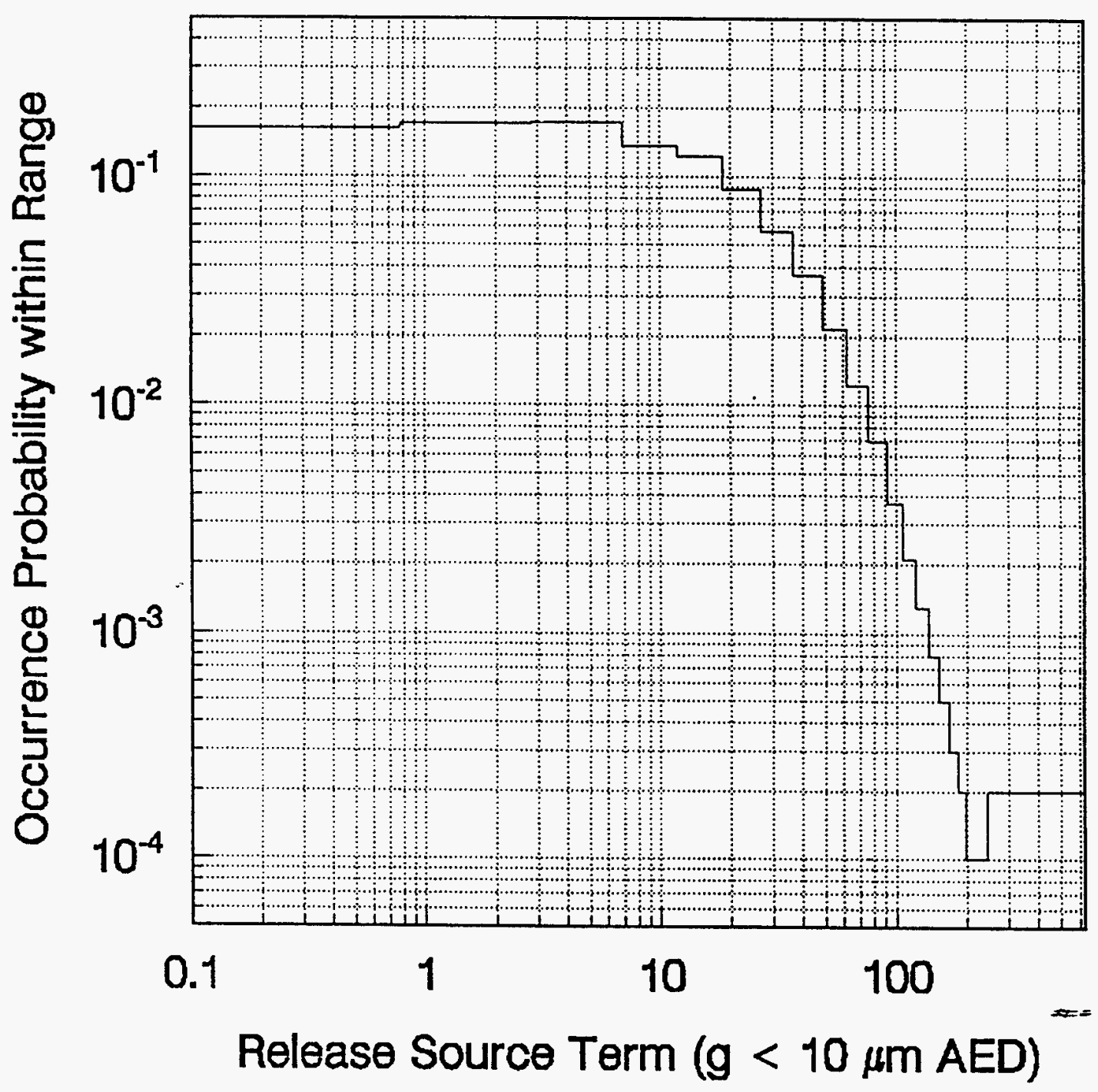

Figure $\mathrm{H} 2-\mathrm{C} 4-3$

Probability State Vector for Cell \#4

Occurrence Probability versus Release Source Term $(\mathrm{g}<10 \mu \mathrm{m}$ AED) 


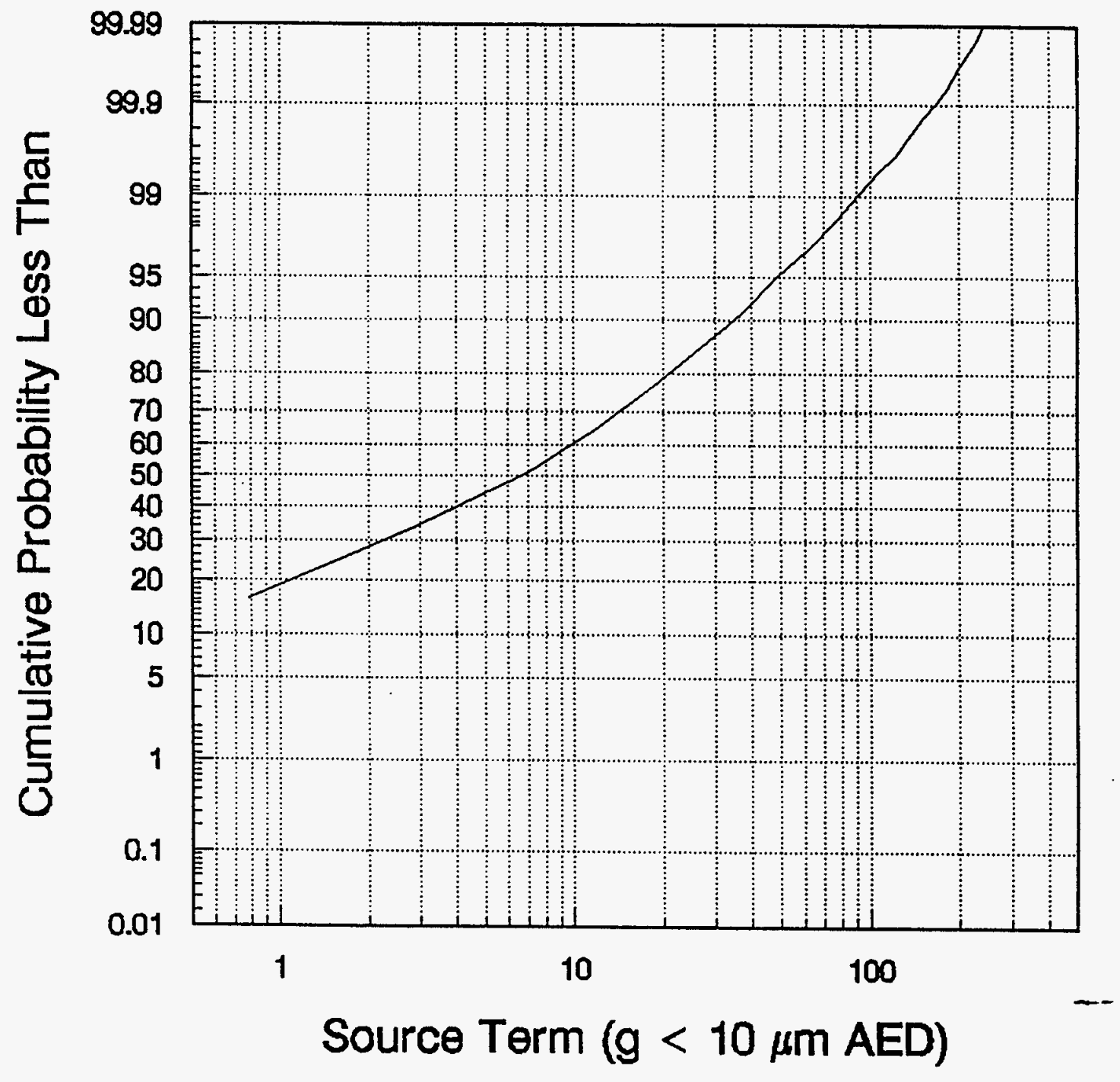

Figure $\mathrm{H} 2-\mathrm{C} 4-4$

Cell \#4 Output Source Term ( $<3 \mu \mathrm{m}$ AED) Probability State Vector as a Cumulative Probability Distribution 


\section{E. Environmental Transport (Cell \#5).}

The goal of this cell is to describe the probability distribution of environmental exposure to released fuel. Thus the environmental transport cell consists of those analytical steps necessary to describe the transition probabilities from the source term states defined in the previous cell to exposure states defined here (i.e., the transition probability matrix). The inputs consist of the source term probability state vector from Cell \#4, atmospheric transport information and engineering analysis.

Both of the current analyses (LA-UR-92-3225 and the SA Rev 8) make use of the computer code AI-RISK and a joint frequency matrix of meteorology data to carry out the functions of this calculational step. Although both document state ". . . a dose is calculated for each joint frequency combination in the matrix and a cumulative dose vs frequency curve is constructed for that receptor location.", only the $95 \%$ doses are given in the current documentation. The text indicates that the $95 \%$ represents the variability due to meteorology. Thus, although frequency distributions may have been generated, they are not presented, and it is not possible to reconstruct them from the existing documentation.

However, the information presented, although sparse, provides a basis for developing the probability transition matrix for this cell when used together with a general judgement about uncertainty distributions. Dispersion data are presented in Table M-3 on page M-3 (Appendix $M, \operatorname{Rev} .8$ ) which gives the value of the dispersion parameter $X / Q\left(\right.$ in $s / \mathrm{m}^{3}$ ) for several locations of interest. For this example the location designated Hwy 240 (this is the site boundary) will be used. The value at that location is $0.0129 \mathrm{~s} / \mathrm{m}^{3}$ (identified as the $95 \%$ value for meteorology). The problem is to devise a rational occurrence probability distribution from this point value. This will be dealt with in the discussion of uncertainty that follows.

\section{Uncertainty}

The INSRP (INSRP 90-07, Uncertainty Analysis Report for Ulysses, Volume II, Table 4-4) provides a basis for approximating the uncertainty due to predicting dispersion through two lognormal probability distributions. These are: (1) Envelope of Variability for Meteerology and Wind Direction and (2) Uncertainty in Using a Gaussian Dispersion Model. Although the first of these is site specific (the Kennedy Space Center) both distributions will be used for describing the uncertainty distribution in the results for this example. In both cases the distributions are stated to be lognormal with a mean of 1.0 and a median of 0.71 (a geometric standard deviation of approximately 2.29 , giving a factor of about 15 for the range $5 \%$ to $95 \%$ ). Note that given the assumed distribution for meteorology and the $95 \%$ value of $0.0129 \mathrm{~s} / \mathrm{m}^{3}$ (for meteorology alone) implies a median value of $0.0033 \mathrm{~s} / \mathrm{m}^{3}$ for exposure at the Hwy 240 location. We can use this value to convert the source term states in grams to exposure state in $\mathrm{g}-\mathrm{s} / \mathrm{m}^{3}$.

Further, the INSRP distribution provides a basis for constructing the probability transition matrix 
for dispersion. The probability transition matrix between the source term states (grams $<10 \mu \mathrm{m}$ AED) from Cell \#4 and a set of exposure states $\left(\mathrm{g}-\mathrm{s} / \mathrm{m}^{3}\right)$ that emanates from the INSRP lognormal distribution is shown in Table H2-C5-1. The sequential application of this probability transition matrix, first for the uncertainty in meteorology and then for the uncertainty in using the Gaussian dispersion model itself, yields the output probability state vector from this cell. Table H2-C5-2 presents the results of those calculations. That table includes: column 1, an identification number for the states; column 2, the upper limit of the range for source term state (g); column 3, the associated upper limit of the range for exposure $\left(\mathrm{g}-\mathrm{s} / \mathrm{m}^{3}\right)$; and column 4, the final probability state vector for this cell that includes both uncertainty due to meteorology and the use of Gaussian dispersion; and (5) column 5, the intermediate probability state vector for this cell that derives only from the uncertainty due to meteorology.

The two probability state vectors shown in Table H2-C5-2 are plotted together with the probability state vector that would obtain without the inclusion of uncertainty in this cell are all shown in Figure H2-C5-1 (all as cumulative probability distributions). Table H2-C5-2 and Figure H2-C5-1 constitute the output from cell \#5.

The event occurrence probability for this cell is 1.0 . However, this clearly does not consider the directional probability of the wind. 
Table H2-C5-1 -- Probability Transition Matrix -- Cell \#5

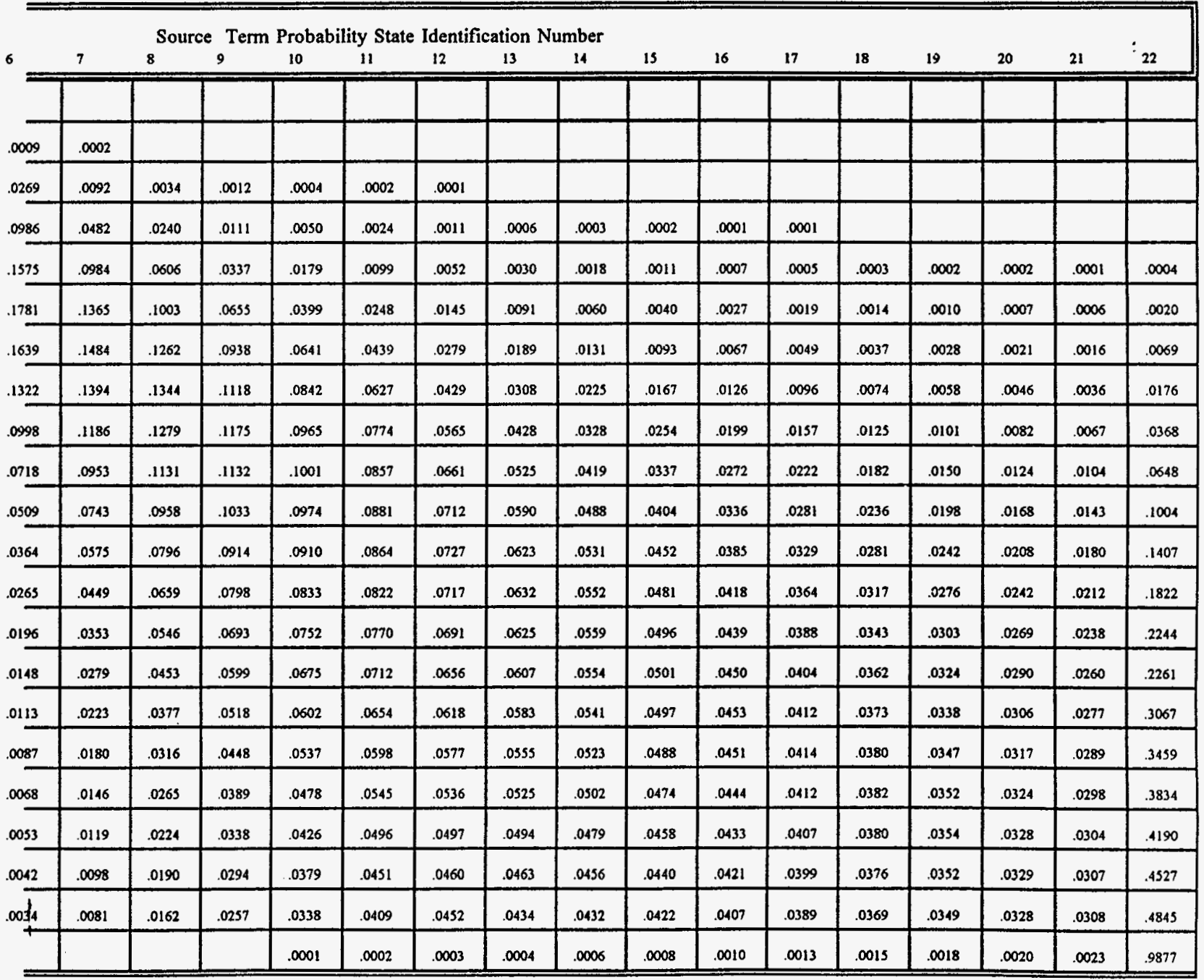


Table H2-C5-2

Cell \#5 Output Probability State Vectors Including Uncertainty for Meteorology \& Gaussian Model -- Output States are Exposure (g-s/m $\mathrm{m}^{3}$ )

\begin{tabular}{|c|c|c|c|c|}
\hline ID\# & $\begin{array}{c}\text { Top of Rarige } \\
\text { Source Term (g) }\end{array}$ & $\begin{array}{c}\text { Top of Range } \\
\text { Exposure }\left(\mathrm{g}-\mathrm{s} / \mathrm{m}^{3}\right)\end{array}$ & $\begin{array}{c}\text { Probability State } \\
\text { Vector (final) }\end{array}$ & $\begin{array}{l}\text { Probability State } \\
\text { Vector (Met only) }\end{array}$ \\
\hline 1 & 0.78 & 0.000026 & 0.2408 & 0.2028 \\
\hline 2 & 2.82 & 0.000093 & 0.1486 & 0.1588 \\
\hline 3 & 6.93 & 0.000229 & 0.1576 & 0.1725 \\
\hline 4 & 11.8 & 0.000391 & 0.1011 & 0.1153 \\
\hline 5 & 18.6 & 0.000616 & 0.0836 & 0.0967 \\
\hline 6 & 27.0 & 0.000894 & 0.0629 & 0.0715 \\
\hline 7 & 36.9 & 0.00122 & 0.0463 & 0.0508 \\
\hline 8 & 48.7 & 0.00161 & 0.0362 & 0.0378 \\
\hline 9 & 62.2 & 0.00206 & 0.0250 & 0.0252 \\
\hline 10 & 76.6 & 0.00254 & 0.0193 & 0.0179 \\
\hline 11 & 92.0 & 0.00304 & 0.0144 & 0.0125 \\
\hline 12 & 107 & 0.00354 & 0.0102 & 0.0083 \\
\hline 13 & 122 & 0.00404 & 0.0077 & 0.0059 \\
\hline 14 & 137 & 0.00453 & 0.0059 & 0.0044 \\
\hline 15 & 152 & 0.00503 & 0.0051 & 0.0037 \\
\hline 16 & 167 & 0.00553 & 0.0038 & 0.0025 \\
\hline 17 & 182 & 0.00602 & 0.0031 & 0.0020 \\
\hline 18 & 197 & 0.00652 & 0.0026 & 0.0016 \\
\hline 19 & 212 & 0.00702 & 0.0022 & 0.0013 \\
\hline 20 & 227 & 0.00751 & 0.0018 & 0.0010 \\
\hline 21 & 242 & 0.00801 & 0.0027 & 0.0015 \\
\hline 22 & $>242$ & $>0.00801$ & 0.0168 & 0.0051 \\
\hline
\end{tabular}




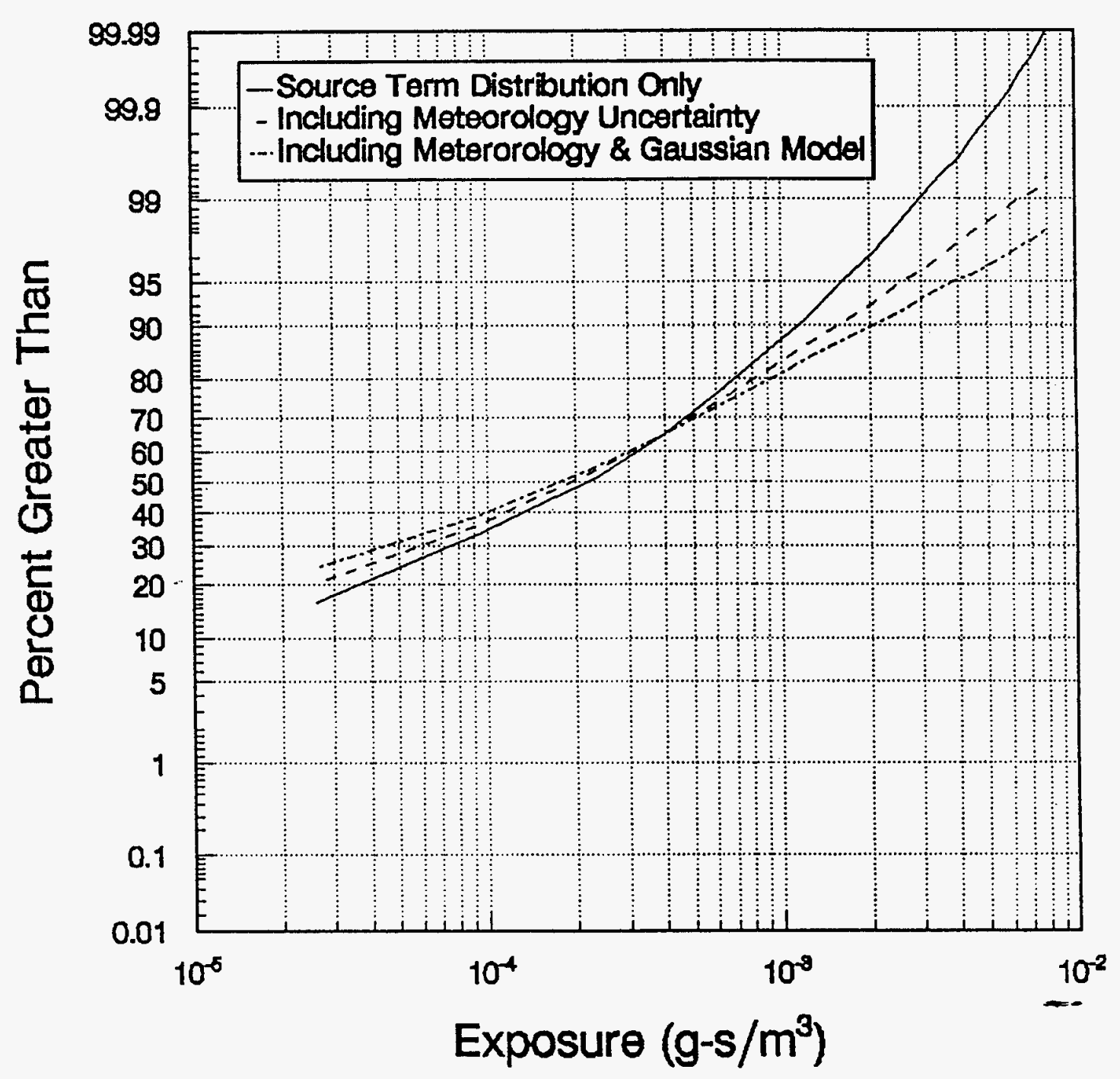

Figure H2-C5-1

Cumulative Probability State Vectors from Cell \#5

Cumulative Probability versus Exposure [g-s $/ \mathrm{m}^{3} \quad(<10 \mu \mathrm{m}$ AED)] 


\section{F. Biological Interaction (Cell \#6).}

The goal of the biological interaction cell is describe the probability distribution of human radiation dose associated with the environmental exposure states that are the output of the previous cell. Thus the biological interaction cell consists of those analytical steps necessary to describe the transition probabilities from the environmental exposure states of the previous cell to a set of radiation dose states defined in this cell (i.e., the transition probability matrix).

In general, the biological interaction cell will use biological models (lung, GI tract, external exposure etc.), diet and/or intake assumptions, and population demographics together with the calculated exposure states from cell $\# 5$ to estimate the distribution of human insult expressed as dose states. However for this illustration, the calculation of radiation dose is limited to an attempt to reproduce the calculational approach used in the SA Rev. 8. Thus for the case at hand, the radiation dose conversion factor is obtained by interrelating Tables M-2 and M-3 of the SA Rev. 8 (both on page M-3 of Appendix M). For a stack release at the Hwy 240 location, these tables yield a radiation dose factor of 77.5 mrem Effective Dose Equivalent (EDE) per g$\mathrm{s} / \mathrm{m}^{3}$ for particles in the respirable range. This dose factor is used to convert the exposure (in $\mathrm{g}$ $\mathrm{sec} / \mathrm{m}^{3}$ ) from Cell \#5 to radiation dose [in mrem (EDE)] in this cell. The resulting state vector is tabulated in Table H2-C6-1 and is shown as a cumulative probability function in Figure H2C6-1. This dose distribution (as a probability state vector) has a total event-occurrence probability of $3.78 \times 10^{-4} / y e a r$ calculated as follows:

Cell \#1 Cell \#2 Cell \#3 $\quad$ Cell \#4 $\quad$ Cell \#5 $\quad$ Cell \#6

$0.0004 \times \quad 1.0 \times \quad 0.927 \times \quad 1.0 \quad \times \quad 1.0 \quad \times \quad 1.0=3.78 \times 10^{-4} /$ year

The doses calculated here are about a factor of 50 below those given in the SA (Rev. 8). This is primarily attributed to source terms, because as mentioned previously, the source terms calculated here may be about a factor of 30 below those in the SA. However, actual comparisons are not possible because the SA does not provide the numerical values of sources terms. Further, in addition to the different method of calculating source terms, the doses calculated here include distributing the dose probability by the uncertainty in the source term calculation, the-uncertainty in the Gaussian dispersion model, and the uncertainty due to meteorology. 
Table H2-C6-1

Cell \#6 Output Probability State Vectors

Output States are Radiation Dose [mrem (EDE)] at Hwy 240

\begin{tabular}{|c|c|c|c|}
\hline Cell & \multicolumn{2}{|c|}{$\begin{array}{c}\text { Range of Radiation Dose } \\
\text { mrem (EDE) }\end{array}$} & \multirow{2}{*}{$\begin{array}{c}\begin{array}{c}\text { Probability of } \\
\text { Occurrence }\end{array} \\
0.2408\end{array}$} \\
\hline 1 & 0 & 0.0020 & \\
\hline 2 & 0.0020 & 0.0073 & 0.1486 \\
\hline 3 & 0.0073 & 0.0180 & 0.1576 \\
\hline 4 & 0.0180 & 0.0307 & 0.1011 \\
\hline 5 & 0.0307 & 0.0483 & 0.0836 \\
\hline 6 & 0.0483 & 0.0702 & 0.0629 \\
\hline 7 & 0,0702 & 0.0956 & 0.0463 \\
\hline 8 & 0.0956 & 0.1265 & 0.0362 \\
\hline 9 & 0.1265 & 0.1616 & 0.0250 \\
\hline 10 & 0.1616 & 0.1990 & 0.0193 \\
\hline 11 & 0.1990 & 0.2390 & 0.0144 \\
\hline 12 & 0.2390 & 0.2780 & 0.0102 \\
\hline 13 & 0.2780 & 0.3170 & 0.0077 \\
\hline 14 & 0.3170 & 0.3560 & 0.0059 \\
\hline 15 & 0.4560 & 0.3949 & 0.0051 \\
\hline 16 & 0.3949 & 0.4339 & 0.0038 \\
\hline 17 & 0.4339 & 0.4729 & 0.0031 \\
\hline 18 & 0.4729 & 0.5119 & 0.0026 \\
\hline 19 & 0.5119 & 0.5509 & 0.0022 \\
\hline 20 & 0.5509 & 0.5898 & 0.0018 \\
\hline 21 & 0.5898 & 0.6288 & 0.0027 \\
\hline 22 & $>0.6288$ & & 0.0168 \\
\hline
\end{tabular}




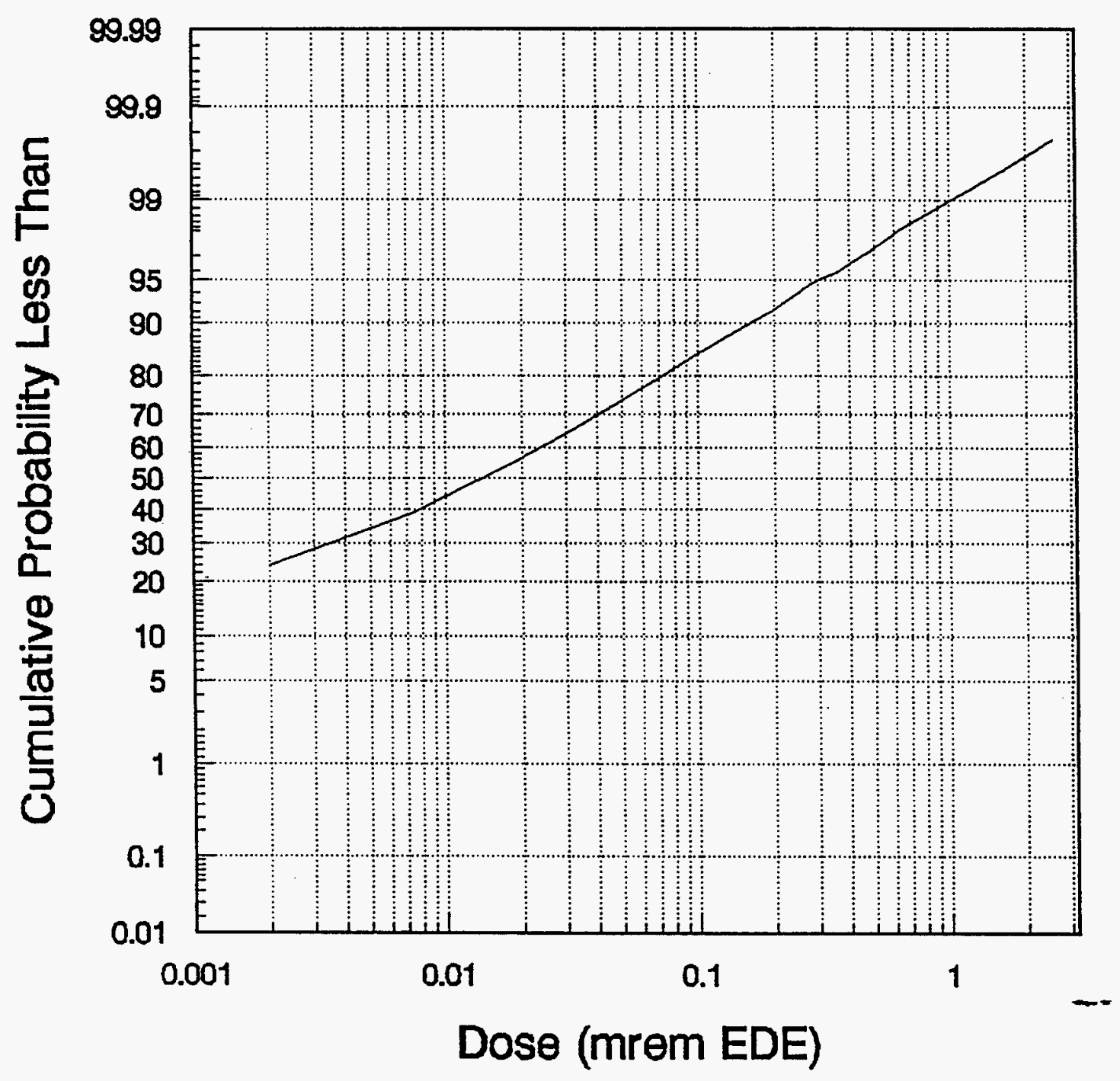

Figure H2-C6-1

Cell \#6 Output Probability State Vector -- Dose (mrem EDE) as a Cumulative Probability Distribution 


\section{G. Risk Valuation (Cell \#7).}

As mentioned earlier, this cell is not a true calculational. This cell is more accurately a discussion and application of some set of value judgements about risk and is included so as not to overlook or underestimate the importance of valuing the risk. In the general case, it may includes the application of risk coefficients, acceptable risk criteria (e. g., de minimis doses or credible limits on occurrence frequencies) or other mechanisms to arrive at the comparable value base necessary to ascribe a relative risk value to the accident dose/consequences calculated; and should include a discussion of the technical basis for those value judgements. Thus, fundamentally, the purpose of this cell is to provide the technical and/or logical basis for valuing the calculated radiation exposures as risks and providing a framework for viewing those risks in the context of some acceptance criteria.

In the SA (Rev. 8) the discussion of "acceptance criteria" is contained in Section 5.0 CONSEQUENCES OF ACCIDENTS and derive from the Westinghouse Nonreactor Facility Safety analysis Manual. Specifically, offsite dose acceptance criteria are summarized in Table 5-2 which is reproduced below.

\begin{tabular}{|c|c|c|}
\hline $\begin{array}{c}\text { Frequency } \\
(1 / \mathrm{yr})\end{array}$ & $\begin{array}{c}\text { EDE } \\
(\mathrm{rem})\end{array}$ & $\begin{array}{c}\text { Maximum Organ } \\
\text { Dose (rem) }\end{array}$ \\
\hline 1.0 & 0.1 & 1 \\
\hline 0.1 & 0.2 & 2 \\
\hline 0.01 & 0.5 & 5 \\
\hline 0.001 & 1.3 & 13 \\
\hline 0.0001 & 3.5 & 35 \\
\hline 0.00001 & 9.4 & 94 \\
\hline 0.000001 & 25.0 & 250 \\
\hline
\end{tabular}

The SA further states that "The acceptance criteria for accident(s) of frequency greater than 1 and less that $1.0 \times 10^{-6}$ are undefined by the Westinghouse Nonreactor Facility Safety analysis Manual.", thus this table constitutes the complete offsite dose acceptance criteria. Because the accident frequency of the accident considered here is $4.0 \times 10^{-4} / y$ ear the criteria clearly apply (overall event-frequency for the scenario considered $3.78 \times 10^{-4} /$ year).

The dose-frequency distribution for the Hwy 240 location calculated using the cumulative dose 
distribution and the event-occurrence frequency from the previous cell is plotted together with the EDE (rem) criteria in Figure H2-C7-1. Two dose frequency distributions are shown, one including multiplication by the normalized event occurrence probability calculated from the analysis, and the other without the multiplication of the earthquake frequency. The first of these pertains to the accident considered here. It is obvious from this curve that the dose consequences for the Hwy 240 location calculated for the earthquake event are well below the applicable criteria.

The second of the curves is comparable (in concept) to the individual data points in Figure 5-1 (page 5-7) in the SA (Rev. 8) if the curve is multiplied by some average accident eventoccurrence frequency. However, no direct comparison is appropriate for two reasons: (1) the difference in source term calculation methodology, and (2) the doses calculated her are distributed by the uncertainty in the source term calculation, the uncertainty in the Gaussian dispersion model, and the uncertainty due to meteorology.

In any event, the event consequences calculated here are far below the applicable criteria as are those calculated in the SA (Rev. 8). 


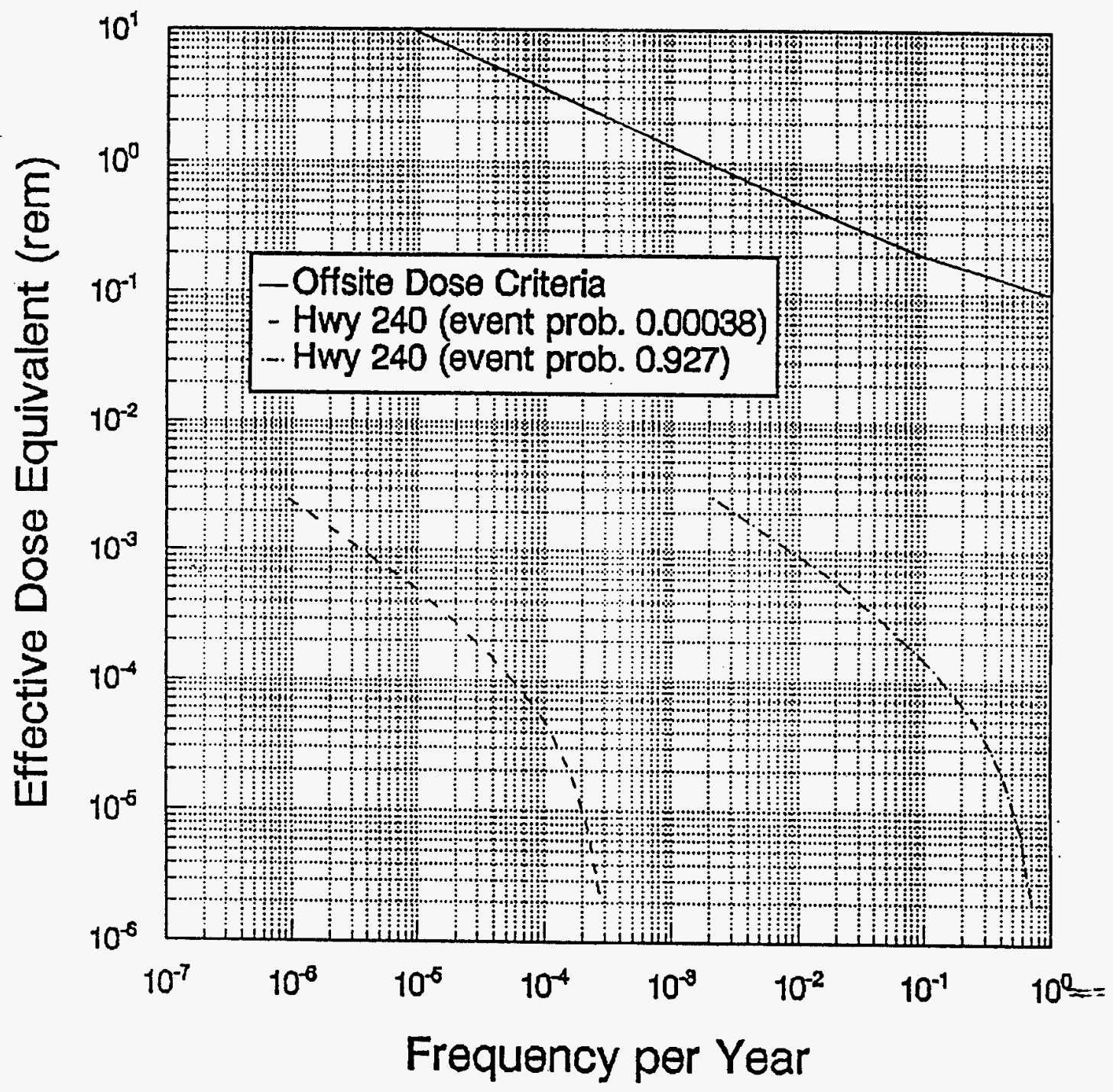

Figure $\mathrm{H} 2-\mathrm{C} 7-1$

Comparison of Calculated Doses (rem EDE) with Offsite Dose Criteria as Complements of the Cumulative Probability Distribution 


\section{H. Summary Comments.}

This analysis has produced the following results;

1. An accident frequency of 0.0004 per year for an earthquake with an associated ground acceleration of greater than about $0.2 \mathrm{~g}$ (the accident case); and a probability state vector related to the size of the combustible gas release as the output from Cell \#1.

2. A tank pressure probability state vector (the only environment of interest) as the output from Cell \#2, with a pressurization and ignition occurrence probability of 1.0 , given an earthquake in 1 . above.

3. A failed HEPA state vector as the output from Cell \#3. The failure occurrence probability is 0.927 given the pressurization state vector of cell \#2 and the conditions of 1 and 2 above.

4. A source term state vector for respirable release $(<10 \mu \mathrm{m} \mathrm{AED)}$ as the outputs from Cell \#4. Source term occurrence probability is 1.0 given the conditions of 1,2 , and 3 above.

5. An exposure probability state vector in $\mathrm{g}-\mathrm{s} / \mathrm{m}^{3}$ calculated from information in the SA (Rev. 8) for the Highway 240 location as the output from Cell \#5. Exposure occurrence probability is 1.0 given a release.

6. A corresponding dose probability state vectors in rems (EDE) for the Highway 240 site boundary as the output from Cell \#6. Dose occurrence probability given exposure $=1.0$

7. A comparison of the dose distribution at the Hwy 240 location to the Westinghouse off site acceptance criteria [identified in the SA (Rev.8)] as the output from Cell \#7. The earthquake event considered here has a event-frequency of $1 \times 10^{-4}$ and therefore the Westinghouse criteria apply. This comparison shows the consequences calculated here to be well within those criteria.

Note that the event-consequence scenario considered here (characterized as earthquake, gas release, ignition, HEPA failure, release, and dose) has an overall event-consequences probability of $3.71 \times 10^{-4}$ per year.

In summary, the methodology used here has produced a relatively lucid exposition of the accident considered and provides a set of intermediate results that promote a clearer understanding of the problem. Unfortunately, no exact comparison with the current documentation [SA (Rev. 8)] is 
appropriate "for the two reasons mentioned previously: (1) the difference in source term calculation methodology, and (2) because the doses calculated here are distributed by the uncertainty in the source term calculation, the uncertainty in the Gaussian dispersion model, and the uncertainty due to meteorology.

However, in any event, it is clear that the availability of the intermediate data is a significant benefit to understanding the problem and illuminates a shortcoming in the current approach to documenting safety analyses. 
Report Number (14) LA-SuB $--95-126$

Publ. Date (11) $\frac{1990601}{\text { DOEIEM; DOEIDP } X F}$
Sponsor Code (18)
UC Category (19) UC-940;UC-744, DOE/EK 